UNIVERSIDADE DE SÃO PAULO

FACULDADE DE FILOSOFIA CIÊNCIAS E LETRAS DE RIBEIRÃO PRETO

MOISÉS OLIVEIRA DOS SANTOS

\title{
Desenvolvimento de um sistema automatizado para a caracterização espacial de feixes lasers
}

Ribeirão Preto 
MOISÉS OLIVEIRA DOS SANTOS

\title{
Desenvolvimento de um sistema automatizado para a caracterização espacial de feixes lasers
}

\author{
Dissertação apresentada à Faculdade de \\ Filosofia, Ciências e Letras de Ribeirão Preto \\ para obtenção do título de Mestre em Física \\ Médica. \\ Área de Concentração: Física Aplicada à \\ Medicina e Biologia \\ Orientador: Prof. Dr. Luciano Bachmann
}


AUTORIZO A REPRODUÇÃO E DIVULGAÇÃO TOTAL OU PARCIAL DESTE TRABALHO, POR QUALQUER MEIO CONVENCIONAL OU ELETRÔNICO, PARA FINS DE ESTUDO E PESQUISA, DESDE QUE CITADA A FONTE.

\section{Ficha Catalográfica}

Santos, Moisés Oliveira

Desenvolvimento de um sistema automatizado para a caracterização espacial de feixes lasers. Ribeirão Preto, 2007. 87 p. : il. ; $30 \mathrm{~cm}$.

Dissertação de Mestrado, apresentada à Faculdade de Filosofia, Ciências e Letras de Ribeirão Preto/USP. Área de concentração: Física Aplicada à Medicina e Biologia.

Orientador: Bachmann, Luciano.

1. Laser. 2. Borda-da-lâmina. 3. Cintura do feixe. 


\section{Folha de Aprovação}

Moisés Oliveira dos Santos

Desenvolvimento de um sistema automatizado para a caracterização espacial de feixes lasers.

Dissertação apresentada à Faculdade de Filosofia, Ciências e Letras de Ribeirão Preto para obtenção do título de Mestre em Física Médica.

Área de Concentração: Física Aplicada à Medicina e Biologia.

Aprovado em:

Banca Examinadora

Prof. Dr.

Instituição Assinatura.

Prof. Dr.

Instituição Assinatura.

Prof. Dr.

Instituição Assinatura 


\section{Dedicatória}

Aos meus pais, Luis Nogueira e Sebastiana, pelo

amor, carinho, dedicação e apoio que sempre me deram. 


\section{Agradecimentos}

Agradeço a Deus, por minha vida e por todas as minhas realizações.

Ao Prof. Luciano, meu orientador, pela paciência, incentivo e orientação acadêmica nesses últimos anos.

A minha namorada Ticiane, pelo amor, carinho, paciência, apoio e incentivo.

Aos meus irmãos, e em especial, a minha irmã Lúcia, pela ajuda, carinho e atenção.

Ao Paulo Bobrowiec, por me ajudar sem medir esforços.

Ao casal, Antonio e Aparecida Bobrowiec, que me acolheram e incentivaram logo quando cheguei a Ribeirão Preto e hoje fazem parte da minha família.

Aos amigos que conheci ainda na seleção do mestrado: Mirko, Lúcio, Ana Paula e Lindomar.

A minha grande amiga Luciana, que me ajudou muito nesses últimos anos.

Aos meus amigos do Grupo de Fotobiofísica: Marina, Ernando, Cássia, Wagner e Pablo, pelos momentos de alegria e descontração.

Aos meus amigos: Ailton, Lucas, Rodrigo, Tiago, João Paulo, pelos jogos de basquete, que além de descontrair, formaram uma grande amizade.

As secretárias: Gisele Maranghetti e Nilza pela ajuda prestada.

Aos técnicos: Aziane, Elcio e Eldereis, pela "co-orientação" prestada na montagem do protótipo.

A todos que, de uma forma ou de outra, ajudaram-me nessa jornada.

À CAPES, pela bolsa que me foi concedida. 
O laser é uma solução que procura um problema

Theodore H. Maiman 


\section{Resumo}

A demanda por qualidade nas aplicações envolvendo radiação laser exigiu melhorias no seu desempenho. Conseqüentemente, equipamentos mais rápidos e precisos nas medidas dos seus parâmetros são indispensáveis. Nas áreas onde o laser é empregado, três parâmetros sobressaem-se nas suas aplicações: (1) potência ou energia, (2) freqüência e (3) comprimento espacial ou largura do feixe. A determinação das bordas, isto é, da largura do feixe, está ligada a um percentual do máximo valor atingido pela energia. O diâmetro do feixe, juntamente com a energia, determina-se a densidade do feixe. Outros parâmetros como: divergência e fator de qualidade $\left(\mathrm{M}^{2}\right)$, podem ser determinados também. O presente trabalho busca desenvolver um sistema de translação bidimensional que possa ser empregado na caracterização espacial do feixe de lasers. Para determinar o perfil do feixe de lasers utiliza-se o método borda-da-lâmina (knife-edge), relacionando o deslocamento da lâmina posicionada transversalmente ao feixe, com a energia transmitida. Obstruindo o feixe com uma lâmina opaca, obtêm-se a variação da energia do feixe em função da posição da lâmina. Esta variação representa a integral do perfil Gaussiano do feixe. Para a automação do sistema foi empregado o programa Labview (National Instruments). O funcionamento do protótipo mostrou-se eficiente na caracterização de feixes laser e com uma instrumentação de baixo custo para a comercialização nacional. No entanto, apresentou-se lento na aquisição de dados, tornando a tarefa de caracterização do laser mais demorada. Fatores como velocidade do motor de passo e linguagem de programação contribuíram para tornar a aquisição lenta.

Palavras chave: Laser, borda-da-lâmina e raio do feixe. 


\section{Abstract}

The demand for quality in the applications involving laser radiation demanded improvements in its performance. Faster equipments in the measures of its parameters are indispensable. In the areas where the laser is employee, three parameters are important in its applications: (1) power or energy, (2) frequency and (3) beam spatial. The determination of the edges, i. e., the width of the beam, is correlated to a percentage of the maximum reached energy. This parameter, together with the energy, determines beam density; beyond this parameter it also possible to determine the divergence and quality factor $\left(\mathrm{M}^{2}\right)$. This work searches to develop a system of bi-dimension translation that can be used in the spatial characterization of laser beam. To determine the profile of laser beam it is used the knife-edge method, that it relates the displacement of the blade located transversally to the beam, with the transmitted energy. Blocking the beam with a blade the energy variation of the beam is correlated with blade position; this variation represents the integral of the beam Gaussian profile. For the automation it will be used the Labview program(National Instruments).

The prototype had showed to be efficient in the characterization of laser beams and a low cost for national commercialization; however was slow in the data acquisition resulting a longer time to acquire the laser parameters. Instrumental components as step motors or programming language had contributed to slowly acquisition.

Key Words: Laser, Knife-edge, Beam Width 


\section{Sumário}

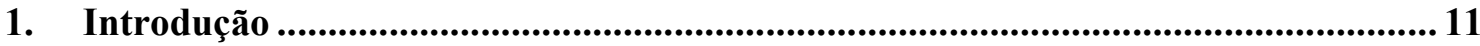

1.1. Feixes Gaussianos e Modos de Propagação do Laser .......................................... 13

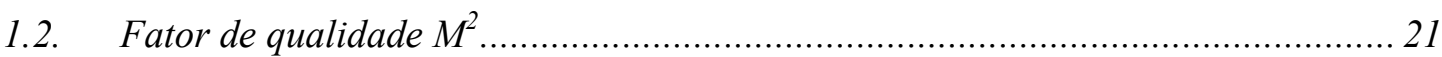

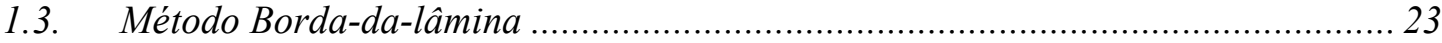

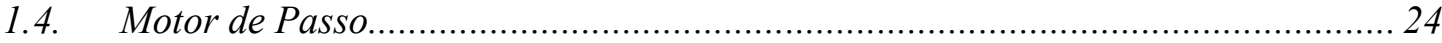

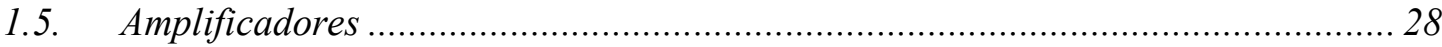

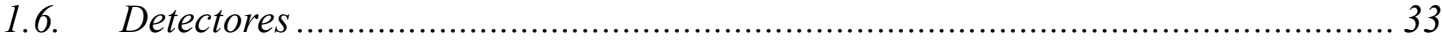

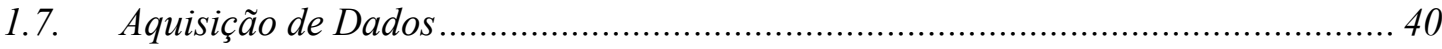

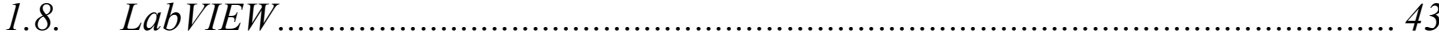

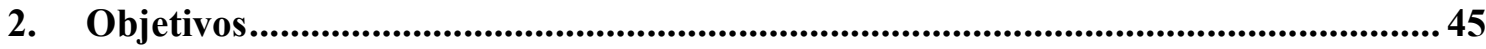

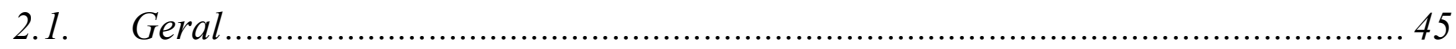

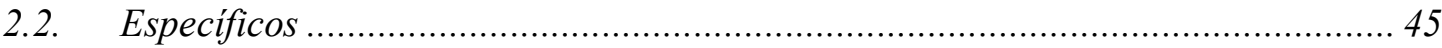

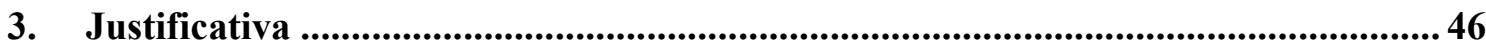

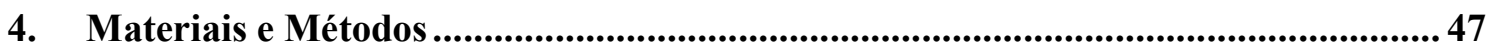

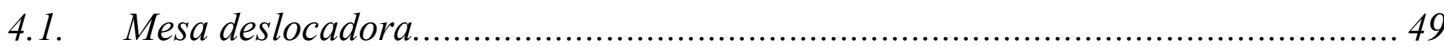

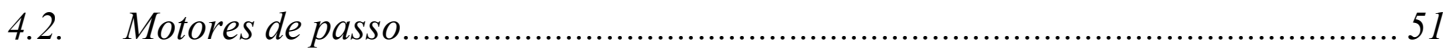

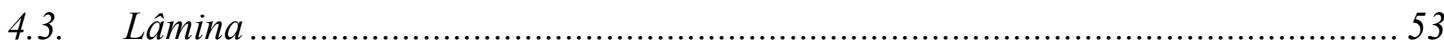

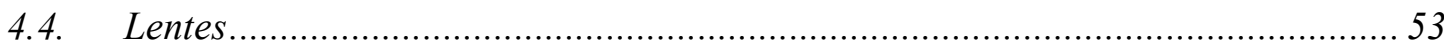

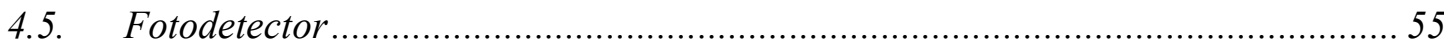

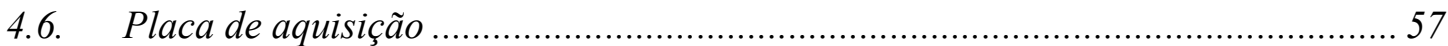

4.7. $\quad$ Sistema de automação, aquisição e análise dos dados. ........................................ 58

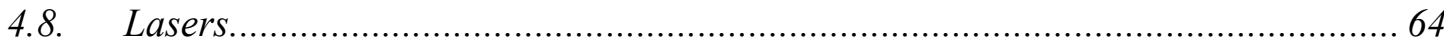

4.9. Dinâmica realizada para a caracterização dos feixes ........................................... 64

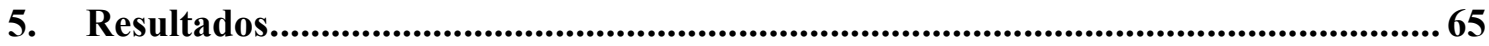

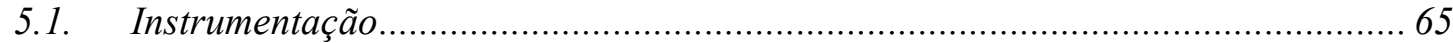

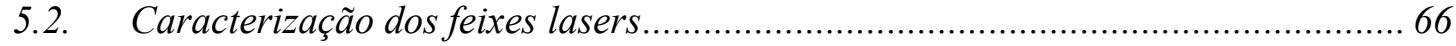

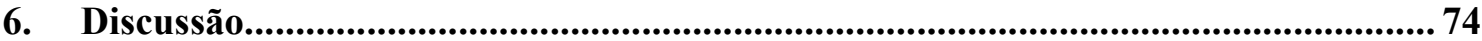

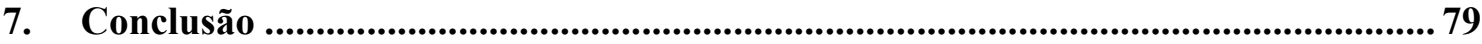

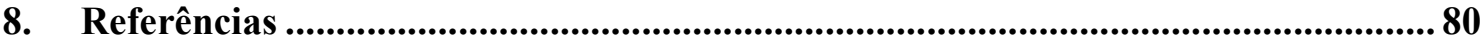

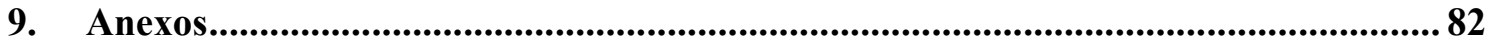




\section{Introdução}

A história do desenvolvimento do laser (acrônimo para Light Amplification by Stimulated Emission of Radiation), inicia com Einstein, passando por Charles H. Townes e Arthur L. Schawlow, cientistas dos laboratórios Bell, os quais em seu artigo de 1958, "Infrared and Optical Masers" [1] influenciaram enormemente T. H. Maiman a demonstrar o primeiro laser em 1960 [2] que a princípio chamava-se Maser (acrônimo para Microwave Amplification by Stimulated Emission of Radiation), chegando a Gordon Gould, que em 1957, ainda estudante de graduação, contribuiu com conceitos importantes, e com o nome laser [3].

Para avaliar o potencial de aplicação do feixe laser na irradiação, os trabalhos de pesquisa são induzidos a utilizar parâmetros similares ou os fornecidos pelo fabricante. Esses parâmetros sofrem influências do meio que comprometem os parâmetros originais. Contudo, a determinação do perfil transversal e longitudinal do feixe, seu raio, fator de qualidade $\left(\mathrm{M}^{2}\right)$ e divergência, faz-se necessário afim de que não afete a qualidade dos dados.

$\mathrm{O}$ conhecimento do valor da cintura do feixe e do $\mathrm{M}^{2}$ permite predizer o comportamento do feixe em qualquer posição ao longo do eixo de propagação, mas não permite estabelecer o perfil espacial de energia, necessitando ainda o conhecimento da energia ou potência do feixe.

Na medicina e na odontologia, o conhecimento dos parâmetros do laser é primordial nas interações laser-tecido, pois nas aplicações in-vivo e ex-vivo, é necessário estabelecer as doses (potência por volume), adequadas para a terapêutica [4].

Os parâmetros geométricos do laser podem ser medidos pelos métodos tradicionais, não eletrônicos; ou pelos métodos eletrônicos, que são mais sofisticados. 
Os métodos não eletrônicos, como mode burns (Figura 1), burn spot (Figura 2) $e$ reflected beam view (Figura 3), são muito baratos, mas não fornecem informações suficientes sobre o feixe para estabelecer suas características, devido a subjetividade visual nas análises.

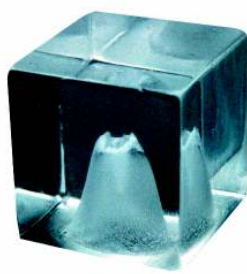

Figura 1 - Impressão em acrílico.

(Fonte: Spiricon, Inc.)

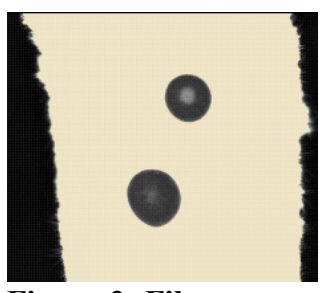

Figura 2- Filme fotográfico. (Fonte: Spiricon, Inc.)

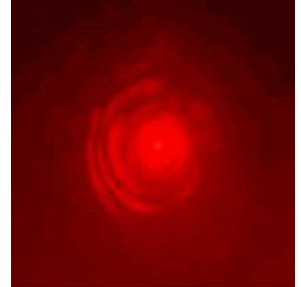

Figura 3 - Feixe laser refletido.

(Fonte: Spiricon, Inc.)

Os métodos eletrônicos são mais vantajosos do que os tradicionais, exibindo o perfil do feixe e sendo muito acurados na determinação do raio. Eles podem ser de movimento mecânico como o borda-da-lâmina e o diafragma óptico ${ }^{1}$, ou com câmera de sensor CCD.

Dos métodos eletrônicos citados, o borda-da-lâmina é o que possui instrumentação mais simples e custo reduzido. O borda-da-lâmina foi descrito pela primeira vez por Arnaud. et al [5] e relaciona o deslocamento da lâmina transversal ao feixe com a energia transmitida.

O método da borda da lâmina possui comercialmente equipamentos que são capazes de visualizar o perfil do feixe em 3D e caracterizar feixes de alta potência atenuando sua intensidade.

Os beam profiler, como são conhecidos comercialmente, são equipamentos importados, e de custo elevado, o que dificulta a sua aquisição por determinados profissionais.

A instrumentação de um equipamento, que caracterize um feixe automaticamente empregando o método da borda-da-lâmina não é muito complicada, contudo, exige rigor na montagem das partes que o compõe e o desenvolvimento de um programa que automatize o processo de aquisição e analise dos dados.

\footnotetext{
${ }^{1}$ Do Inglês: Pinhole
} 
Nosso trabalho visa construir um protótipo simples e econômico, e também desenvolver um sistema de automação de fácil uso com o protótipo. Pretendemos ao término do trabalho expor as características inovadoras do protótipo e propor uma alternativa que atenda as necessidades nacionais, com custos de montagem e comercialização abaixo do mercado internacional.

\subsection{Feixes Gaussianos e Modos de Propagação do Laser}

O estudo das cavidades ressonantes é baseado nas equações de campos eletromagnéticos no espaço livre ou em qualquer meio isotrópico e uniforme. Em nosso estudo levaremos em consideração os efeitos da difração e interferência dentro da cavidade, não considerando a polarização.

Para a teoria das cavidades estamos interessados em campos elétricos transversais $E(r)$, no vácuo como da equação (1).

$$
\nabla^{2} E(r)+\frac{1}{c^{2}} \frac{\partial^{2}}{\partial r^{2}} E(r)=0
$$

sendo $c$ a velocidade da luz no vácuo.

Admitindo que $E(r)$ varie apenas na direção z, e seja independente de x e y, as soluções para a equação (1) são dadas pela equação (2) na forma abaixo.

$$
E(r)=u_{0}(r) e^{-i k z}
$$

Onde $u_{0}$ é uma amplitude constante nas direções transversais x e y; $k$ a constante de propagação do meio que será definido a seguir.

A solução tem uma dependência espacial que varia com $e^{-i k z}$ na direção de propagação z. Esta variação tem um período espacial de um comprimento de onda $\lambda$. Para ondas transversais, o perfil dado por $u$, na equação (2) terá alguma variação em x e y. Isto ocorrerá lentamente com a distância $\mathrm{z}$ devido aos efeitos de difração e propagação. 
A lenta variação transversal com a distância $z$ e a variação do perfil do feixe com a distância ao longo de z será menor quando comparados à variação de $e^{-i k z}$ na direção z para feixes colimados.

Substituindo a equação (2) na equação (1), obtemos a equação (3) que tem a forma da equação de Helmoltz para $u(\mathrm{x}, \mathrm{y}, \mathrm{z})$.

$$
\left[\nabla^{2}+k^{2}\right] u_{0} e^{-i k z}=0
$$

onde

$$
k=\frac{2 \pi}{\lambda}
$$

$\mathrm{e}$

$$
\lambda=\frac{\lambda_{0}}{n}
$$

Desenvolvendo a equação (3) em coordenadas retangulares e derivando o termo em z, obtemos a equação abaixo, onde a $e^{-i k z}$ é fatorada da equação.

$$
\frac{\partial^{2} u}{\partial x^{2}}+\frac{\partial^{2} u}{\partial y^{2}}+\frac{\partial^{2} u}{\partial z^{2}}-2 i k \frac{\partial u}{\partial z}=0
$$

Assumindo que $u_{0}(r)$ varia aproximadamente com $e^{-i k z}$ em $\mathrm{z}$, da ordem de vários comprimentos de onda. Isto pode ser expresso matematicamente pela aproximação paraxial

$$
\left|\frac{\partial^{2} u}{\partial z^{2}}\right|<<\left|2 k \frac{\partial u}{\partial z}\right|,\left|\frac{\partial^{2} u}{\partial x^{2}}\right|,\left|\frac{\partial^{2} u}{\partial y^{2}}\right|
$$

Desprezando a derivada segunda em z na equação (6), obtemos a equação paraxial da onda.

$$
\frac{\partial^{2} u}{\partial x^{2}}+\frac{\partial^{2} u}{\partial y^{2}}-2 i k \frac{\partial u}{\partial z}=0
$$

de forma mais geral 


$$
\nabla_{T}^{2} u(s, z)-2 i k \frac{\partial u(s, z)}{\partial z}=0
$$

onde s refere-se as coordenadas transversais $s \equiv(x, y)$ ou $s \equiv(r, \theta)$ dependendo do sistema de coordenadas adotado e $\nabla_{T}^{2}$ é o laplaciano transversal operando sobre o sistema de coordenadas adotado no plano transversal.

A validade da aproximação paraxial pode ser analisada quando tomamos um feixe óptico como sendo uma superposição dos componentes das ondas planas viajando em vários ângulos ao longo do eixo z. Segundo Siegman [6], para as componentes que viajam ao longo do eixo z, com ângulo menor que $30^{\circ}$, o termo $\frac{\partial^{2} u}{\partial z^{2}}$ será muito pequeno quando comparado aos outros termos, o que concorda com a aproximação paraxial.

Para a equação diferencial parcial (8) Kolgelnik e Li [7], propuseram uma solução com duas variáveis no espaço (x e y), com t sendo substituído por z.

$$
u(r)=\exp \left[-i\left(P+\frac{k r^{2}}{2 q}\right)\right]
$$

onde

$$
r^{2}=x^{2}+y^{2}
$$

O parâmetro $P$ representa um deslocamento complexo de fase o qual é associado com a propagação do feixe, e $q(z)$ é um parâmetro complexo do feixe, que descreve a variação na intensidade do feixe com a distância $r$ e a curvatura de fase próxima ao eixo. Substituindo a equação (10) em (8) e comparando os termos de mesma potência em $r$, extraímos as seguintes relações

$$
\frac{d q}{d z}=1
$$




$$
\frac{d P}{d z}=-\frac{i}{q}
$$

cujas soluções são:

$$
q(z)=q_{0}+z
$$

$\mathrm{e}$

$$
\exp [-i P(z)]=\frac{q_{0}}{q(z)}
$$

Como $q(z)$ é um parâmetro complexo, podemos escrevê-lo como

$$
\frac{1}{q(z)}=\frac{1}{R(z)}-i \frac{\lambda}{\pi w^{2}(z)}
$$

onde $R(z)$ e $w(z)$ são reais e representam o raio de curvatura da onda e o raio do feixe em qualquer plano $\mathrm{z}$.

Substituindo as equações (15) e (53) na equação (10), obtemos a equação (54) para ondas esféricas divergindo de uma fonte puntual complexa.

$$
u(x, y, z)=\frac{q_{0}}{R(z)+j \frac{\lambda}{\pi w(z)^{2}}} \exp \left[-i\left(k z-\phi+\frac{k r^{2}}{z R(z)}\right)\right] \exp \left(-\frac{r^{2}}{w(z)^{2}}\right)
$$

Para um feixe propagando no espaço livre o parâmetro complexo assume um valor puramente imaginário na cintura do feixe $(z=0)$ quando $\mathrm{R}$ é muito grande $(\mathrm{R}=\infty)$.

$$
q_{0}=i \frac{\pi w_{0}^{2}}{\lambda}
$$

A intensidade de um feixe propagando na direção $z$ é desprezível em pontos muito distantes do eixo $z$. O perfil de intensidade radial de um feixe gaussiano é proporcional ao quadrado da amplitude do campo, isto é

$$
I(r, z) \approx \frac{\left|q_{0}\right|^{2}}{\left|q_{z}\right|^{2}} \exp \left(\frac{-2 r^{2}}{w(z)^{2}}\right)
$$


no plano normal à direção de propagação $z$. À uma distância lateral $w$ do eixo z, a intensidade é reduzida por um fator de $e^{2}$. Projetando o feixe sobre um plano, observamos que o raio do feixe é dado por $w$, e seu diâmetro por

$$
d=2 w
$$

Para um feixe gaussiano o diâmetro $d$ possui aproximadamente $86 \%$ ou $\frac{1}{e}$ da intensidade do feixe.

Substituindo (36) em (14), temos

$$
q(z)=i \frac{\pi w_{0}^{2}}{\lambda}+z
$$

Igualando as partes reais e imaginárias das equações (50) e (16), obtemos

$$
w^{2}(z)=w_{0}{ }^{2}\left[1+\left(\frac{\lambda z}{\pi w_{0}{ }^{2}}\right)^{2}\right]
$$

$\mathrm{e}$

$$
R(z)=z\left[1+\left(\frac{\pi w_{0}^{2}}{\lambda z}\right)\right]
$$

Na Figura 4 é mostrada a expansão do feixe de acordo com a equação (22) 


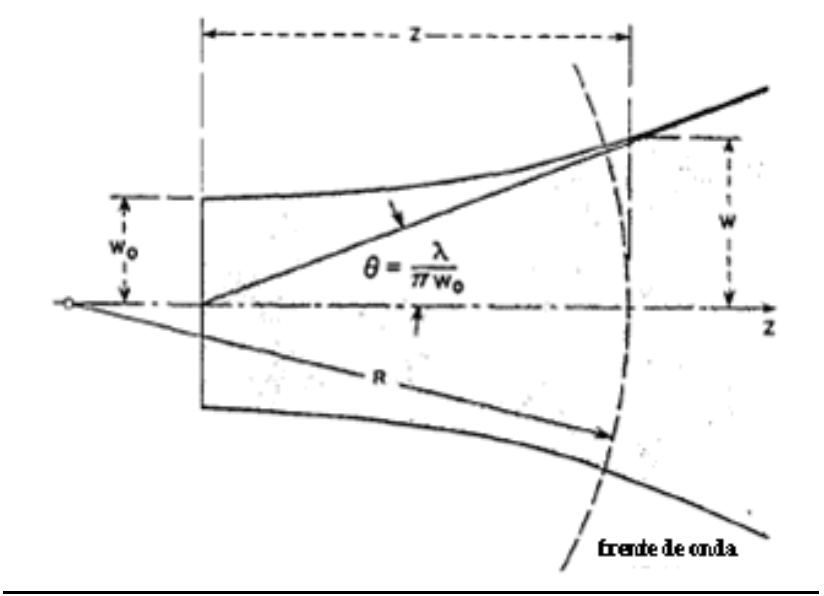

Figura 4 - Crescimento do diâmetro do feixe como função da distância da cintura.

(Fonte: Kogelnik, H. e Li, T.)

$\mathrm{Na}$ figura o feixe inicialmente está numa região concentrada $(z=0)$, denominada cintura do feixe, onde o raio $\mathrm{w}_{0}$ é mínimo, a partir desse ponto o raio começa a aumentar e o feixe diverge. A região, próxima a cintura do feixe é conhecida como região de Rayleigh e é definida por:

$$
Z_{R}=\frac{\pi w_{o}^{2}}{\lambda}
$$

Nessa região, a cintura do feixe varia muito pouco e em $z=Z_{R}, w\left(Z_{R}\right)=w_{0} \sqrt{2}$.

Quanto menor for o raio do feixe na cintura, menor a região de Rayleigh, e assim maior a divergência do feixe ao longo do sentido de propagação z, a partir da cintura. Dessa forma, o ângulo de divergência do feixe obtido da inclinação da assíntota de w(z) é da forma:

$$
\theta=\left.\frac{d w(z)}{d z}\right|_{z \gg>Z_{R}}=\frac{\lambda}{\pi w_{0}}
$$

Este é o ângulo de difração para campos distantes do modo fundamental do feixe.

As soluções apresentadas pela equação (8), referem-se a feixes gaussianos de baixa ordem, ou no modo fundamental $\mathrm{TEM}_{00}$, no entanto existem outras soluções de ordem superior para a equação (8). Essas soluções formam um grupo completo e ortogonal de funções chamados de modos de propagação e podem ser escritos em coordenadas retangulares 
ou em coordenadas cilíndricas, dependendo das características da cavidade. Para sistemas com geometria retangular a equação (8), tem as seguintes soluções

$$
u=g\left(\frac{x}{w(z)}\right) h\left(\frac{y}{w(z)}\right) \exp \left\{-i\left[P+\frac{k\left(x^{2}+y^{2}\right)}{2 q}\right]\right\}
$$

onde $g(x, z)$ e $h(y, z)$ descrevem a propagação do feixe, e dependem do parâmetro $w$ que é a dimensão do feixe.

Substituindo (26) em (8), encontramos a equação diferencial para os polinômios de Hermite $\mathrm{H}_{\mathrm{m}}(\mathrm{x})$ de ordem $\mathrm{m}$.

$$
\frac{d^{2} H_{m}}{d x^{2}}-2 x \frac{d H_{m}}{d x}+2 m H_{m}=0
$$

As seguintes soluções são aceitas para g e h

$$
g(x, z)=H_{m}\left(\sqrt{2} \frac{x}{w(z)}\right), \mathrm{m}=0,1,2, \ldots
$$

e

$$
h(y, z)=H_{n}\left(\sqrt{2} \frac{y}{w(z)}\right), \mathrm{n}=0,1,2, \ldots
$$

m e n são os modos transversais eletromagnéticos $\mathrm{TEM}_{\mathrm{mn}}$.

Abaixo temos alguns polinômios de Hermite de baixa ordem.

$$
\begin{array}{ll}
H_{0}(x)=1 & H_{2}(x)=4 x^{2}-2 \\
H_{1}(x)=2 x & H_{3}(x)=8 x^{3}-12 x
\end{array}
$$

$\mathrm{Na}$ Figura 5 são mostrados alguns modos transversais de um laser de He-Ne. O número do modo (m ou n), representam as regiões escuras (baixa intensidade) nas direções $\mathrm{x}$ ou y. 


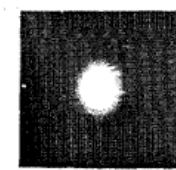

TEM 00

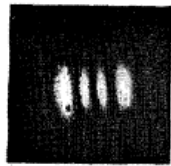

$\mathrm{TEM}_{30}$

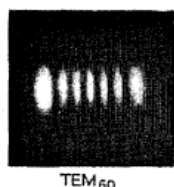

TEM 60

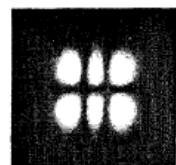

$\mathrm{TEM}_{21}$

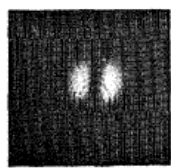

TEM $_{10}$

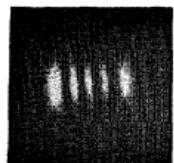

$\mathrm{TEM}_{40}$

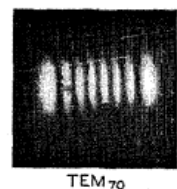

$\mathrm{TM}_{70}$

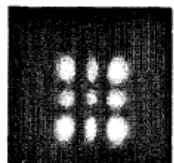

$\mathrm{TEM}_{22}$
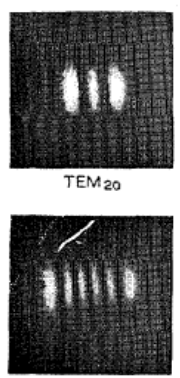

TEMso
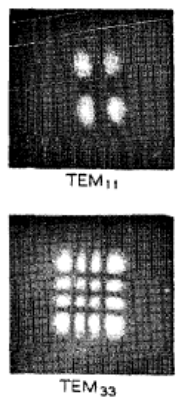

Figura 5 - Modos de propagação obtidos do laser de He-Ne.

(Fonte: Kogelnik, H. e Li, T.)

Os parâmetros $w(z)$ e $R(z)$ são os mesmos para todos os modos. Nos sistemas com geometria cilíndrica $(r, \phi, z)$ a solução para a equação (8) é da forma

$$
u=g\left(\frac{r}{w}\right) \exp \left\{-i\left(P+\frac{k}{2 q} r^{2}+l \phi\right)\right\}
$$

onde

$$
g=\left(\sqrt{2} \frac{r}{w}\right)^{l} L_{P}{ }^{l}\left(2 \frac{r^{2}}{w^{2}}\right)
$$

Onde $L_{p}{ }^{l}$ é o polinômio de Laguerre, e p e 1 são os modos radial e angular. $L_{p}^{l}(x)$ obedece a equação diferencial

$$
x \frac{d^{2} L_{p}^{l}}{d x^{2}}+(l+1-x) \frac{d L_{p}^{l}}{d x}+p L_{p}^{l}
$$

Abaixo são listados os polinômios de Laguerre de baixa ordem

$$
L_{0}^{l}(x)=1
$$




$$
\begin{aligned}
& L_{l}^{l}(x)=l+1-x \\
& L_{2}^{l}(x)=1 / 2(l+1)(l+2)-(l+2) x+1 / 2 x^{2}
\end{aligned}
$$

Como no modo de geometria retangular, os parâmetros $w(z)$ e $R(z)$ são os mesmos para todos os modos.

Cada distribuição arbitrária de luz monocromática pode ser expandida em termos desses modos de propagação.

\subsection{Fator de qualidade $M^{2}$}

Nos itens anteriores, analisamos o feixe gaussiano no modo fundamental e seus modos de propagação. Neste item, definiremos o conceito de $\mathrm{M}^{2}$ e como medí-lo.

O fator de qualidade, $\mathrm{M}^{2}$, descreve o desvio de um feixe laser do seu modo fundamental TEM 00 .

A idéia fundamental sobre a qualidade de um feixe está na comparação da divergência do feixe com distribuição de energia arbitrária e a divergência no modo fundamental. Dessa forma, podemos definir o $\mathrm{M}^{2}$ como:

$$
\theta \cdot w_{0}=M^{2} \frac{\lambda}{\pi}
$$

A equação (33) mostra que a cintura do feixe aumentará proporcionalmente com o $\mathrm{M}^{2}$ [8]. Outra conclusão é que para a determinação do $\mathrm{M}^{2}$, é necessário primeiro determinar: o raio ou diâmetro mínimo do feixe $\left(d=2 w_{0}\right)$; e seu ângulo de divergência $(\theta)$.

Para feixes gaussianos teóricos $\mathrm{o} \mathrm{M}^{2}=1$; para lasers reais $\mathrm{M}^{2}>1$. Na Europa o fator pode ser representado por K e eles são relacionados por: [9] 


$$
M^{2}=\frac{1}{K}
$$

$\mathrm{O}$ aumento de $\mathrm{M}^{2}$ ou a redução de $\mathrm{K}$ são associados a uma perda na qualidade do feixe.

$\mathrm{O} \mathrm{M}^{2}$ não é um fator simples de se medir, como acontece com o raio do feixe. Para determiná-lo, é necessário mapear a propagação do feixe no espaço.

O padrão ISO [10], estabelece que se deve efetuar pelo menos 10 medições do raio do feixe em posições distintas, após ser focado por uma lente de posição fixa.(Figura 6)

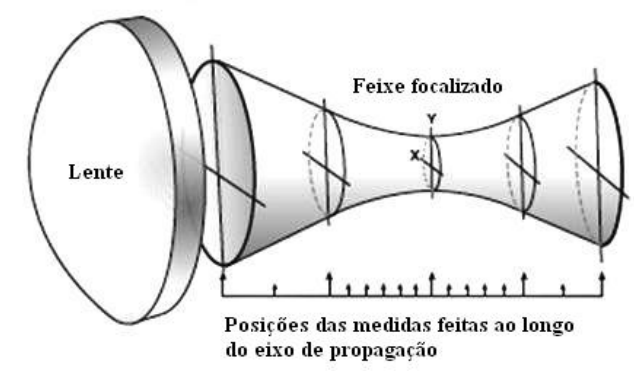

Figura 6 - Medidas do $M^{2}$ ao longo do feixe.

Os raios obtidos pelos cortes são ajustados pela equação (35), considerando um feixe não gaussiano, para determinar o $\mathrm{M}^{2}$.

$$
M^{2}=\frac{\pi d_{0}^{2}}{2 \lambda\left(z-z_{0}\right)}\left(\frac{d^{2}}{d_{0}{ }^{2}}-1\right)^{\frac{1}{2}}
$$

onde $d_{0}$ representa o diâmetro do feixe na cintura, dado por $d_{0}=2 w_{0}$; e $z_{0}$ a posição da cintura. 


\subsection{Método Borda-da-lâmina}

Para a instrumentação do protótipo, baseamos sua montagem no método borda-dalâmina. O método consiste em relacionar o deslocamento de uma lâmina transversal ao feixe com a energia transmitida, a qual é captada por um detector. No início do deslocamento da lâmina o sinal captado terá intensidade máxima (Figura 7), e a medida que o feixe é obstruído a intensidade do sinal diminui gradativamente até atingir um patamar, ou intensidade mínima do sinal. O sinal captado terá a forma mostrada na Figura 7 e representará a integral da função Gaussiana que descreve o feixe.

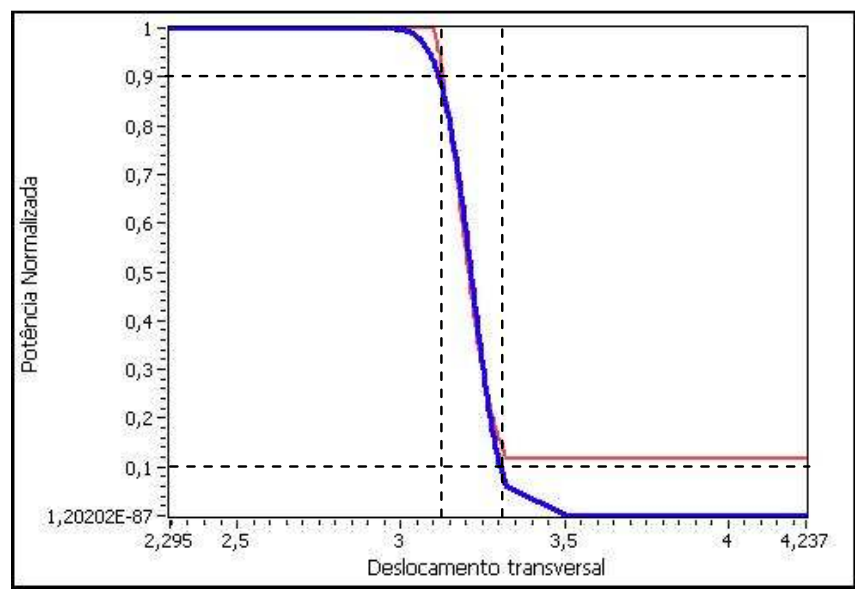

Figura 7 - Perfil do feixe em vermelho com o respectivo ajuste em azul.

Como procedimento para melhorar o ajuste da função ao perfil medido, Khosrofian e Garetz[11], proporam um método analítico de aproximações para o perfil do feixe utilizando o polinômio abaixo:

$$
P_{N}(x)=\frac{1}{1+\exp \left(-\left[a_{0}+a_{1} t+a_{2} t^{t}+a_{3} t^{3}\right]\right)}
$$

Onde $\mathrm{a}_{0}=-6.71387 \times 10^{-3}, \mathrm{a}_{1}=-1.55115, \mathrm{a}_{2}=-5.13306 \times 10^{-2}, \mathrm{a}_{3}=-5.49164 \times 10^{-2}, \mathrm{t}=$ $\left(2 / w_{x}\right)\left(x-x_{0}\right)$ e $P_{N}(x)$, dado pela equação (37), que representa a potência normalizada calculada pela razão das integrais da potência transmitida pela potência total, onde os limites de 
integração representam as posições assintóticas para o qual o diâmetro do feixe é determinado.

$$
P_{N}(x)=\frac{\int_{-\infty}^{x} d x \int_{-\infty}^{+\infty} I(x, y) d y}{\int_{-\infty}^{+\infty} \int_{-\infty}^{+\infty} I(x, y) d x d y}
$$

Uma expressão similar para $\mathrm{P}_{\mathrm{N}}(\mathrm{y})$ pode ser escrita utilizando esta razão. $\mathrm{O}$ valor analítico encontrado para w representará o raio do feixe para o nível de corte igual a 1/e do valor máximo da intensidade (Figura 7), e $\mathrm{x}_{0}$ a posição da intensidade máxima.

O erro teórico na determinação analítica de w é de 0,05\%[11]. Esta ordem de erro é encontrada para uma boa condição de montagem do método.

\subsection{Motor de Passo}

Fizemos nos itens 1.1, 1.2 e 1.3, uma análise do comportamento do feixe laser ao se propagar e de como podemos caracterizá-lo. Neste e nos próximos quatro itens enfocaremos nossa análise na teoria de funcionamento das partes instrumentais do protótipo. Neste item nossa análise será sobre o funcionamento do motor de passo, como é composto e os tipos encontrados no mercado.

Motor de passo é um tipo de motor elétrico que pode ser controlado por sinais digitais, ou seja, é um transdutor que converte energia elétrica em energia mecânica, especialmente, energia cinética. Eles são utilizados em aplicações que envolvem controle e medida. Nas aplicações onde são utilizados os motores de passo, em geral, possuem as seguintes características:

1. Controle digital de velocidade e posição - motores de passo podem ser controlados por sinais digitais.

2. Sem escovas - motores de passo não possuem escovas que são uma das principais causas de problemas em motores convencionais. 
3. Posicionamento em caminho aberto - os motores movem-se em incrementos quantificados ou passo. O posicionamento do eixo a medida que ocorre o movimento é bem definida, não necessitando de mecanismo de realimentação de posição.

4. Carga independente - o motor de passo pode rodar a uma velocidade constante desde que a carga aplicada ao eixo não exceda o torque do motor.

5. Holding torque - É o máximo torque que pode ser aplicado ao eixo de um motor energizado sem causar rotação.

6. Excelente resposta ao iniciar, parar e girar no sentido reverso.

7. Erro de posicionamento não acumulativo ( $\pm 5 \%$ do ângulo de passo).

$\mathrm{O}$ motor de passo fundamentalmente pode ser dividido em: rotor e estator (Figura $8 \mathrm{e}$ 9). O rotor é um conjunto eixo-imã que rodam solidariamente na parte móvel do motor; o estator, ou a parte fixa do motor, é onde se localizam as bobinas.

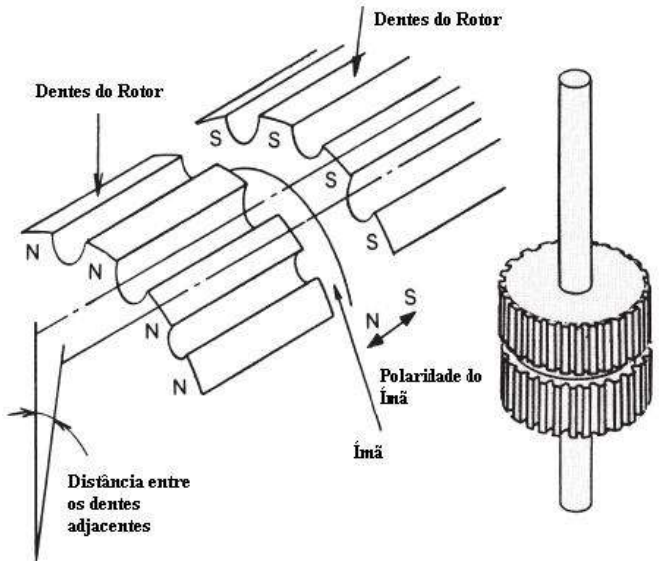

Figura 8 - Esquema do Rotor.

(Fonte: Shinano Kenshi Co.)

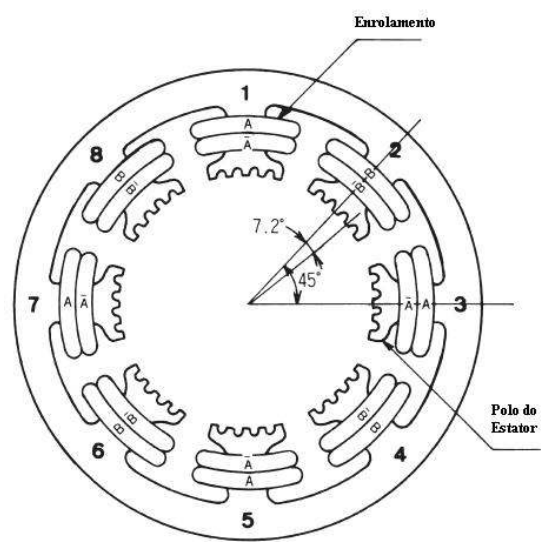

Figura 9 - Esquema do estator. (Fonte: Shinano Kenshi Co.)

Os motores de passo são classificados como: ímã permanente, relutância variável e híbrido [12]. Os motores do tipo ímã permanente possuem rotor magnetizado, enquanto que os motores de relutância variável, apresentam um rotor com muitas polaridades construído a partir de ferro doce. Os motores híbridos combinam características dos motores ímã permanente e relutância variável. Os motores de ímã permanente e os híbridos podem ter 
enrolamento do tipo unipolar, bipolar ou bifiliar. A Tabela 1 mostra as principais características dos motores de passo.

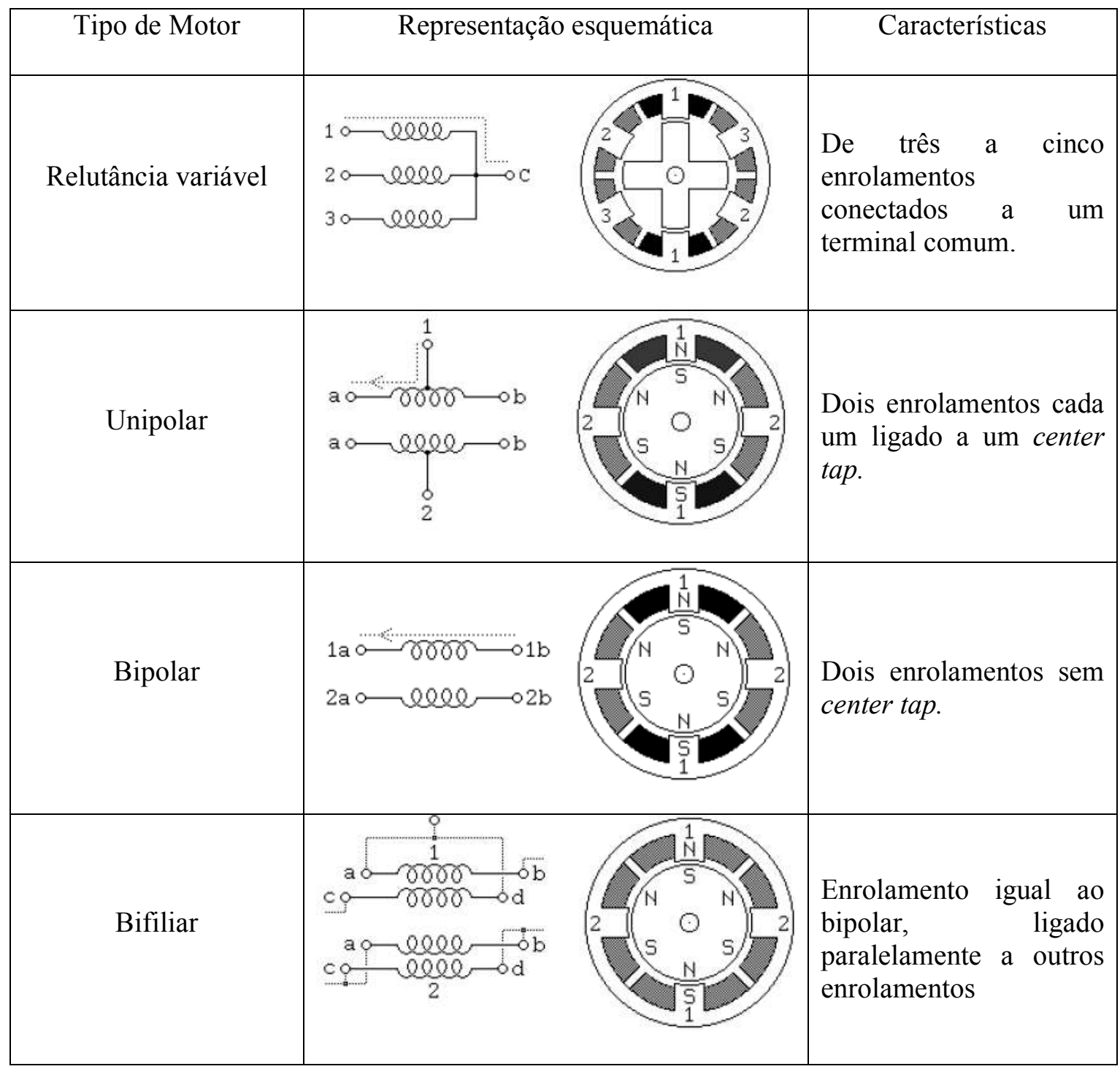

Tabela 1 - Tabela descritiva dos tipos de motores de passo.

O motor de passo utiliza ímãs para girar o eixo numa distância precisa quando um pulso elétrico é fornecido. Na Figura 10 é mostrada a seção transversal do motor com os seis pólos do rotor e quatro pólos do estator. Para esta representação, o rotor requer 12 pulsos elétricos para mover 12 passos completando uma revolução ou uma volta. Outra maneira de representar é girando o rotor precisamente $30^{\circ}$ por cada pulso elétrico recebido pelo motor. $\mathrm{O}$ 
número de graus do rotor pode ser calculado dividindo o número de graus de uma volta pelo número de pólos do rotor. Para a representação serão $360^{\circ}$ dividido por 12 resultando em $30^{\circ}$.

Quando nenhum pulso elétrico é aplicado ao motor, o magnetismo residual nos ímãs do rotor causará "detenção" ou alinhamento dos seus pólos magnéticos com os pólos magnéticos do estator, mantendo o eixo estacionado nesta posição.

Quando um pulso elétrico é aplicado, ele é direcionado para o par de bobinas do estator, tornando-a magnetizada com os respectivos pólos Norte e Sul. Ao magnetizar o estator, ele atrairá o pólo do rotor mais próximo ao que possui polaridade oposta. O fluxo de corrente pelos pólos permitira que o rotor tenha muito mais força de atração ao pólo do estator, aumentando o torque, que é chamado de holding torque.

Mudando o fluxo de corrente para a próxima bobina do estator, o campo magnético mudará em $90^{\circ}$. O rotor somente irá girar em $30^{\circ}$ antes que seu campo magnético novamente alinhe com a mudança no campo do estator. O campo magnético no estator é continuamente mudado a medida que o rotor move-se completando uma revolução (Figura 11)

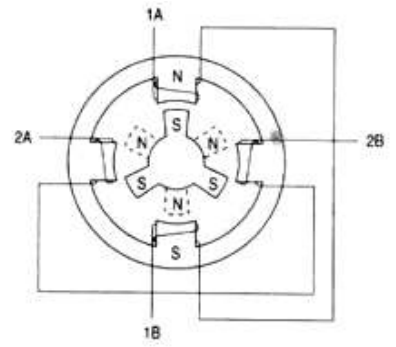

Figura 10 - Diagrama representando os pólos do rotor e estator de um motor de passo. (Fonte: Parker Compumotor Division) 

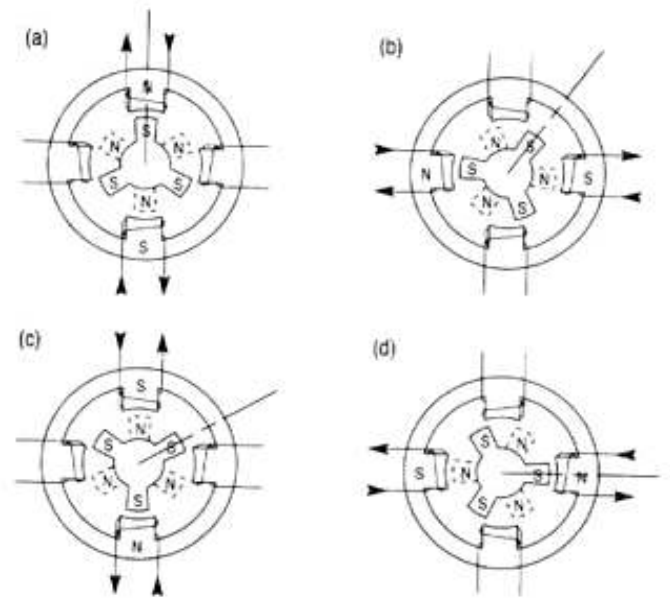

Figura 11 - Movimentos do motor de passo pelos pulsos de corrente. (a) a corrente é aplicada as bobinas superior e inferior; (b) corrente aplicada as bobinas direita e esquerda do estator; (c) novamente as bobinas superior e inferior são magnetizadas, mas com pólos invertidos; (d) bobinas direita e esquerda magnetizada com os pólos invertidos

(Fonte: Parker Compumotor Division)

\subsection{Amplificadores}

Os amplificadores operacionais (amp-op), são circuitos amplamente utilizados na eletrônica e extremamente versáteis.

Os amp-op são amplificadores de acoplamento direto, de alto ganho que usam realimentação para o controle de suas características, sendo representados pelo símbolo (Figura 12):

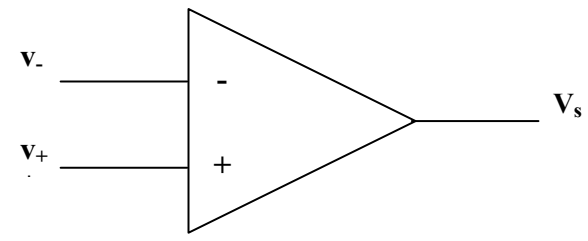

Figura 12 - Símbolo do amp-op, com $v_{\text {_: }}$ entrada inversora; $v_{+}$: entrada nãoinversora; e $\mathrm{v}_{\mathrm{s}}$ : saída.

São utilizados em algumas operações matemáticas simples (adição, subtração, multiplicação, divisão, integração e diferenciação), de onde resulta o seu nome amplificador 
operacional. São úteis ainda em várias aplicações em instrumentação, sistemas de controle, sistema de regulação de tensão e corrente, processamento de sinais e etc.

O amp-op ideal possui as seguintes características (Figura 13):

- ganho de tensão diferencial infinito;

- ganho de tensão de modo comum igual a zero

- tensão de saída nula para tensão de entrada igual a zero

- impedância de entrada infinita

- impedância de saída igual a zero

- faixa de passagem infinita

- deslocamento de fase igual a zero

- deriva nula da tensão de saída para variações de temperatura

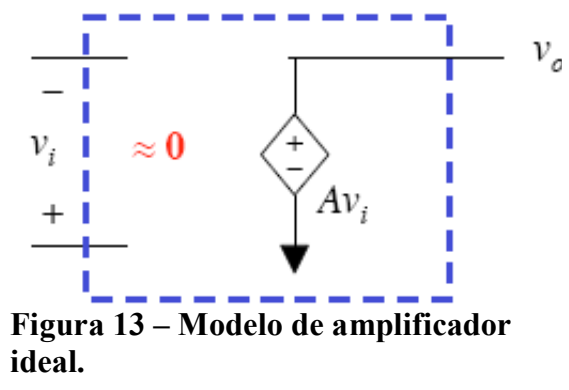

Admitindo um amplificador ideal, sua impedância de entrada é infinita e não há corrente nas suas entradas, então para uma configuração inversora (Figura 14), a tensão é dada por:

$$
\frac{v_{s}+v_{i}}{R_{s}}=\frac{v_{o}+v_{i}}{R_{f}}
$$

Onde para um ganho $\mathrm{A} \approx \infty \rightarrow v_{i} \approx 0$. Como a corrente na entrada $i_{-} \approx 0$, então $i_{s}=-i_{f}$, dessa forma a razão entre as tensões da saída e da entrada é igual a:

$$
\frac{v_{o}}{v_{s}}=\frac{-R_{f}}{R_{s}}
$$

desde que $-V_{c c} \leq v_{o} \leq V_{c c}$ 


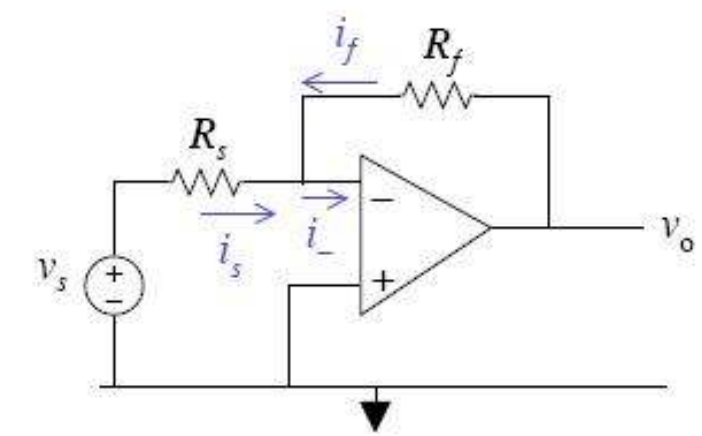

Figura 14 - Circuito amplificador inversor.

$\mathrm{Na}$ análise da configuração não inversora (Figura 15), o sinal a ser processado é aplicado na entrada não-inversora e o sinal de saída é realimentado na entrada inversora.

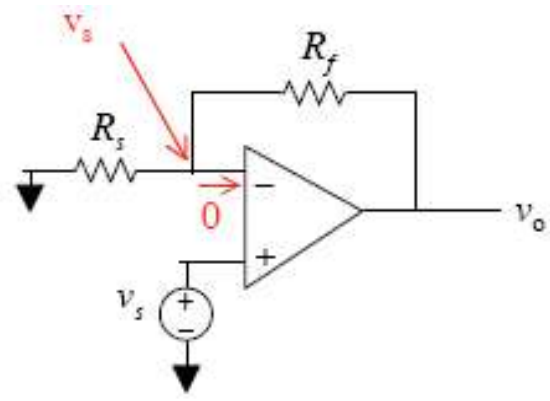

Figura 15 - Circuito amplificador não- inversor.

Assim temos que:

$$
\begin{gathered}
\frac{v_{s}}{R_{s}}+\frac{v_{s}-v_{o}}{R_{f}}=0 \\
\frac{v_{o}}{v_{s}}=1+\frac{R_{f}}{R_{f}}
\end{gathered}
$$

Com o amplificador operacional, pode-se, ainda, implementar funções como a multiplicação ou divisão (Figura 16) de um sinal (forma de onda) por uma constante, soma de dois ou mais sinais, integração de um sinal, diferenciação de um sinal e etc. 
Na multiplicação ou divisão de um sinal, dado a equação (42)

$$
v_{o}=-\frac{R_{2}}{R_{1}} v_{i}
$$

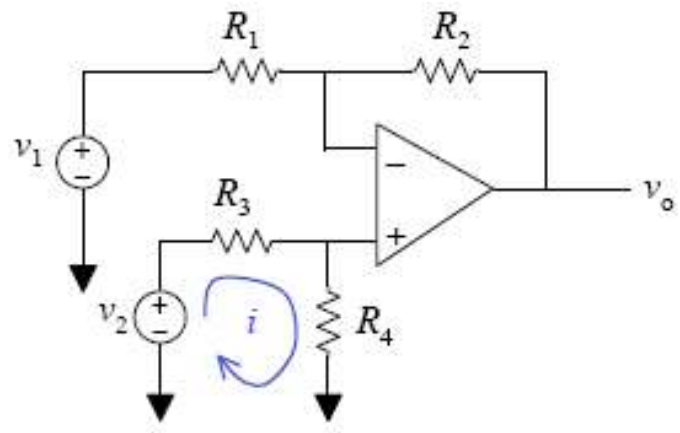

Figura 16 - Circuito amplificador multiplicador ou divisor.

Onde as resistências $R_{1}$ e $R_{2}$ são iguais, vemos que o amplificador pode executar operações de multiplicação e divisão do sinal de entrada por uma constante.

Para o circuito somador da Figura 17, com inversão de sinal de saída, temos

$$
v_{o}=-R_{f}\left(\frac{v_{1}}{R_{1}}+\frac{v_{2}}{R_{2}}+\frac{v_{3}}{R_{3}}\right)
$$

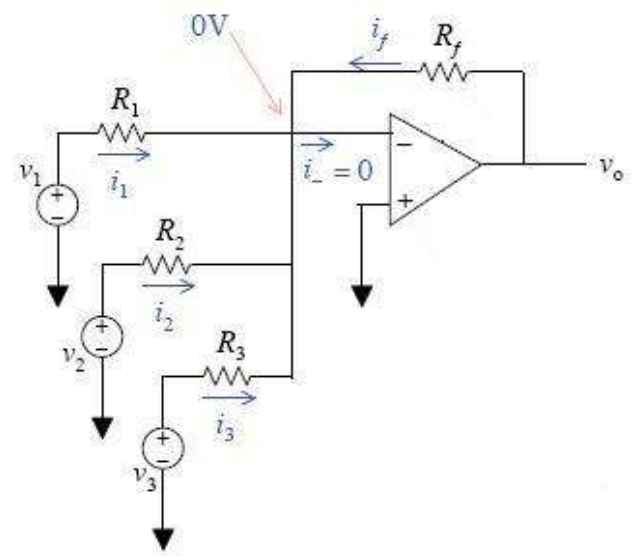

Figura 17 - Circuito amplificador somador.

onde a corrente $i_{f}$ é a soma das correntes $i_{1}, i_{2}, i_{3}$, assim, o circuito é um circuito amplificador somador, no qual cada entrada pode ser operada com fatores de escala diferentes. 
Para um circuito integrador, tomamos a configuração inversora e trocamos a resistência $\mathrm{R}_{2}$ por um capacitor (Figura 18)

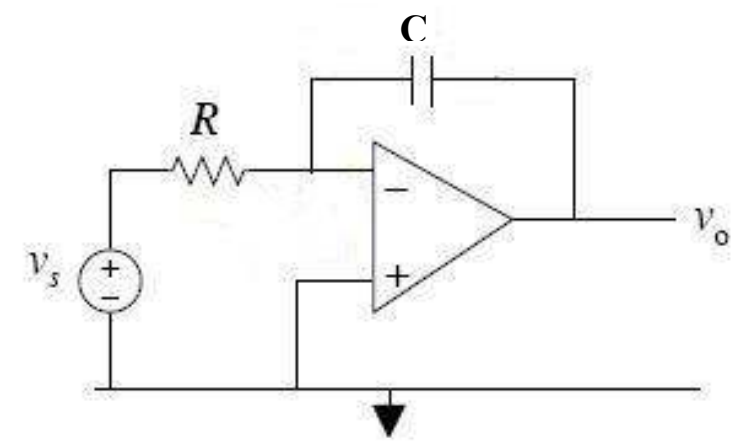

Figura 18 - Circuito amplificador integrador.

Aplicando a transformada de Laplace a equação (39), e substituindo a resistência $R_{s}$ por $\mathrm{R}$; e $\mathrm{R}_{\mathrm{f}}$ por $1 / \mathrm{sC}$, temos:

$$
v_{o}=-\frac{1}{R C} \cdot \frac{v_{s}}{s}
$$

Aplicando a anti-transformada de Laplace à equação (44), temos:

$$
v_{o}=-\frac{1}{R C} \int v_{s}(t) d t
$$

A equação (45), mostra que o sinal na saída é proporcional à integral do sinal de entrada.

Procedendo de maneira análoga ao circuito integrador, trocando o resistor $R_{s}$ por um capacitor $C$, e utilizando a equação (42), temos:

$$
v_{o}=-R C s v_{s}
$$

Aplicando a anti-transformada:

$$
v_{o}(t)=-R C \frac{d v_{s}(t)}{d t}
$$

A equação (47) mostra que o sinal de saída é igual a derivada do sinal de entrada. 


\subsection{Detectores}

Detectores são instrumentos que captam uma radiação óptica através de processos eletrônicos, podendo ser quânticos ou térmicos e apresentar vantagens e desvantagens na medição da radiação óptica no comprimento de onda de interesse. Assim, um detector pode medir radiação de alta potência, mas não possuir sensibilidade para baixa potência. Neste item, estudaremos os fotodiodos que são detectores quânticos sensitivos a radiação na região entre $200 \mathrm{~nm}$ e $1100 \mathrm{~nm}$ e os piroelétricos que detectam variações térmicas não sendo restritos a determinado comprimento de onda.

Os fotodiodos convertem energia luminosa em sinal elétrico; nestes dispositivos, o mecanismo fundamental de conversão de luz em corrente elétrica é a geração de pares elétron-lacuna, por absorção de fótons.

À medida que os fótons penetram no material, a quantidade absorvida diminui com a profundidade de penetração, resultando numa queda que é função de $\alpha$, o coeficiente de absorção do material na freqüência da luz; e de x, o caminho de penetração óptico, conforme vemos na equação (48).

$$
I_{p}(x)=I_{0} e^{(-\alpha x)}
$$

onde $\mathrm{I}_{0}$ é a intensidade máxima na superfície. Para que todos os fótons incidentes sejam absorvidos pelo material, é preciso que a espessura do material seja muito maior que $\alpha^{-1}$.

Para assegurar uma totalidade de fótons absorvidos a poucos $\mu \mathrm{m}$ da superfície, adotase um valor para $\alpha \sim 10^{6} \mathrm{~m}^{-1}$. Na região do visível os melhores materiais para fotodetecção são o Si e o GaAs. 
Os fotodiodos são formados por duas camadas dopadas com portadores do tipo $\mathrm{p}$ e $\mathrm{n}$, estabelecendo uma junção p-n que opera como um conversor fotoelétrico (Figura 19). A camada do tipo p é formada por portadores de carga positiva, as lacunas; a camada do tipo n é formada por portadores de carga negativa, os elétrons. Na região da junção entre as camadas ocorre difusão de portadores do tipo $\mathrm{p}$ para o lado $\mathrm{n}$ e vice-versa, recombinando-se, e formando a camada de depleção, que é livre de portadores de cargas.

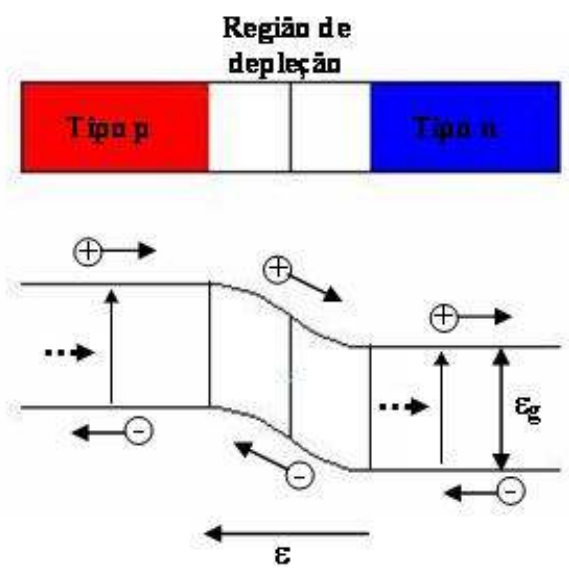

Figura 19 - Processo de criação dos pares elétron-lacuna na região de depleção.

Quando a luz atinge o fotodiodo, estimula os elétrons dentro da estrutura. Se a energia da luz for maior que a energia $\mathrm{E}_{\mathrm{g}}$ da banda de gap, os elétrons da banda de valência passam para banda de condução, deixando uma lacuna no seu lugar. Os pares elétron-lacuna são formados em todas as camadas do fotodiodo. Na camada de depleção, os pares elétron-lacuna gerados são separados pelo campo elétrico existente. Como o campo tem sentido do lado $\mathrm{n}$ para o lado $\mathrm{p}$, os buracos são acelerados no sentido $\mathrm{n} \rightarrow \mathrm{p}$, enquanto os elétrons movem-se no sentido $\mathrm{p} \rightarrow \mathrm{n}$.

$\mathrm{Na}$ camada tipo $\mathrm{n}$, os elétrons vindos da banda de valência encontram os elétrons vindo da camada do tipo $\mathrm{p}$, aumentando o número de portadores no lado $\mathrm{n}$ da banda de condução. As lacunas difundidas da camada do tipo n para a camada de depleção são aceleradas e coletadas na camada tipo $\mathrm{p}$ da banda de valência. Dessa forma, a quantidade de 
portadores gerados principalmente pela luz incidente, é coletada pelas camadas tipo $\mathrm{p}$ e $\mathrm{n}$. Isto resulta numa corrente positiva devido aos portadores da camada $\mathrm{p}$ e uma corrente negativa devido aos portadores da camada $n$.

A corrente total do fotodiodo, quando pares elétron-lacuna são gerados pela radiação incidente, é dada por uma corrente de escuro, mostrada na equação (49).

$$
I_{e}=I_{s}\left(e^{q V / \kappa_{B} T}-1\right)
$$

onde $I_{s}$ é a corrente de saturação reversa, que é função dos parâmetros do semicondutor que forma a junção e a fotocorrente gerada pelos fótons absorvidos próximos a camada de depleção. Esta fotocorrente é calculada em função do número de pares criados por unidade de volume e de tempo, da densidade de portadores gerados que são separados pelo campo elétrico que difundirão para os lados opostos da junção, resultando na corrente da junção dada pela equação

$$
I_{p}=\frac{\eta q P_{o p t} \lambda}{h c}
$$

Sendo a corrente $\mathrm{I}_{\mathrm{p}}$ de sentido reverso, a corrente total gerada no processo de fotodetecção é escrita na forma da equação (51)

$$
I=I_{s}\left(e^{q V / \kappa_{B} T}-1\right)-I_{p}
$$

A Figura 20 mostra a curva característica da corrente pela tensão de um fotodiodo no escuro e sob iluminação.

$\mathrm{Na}$ detecção da radiação os fotodiodos operam em dois modos distintos, esses modos dependem da aplicação a qual se destina. Segundo Rezende [13], o fotodiodo opera nos modos fotovoltaico e fotocondutivo. No modo fotovoltaico, o dispositivo trabalha em circuito aberto ou corrente de polarização zero, nesta situação quando a junção é iluminada, aparece uma tensão entre os lados $\mathrm{p}$ e $\mathrm{n}$ que pode ser medida externamente, cujo valor pode ser obtido da equação (52). 


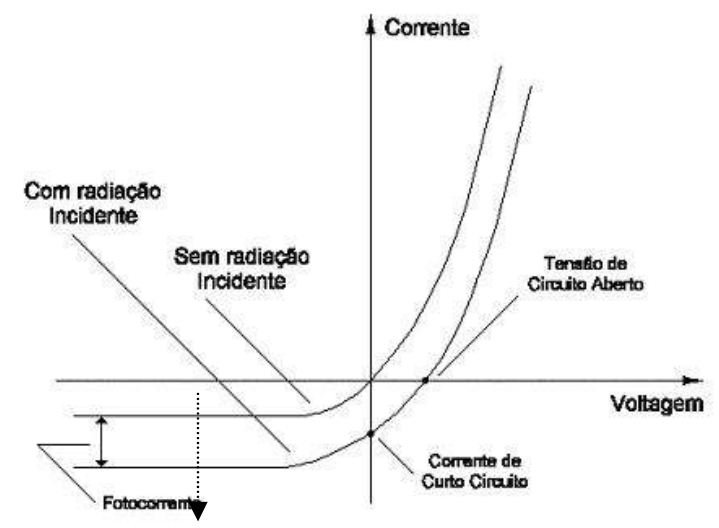

Figura 20 - Curva característica corrente versus tensão do fotodiodo. (Fonte: http://www.las.inpe.br/ cesar/Infrared/detetor/fotocorr2.gif)[14]

$$
V_{c a}=\frac{\kappa_{B} T}{q} \ln \left(\frac{I_{P}}{I_{S}}+1\right)
$$

O ponto de operação $\mathrm{I}=0, \mathrm{~V}=\mathrm{V}_{\mathrm{ca}}$ é a intersecção do eixo de tensão com a curva $\mathrm{V}$-I.

O modo fotovoltaico é indicado para aplicações que exigem alta sensibilidade. Muitos fotodiodos trabalham mais efetivamente com polarização zero, mesmo aqueles que originalmente trabalham com polarização reversa; no modo fotocondutivo o dispositivo opera polarizado reversamente, sob tensão externa no sentido reverso do fotodiodo. Dessa forma, uma corrente flui no sentido reverso quando a junção é iluminada. Aplicações que envolvem respostas rápidas e maior largura de banda são indicadas para este modo.

As características do fotodiodo podem ser descritas pela eficiência quântica; responsividade ou tempo de resposta; e o ruído.

A eficiência quântica $\eta$ é dada pelo número de pares elétron-lacuna gerados por fóton incidente e é dado pela equação (53).

$$
\eta=\frac{I_{p} h v}{q P_{o p t}}
$$

onde $I_{p}$ é a corrente fotogerada pela absorção da potência óptica incidente $P_{o p t}$ no comprimento de onda $\lambda$, representada pela energia $h v$ do fóton. 
A responsividade do fotodiodo é o tempo que o dispositivo leva para responder a uma rápida mudança nos níveis de luminosidade, esta grandeza é a razão entre a fotocorrente e a potência óptica incidente dado pela equação (54).

$$
\mathfrak{R}=\frac{I_{P}}{P_{\text {opt }}}=\frac{\eta q}{h v}[A / W]
$$

O tempo de resposta do fotodiodo é limitado pela combinação de três fatores: difusão de portadores, tempo de deriva na camada de depleção e a capacitância na camada de depleção. Os portadores gerados fora da camada de depleção levam certo tempo para difundirem-se. Para minimizar a difusão, forma-se a junção mais próxima à superfície do dispositivo. Quanto mais largo for a camada de depleção mais luz será absorvida, segundo Sze [15], a camada deve ser da ordem de $1 / \alpha$, o que resulta numa maior polarização reversa saturando a velocidade dos portadores. Baseado no exposto, concluímos que a camada de depleção não deve ser tão larga, pois afetará o tempo de trânsito limitando a freqüência de resposta, nem tão estreita, levando a uma elevada capacitância $C$, resultando num constante de tempo RC elevada, onde R é a resistência de carga. A espessura ideal da camada de depleção ocorre quando o tempo de trânsito é da ordem de um meio do período da freqüência de modulação.

No processo de fotodetecção generalizado, o fotodiodo agirá como uma fonte de ruídos elétricos e gerará uma corrente de ruídos. A corrente de ruídos limitará a utilidade do fotodiodo a níveis de corrente muito baixos, onde a magnitude do ruído aproxima-se da corrente gerada pelo processo fotoelétrico. O ruído gerado é dependente das características do fotodiodo e das condições de operação.

O fotodiodo p-i-n é um dos mais comuns fotodetectores. Sua estrutura possui adaptação à espessura da camada de depleção, otimizando a eficiência quântica e a freqüência de resposta. Sua operação é semelhante ao fotodiodo p-n, que foi discutida anteriormente. A espessura da região intrínseca (que na realidade não é intrínseca devido à baixa dopagem de 
portadores do tipo $\mathrm{n}$ ou $\mathrm{p}$ ), eleva em muito a resistividade da camada. Isto resulta numa região de depleção que se estende até o lado dopado com mais impurezas, fazendo com que a espessura útil do fotodiodo seja muito maior que na estrutura $\mathrm{p}-\mathrm{n}$, melhorando a resposta na região de maior comprimento de onda, pois assegura que toda radiação é absorvida mesmo nesta região de menor coeficiente de absorção.

Outro tipo de detector muito utilizado são os piroelétricos. Os detectores piroelétricos baseiam-se numa propriedade pouco conhecida dos sólidos que é a piroeletricidade, definida como a dependência da temperatura para a polarização espontânea de certos sólidos anisotrópicos.

Um cristal piroelétrico quando é posto entre dois eletrodos e ligado a um medidor de corrente e a temperatura desse cristal mantida constante, nenhuma corrente flui no circuito devido a polarização $\boldsymbol{P}_{\boldsymbol{S}}$ do cristal.

Se a temperatura aumenta, causa um momento de dipolo líquido e consequentemente, a polarização espontânea diminui. A quantidade de ligações diminui, e a redistribuição de cargas livres compensa as ligações de carga resultando num fluxo de corrente no circuito, corrente piroelétrica.

A existência do efeito piroelétrico em qualquer sólido requer que três condições sejam satisfeitas:

- A estrutura molecular deve ter momento de dipolo diferente de zero;

- O material não deve ter nenhuma simetria rotacional no eixo ou um único eixo de simetria rotacional que não seja incluído num eixo de inversão. Segundo Lang [16], de 32 cristais com grupo de simetria puntual, somente 10 permitem a existência de piroeletricidade, desses podemos citar o Titanato de Bário $\left(\mathrm{BaTiO}_{3}\right)$.

Os detectores piroelétricos são usados na detecção de radiação no infravermelho, convertendo a energia dos fótons em calor e usualmente operam em temperatura ambiente. $\mathrm{O}$ 
uso dos detectores piroelétricos não é restrito a limitado comprimentos de onda como os detectores quânticos, porém menos sensitivos.

Nos detectores piroelétricos a corrente $I$ gerada por Watt de potência detectada, $W_{0}$, é chamada de corrente de responsividade,

$$
R_{i}=\frac{I}{W_{0}}=\frac{\eta p A \omega}{G\left(1+\omega^{2} \tau_{T}^{2}\right)^{1 / 2}}
$$

onde $p$ é o coeficiente de amplitude piroelétrica; $\eta$ é a absorvidade do eletrodo; $A$ é a área da seção transversal do detector; $\omega$ é a freqüência de modulação da radiação; $G$ a condutância térmica e $\tau_{T}$ é a constante de tempo térmica.

O produto da corrente de responsividade pela impedância, é igual a tensão de responsividade, dado pela equação

$$
R_{V}=\frac{V_{p}}{W_{0}}=\frac{R_{T} \eta p A \omega}{G\left(1+\omega^{2} \tau_{T}{ }^{2}\right)^{1 / 2} \cdot\left(1+\omega^{2} \tau_{E}{ }^{2}\right)^{1 / 2}}
$$

onde $\tau_{E}$ é a constante de tempo para o circuito $\mathrm{RC} ; \mathrm{R}_{\mathrm{T}}$ é a resistência total do detector mais a resistência do circuito. De acordo com Lang[15], $\mathrm{R}_{\mathrm{v}}$ tem máxima freqüência entre os valores recíprocos das constantes de tempo térmica e elétrica.

As fontes de ruído nos detectores piroelétricos podem ser devido a: ruído térmico; ruído dielétrico ou Johnson; e ruído de amplificação.

O ruído Johnson aparece para freqüências acima de $20 \mathrm{~Hz}$. O ruído de amplificação é devido a corrente e a tensão de entrada do circuito e da resistência do elemento sensitivo. As variações na temperatura ambiente, as vibrações mecânicas e flutuações eletromagnéticas, podem ser fontes de ruído térmico do ambiente.

Para garantir uma boa responsividade, o sólido detector deve ser fino para maximizar a resposta devido ao aumento da temperatura e montado de forma a minimizar as perdas de temperatura pelo substrato. Ainda, isolantes com baixa condutividade térmica são usados nos 
dispositivos. Coeficiente piroelétrico alto e pequeno valor de permissividade dielétrica são também requeridos.

\subsection{Aquisição de Dados}

A tarefa de aquisição de dados envolve gerar informações do mundo real para serem manipulados por um computador. A aquisição de dados ${ }^{2}$, envolve adquirir sinais e formas de onda para posterior processamento e obtenção dos valores desejados. O processo de aquisição e análise dos dados faz uso de sensores, amplificadores, placa de aquisição, computadores e softwares, e estes devem ser bem dimensionados para não afetar os dados obtidos. Segue abaixo a descrição dos elementos mais importantes para aquisição e os seus principais parâmetros.

De acordo com o documento da National Instruments ${ }^{\circledR}$ sobre aquisição de dados [17], atualmente, nos laboratórios de pesquisa de cientistas e engenheiros, nos processos de medidas e testes, e nas automações industriais, a grande maioria utiliza computadores para adquirir dados. No entanto, a aquisição pode ser comprometida se o dispositivo de aquisição não tirar proveito das capacidades do computador que incluem o processamento em tempo real, a capacidade de trabalhar com gráficos complexos, a alta taxa de fluxo de acesso aos discos, taxa de transferência de dados dos barramentos (PCI, USB, PCMCIA, FIREWIRE etc).

Ao escolher a placa de aquisição e a arquitetura do barramento usados, saiba das taxas de transferência de dados alcançados por eles.

Outro fator importante é a escolha do sistema operacional (SO) para gerenciar o hardware do computador, o que é muito importante, pois o custo na compra, a facilidade de operação pelos usuários, a facilidade de implementação de ferramentas para aquisição e o

\footnotetext{
2 do inglês: data acquisition - DAQ
} 
reconhecimento da placa de aquisição, são fatores determinantes na adoção de um SO eficiente.

A interface entre o sinal e o computador é feito por um hardware de aquisição. O hardware pode ser em módulos que são conectados ao computador pelas portas, ou placas conectadas aos slots da placa-mãe. O hardware de aquisição é dividido de acordo com sua funcionalidade em:

- Entrada/Saída analógico;

- Entrada/Saída digital

- Contador/Temporizador;

- Multifuncionais, uma combinação dos três modos acima.

As especificações básicas da entrada analógica e que definem a precisão e a capacidade de manipulação dos dados de entrada são:

- Número de canais: definido pelo número de canais que operam no modo diferencial e terminação única. Os modos diferem entre si pela maneira como são aterrados. No modo terminação única às entradas possuem um terra comum a todos os canais; no modo diferencial cada canal tem seu próprio terra de referência. De acordo com a National Instruments [16], o modo terminação única é indicado para sinais que compartilham de um único terra e nível de tensão acima de $1 \mathrm{~V}$, já o modo diferencial beneficia pela redução no ruído, que é perdido ao longo dos cabos.

- Taxa de amostragem: freqüência com que os dados são convertidos. A conversão pode ser de forma multiplexada, onde um conversor analógico-digital (CAD) ${ }^{3}$ converte simultaneamente os dados.

- Resolução: o número de bits que o CAD usa pra representar o sinal analógico. Quanto maior a resolução, maior o número de divisões da amplitude do sinal e menor será a

\footnotetext{
${ }^{3}$ Do inglês: analog-to-digital converter (ADC)
} 
mudança detectável. Como exemplo, um CAD com resolução de 3 bits pode dividir a amplitude do sinal analógico em pacotes $\left(2^{3}\right)$, cada divisão é representada por um sinal binário, isto é, ele varia da sua representação mínima 000 até 111, a máxima representação binária do sinal. Para que essa representação seja precisa, além de uma boa resolução do CAD, é necessário que outra parte do circuito de aquisição tenha sido bem projetada.

- Faixa: nível máximo e mínimo que a placa de aquisição pode quantizar a voltagem.

- Comprimento do código: menor bit significante (MBS) ${ }^{4}$ que se pode representar a mudança na voltagem. O comprimento ideal é encontrado dividindo a faixa de voltagem pelo ganho vezes duas ordens de magnitude da resolução do bit. Para uma placa multifuncional de 16 bits com faixa de voltagem de $0-10 \mathrm{~V}$, e ganho de 100 , temos um comprimento de código calculado da maneira abaixo:

$$
\text { código }=\frac{10}{100 \times 2^{16}}=1,525 \mu \mathrm{V}
$$

o resultado representa a menor variação na voltagem que o dispositivo de aquisição pode detectar.

Na saída analógica, frequentemente é necessário associar um circuito a essa saída para amplificar o sinal de saída da placa de aquisição. A qualidade do sinal de saída depende do tempo de estabilização do sinal de saída; do slew rate e da resolução de saída.

- Tempo de estabilização é o tempo requerido para a saída estabelecer a sua acurácia.

- Slew Rate é a máxima taxa que a placa de aquisição pode produzir ao sinal de saída.

- A resolução de saída, assim como a resolução de entrada, representa o número de bits usados pela porta de saída.

As interfaces de entrada/saída digital controlam processos, geram sinais de teste e se comunicam com outros periféricos. Em cada um desses casos, o número de linhas digitais

\footnotetext{
${ }^{4}$ Do inglês: least significant bit (LSB)
} 
disponíveis; a taxa de fluxo dos sinais digitais; e a capacidade de acionamento de outros circuitos por estas linhas, são parâmetros importantes na escolha desta interface.

O circuito temporizador/contador é utilizado nas aplicações que envolvem contagem de ocorrências de eventos digitais, tempo de um pulso digital e a geração de pulsos de onda quadrada.

\subsection{LabVIEW}

LabVIEW é um ambiente de desenvolvimento virtual que utiliza ícones em vez de linhas de texto para criar aplicações[18]. O LabVIEW utiliza a linguagem gráfica de programação “G”, nela os dados são tratados como um fluxo e sua execução é determinada pela estrutura do diagrama de bloco gráfico no qual o programador conecta diferentes nós de funções através de "fios virtuais". Os nós de funções podem ser variáveis, constantes ou funções do programa. Pelos fios é que as variáveis são propagadas e executadas pelas funções específicas dos nós. Aparentemente esse fluxo de dados pode ser não linear ou contra a nossa intuição, mas logo que os dados fluem pelos fios, nota-se que a seqüência de execução do programa é determinada a medida que os nós são executados propagando os dados para o nó ou os nós subseqüentes. Isso mostra que a linguagem " $G$ " é inerentemente uma linguagem de processamento paralelo.

No LabVIEW os programas são chamados de instrumentos virtuais (do inglês: virtual instruments - VI ), e são construídos na área denominada de painel frontal usando controles e indicadores que são as entradas e saídas interativas da VI. Os controles e indicadores são as representações gráficas dos códigos das funções. Os códigos estão contidos no diagrama de blocos onde é construído o código fonte gráfico da interface.

O poder do LabVIEW está na natureza hierárquica da VI, que pode ser usada como uma subVI no diagrama de blocos de uma outra VI de hierarquia mais elevada. Não existe um 
número limitado de camadas hierárquicas, o que ajuda a administrar alterações e avaliar o funcionamento da VI pelo diagrama de blocos.

Uma característica muito importante do LabVIEW é a capacidade compreensiva de suas funções dedicadas a adquirir sinais, processar e analisar, permitindo o desenvolvimento de VI's de maneira interativa.

O LabVIEW é integrado a muitos padrões de hardware do mercado e a dispositivos de aquisição. Ele também permite a conexão dos aplicativos a internet usando o LabVIEW Web Server e os programas de rede TCP/IP e ActiveX. 


\section{Objetivos}

\subsection{Geral}

Desenvolver um sistema automatizado para a caracterização espacial de feixes lasers.

\subsection{Específicos}

- Projetar um protótipo eletromecânico baseado no método da borda-da-lâmina que se adapte a lasers com diferentes comprimentos de onda, divergências e diâmetros transversais;

- Desenvolver um sistema baseado na plataforma LabVIEW (National Instruments ${ }^{\circledR}$ ) para automatizar a técnica borda-da-lâmina;

- Determinar, utilizando o sistema desenvolvido, os perfis transversal e longitudinal do feixe laser, a posição da cintura de um feixe focalizado, o diâmetro do feixe, o $\mathrm{M}^{2}$ e o ângulo de divergência;

- Analisar as perspectivas de inovação do protótipo e implementação comercial. 


\section{Justificativa}

Nas aplicações médicas, industriais e laboratoriais o conhecimento da potência e energia do laser não é suficiente para sua utilização. Saber os perfis transversal e longitudinal do feixe é também fundamental para extrair as densidades de energia e potência do feixe laser [4]. Conhecendo estes perfis do feixe laser é também é possível determinar o diâmetro e posição da cintura do feixe, divergência e o fator de qualidade do feixe [9].

Para caracterizar o perfil espacial do feixe podem ser empregados equipamentos que são vendidos comercialmente que utilizam câmeras com sensor CCD ou empregar métodos mecânicos como a borda-da-lâmina e o diafragma óptico, para analisar o feixe. [19].

Dos métodos mecânicos, o borda-da-lâmina é o que possui metodologia mais simples de ser implementada, pode ser aplicado em lasers com qualquer comprimento de onda [11][20][21][22][23] e demonstra-se prático e confiável para a determinação do diâmetro de feixes Gaussianos [24].

Pensando na versatilidade do método borda-da-lâmina e na contribuição que pode trazer a dosimetria das radiações laser, propomos o desenvolvimento e a implementação de um protótipo prático, de baixo custo, que possa ser melhorado e que sirva como uma alternativa nacional para esse tipo de instrumentação. A implementação do protótipo no mercado poderá ser feita com a transferência da tecnologia para uma empresa interessada na comercializado do equipamento. 


\section{Materiais e Métodos}

O protótipo foi desenvolvido em parceria com a oficina mecânica e os laboratórios de eletrônica e informática do Departamento de Física e Matemática da Faculdade de Filosofia, Ciências e Letras USP-RP. O principal material empregado na montagem da estrutura do protótipo foi o acrílico. No corte das peças em acrílico foi usada a serra industrial; a perfuração das peças, para posterior fixação por parafusos, foi feita por uma furadeira industrial dando mais precisão aos furos; na confecção da haste cilíndrica das bases eletrônica e óptica e da base cilíndrica do detector, além de usar a serra industrial, foi necessária a utilização do torno industrial nos detalhes. Todas as peças do protótipo tiveram acabamento após preparadas, para a uniformização das superfícies.

As placas de circuito impresso usadas na montagem da parte eletrônica do protótipo, consistem de uma placa de fenolite coberta numa face por fina película de cobre, na qual foram desenhadas pistas condutoras que representam o circuito onde foram fixados os componentes eletrônicos. A influência da freqüência de $60 \mathrm{~Hz}$ nos sinais medidos foi minimizada instalando as placas de circuito impresso em caixa de alumínio.

$\mathrm{O}$ arranjo experimental do protótipo foi montado sobre uma base principal de acrílico medindo $500 \mathrm{~mm} \times 270 \mathrm{~mm}$ x $8 \mathrm{~mm}$, com seis pés reguláveis. A base principal, maior peça do protótipo, é vista na Figura 21, onde a montagem final do protótipo é mostrada. A vista superior da localização das partes eletromecânica, óptica e eletrônica que o compõe o protótipo é mostrada na Figura 22. 


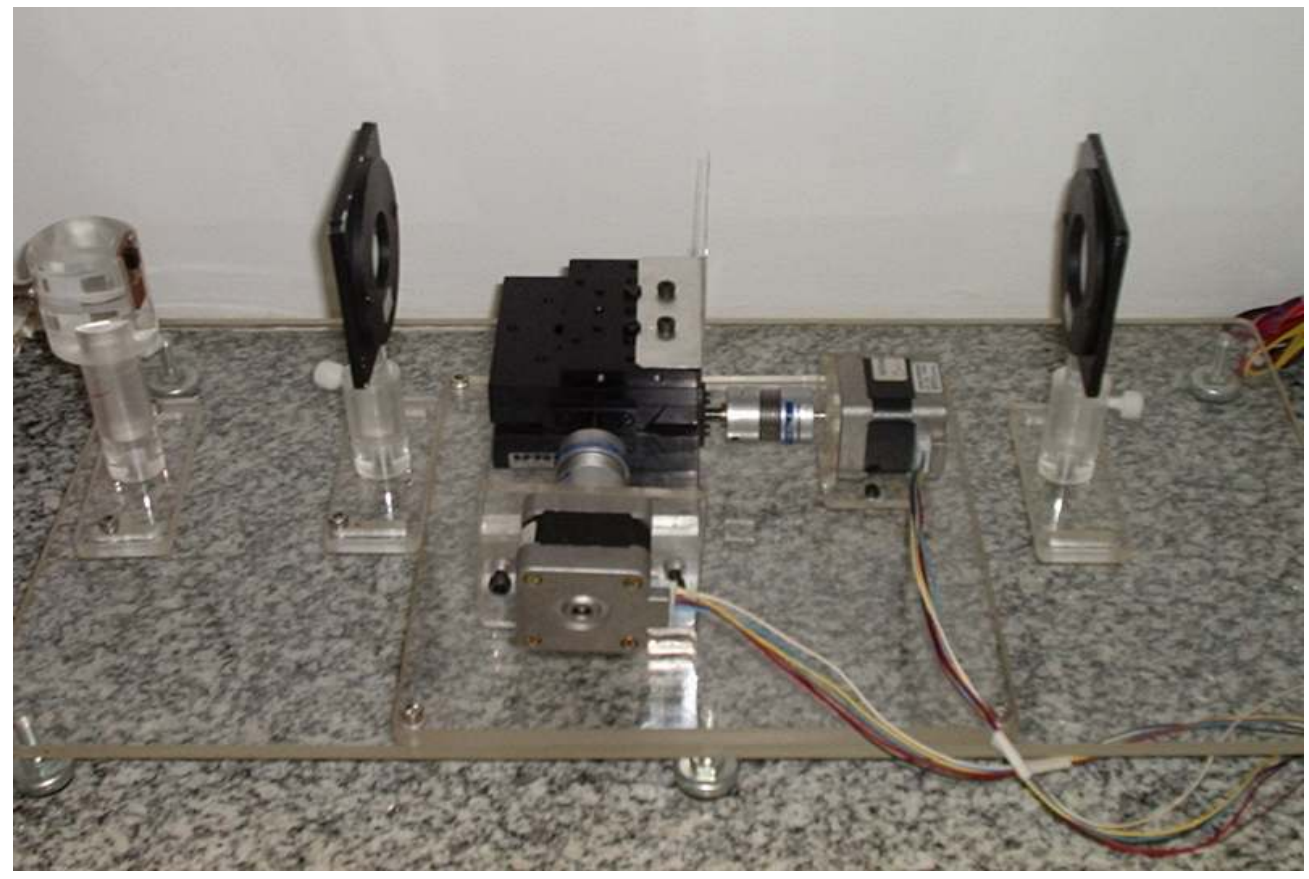

Figura 21 - Vista lateral do protótipo

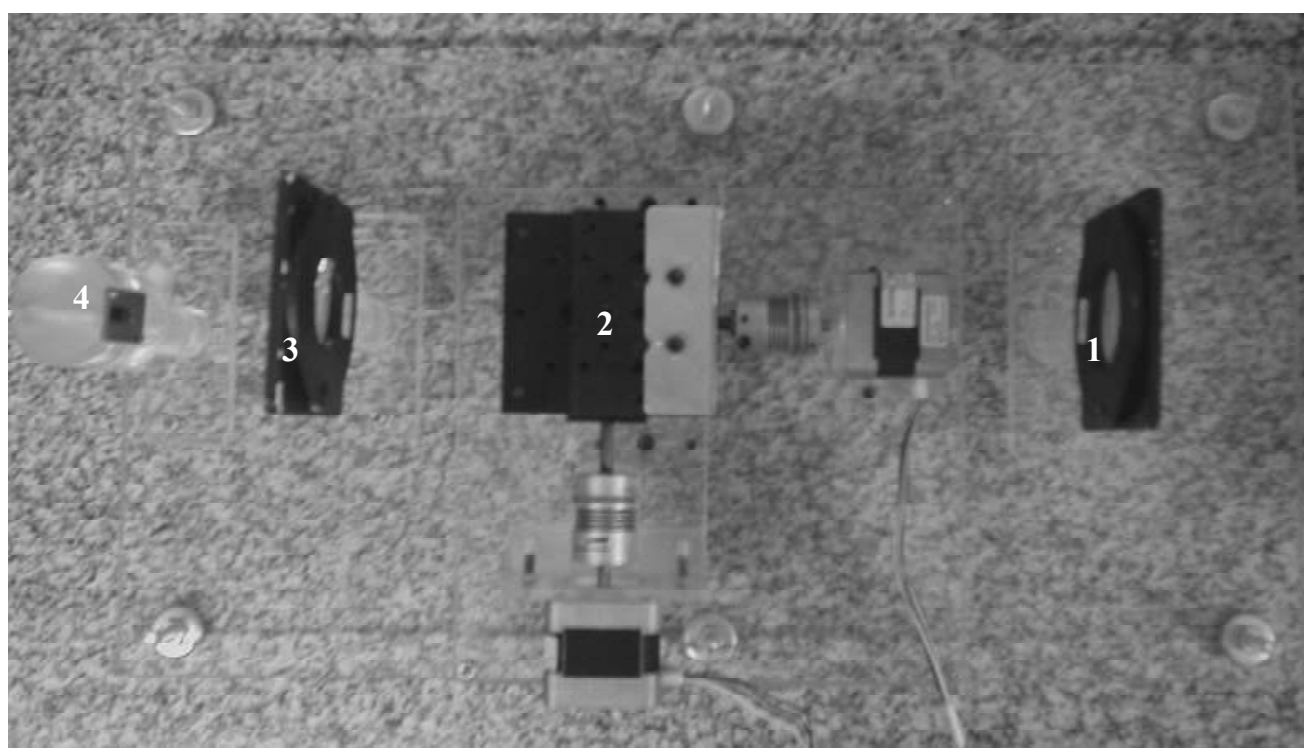

Figura 22 - Vista superior do protótipo, com o destaque de cada parte; (1) lente biconvexa $\mathrm{L}_{1}$; (2) mesa eletromecânica XY; (3) lente biconvexa $\mathrm{L}_{2}$; (3) detector. 


\subsection{Mesa deslocadora}

Para a montagem da mesa deslocadora com resolução de $5 \mu \mathrm{m}$, comandado por motores de passo, foram utilizados dois transladores horizontais quadrados (Optron Micromecânica Optica LTDA), de lado $76 \mathrm{~mm}$ (Figura 23) (Anexo A), dispostos perpendicularmente entre si, sendo que, entre os transladores foi colocada uma base de acrílico de dimensões 75,3 $\mathrm{mm}$ x 138,35 $\mathrm{mm}$ x 8,0 $\mathrm{mm}$ servindo como base de apoio para o motor de passo que comanda o translador superior (Figura 24). O translador possui curso útil de 30,0 $\mathrm{mm}$ e parafuso acionador com deslocamento de $1,0 \mathrm{~mm}$ por volta. A mesa deslocadora foi fixada numa base de acrílico, de altura regulável medindo $116,50 \mathrm{~mm}$ x 50,25 mm e está, numa outra base maior, quadrada, de acrílico, de lado igual a $210 \mathrm{~mm}$ e espessura $9,25 \mathrm{~mm}$. 


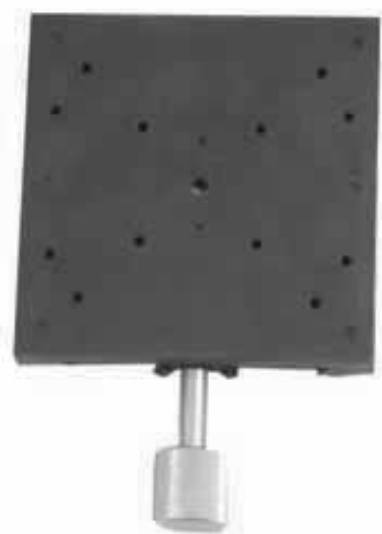

Figura 23 - Translador de guia prismático.

(Fonte: Optron)

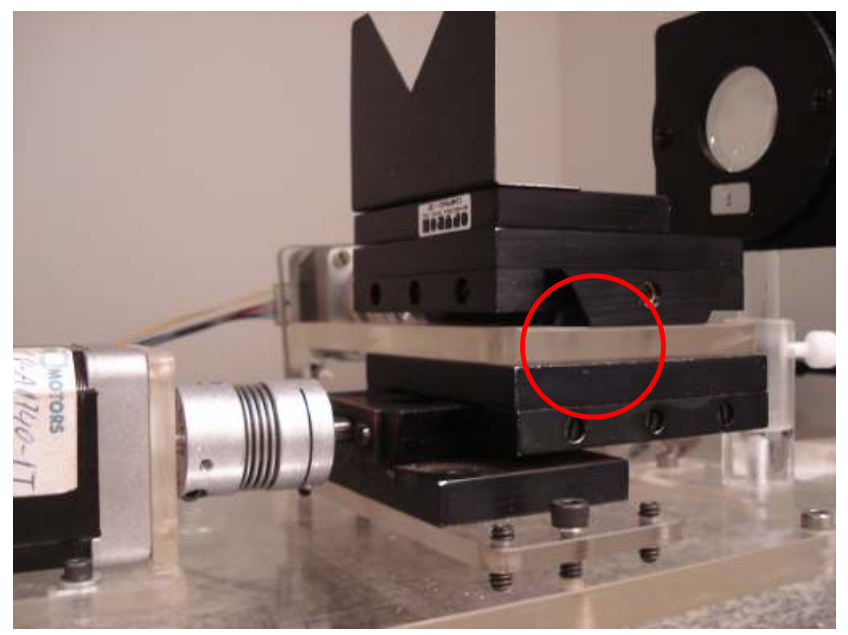

Figura 24 - Vista de perfil da montagem dos transladores, no detalhe o "sanduíche" formado pelos transladores 


\subsection{Motores de passo}

No processo de controle com precisão da mesa deslocadora, foram utilizados dois motores de passo híbridos e unipolares (Saehan Electronics) (Figura 25), modelo SM1.8A1740IT-SE, com resolução de $1,8^{\circ}$ por passo e tensão nominal de $4,9 \mathrm{~V}_{\mathrm{DC}}$ (Anexo B). No intuito de diminuir a propagação da vibração produzida pelo motor de passo e a transmissão do torque a mesa deslocadora, optamos por utilizar acopladores flexíveis (Rimtec Corporation), modelo DKN 20/32 (Anexo C), para unir, no sentido longitudinal, o motor ao parafuso acionador (Figura 26) .

Para fixar os motores sobre a base de montagem da mesa deslocadora, foram utilizadas bases de acrílico com posição regulável.

O motor de passo é controlado pelo circuito digital implementado na placa controladora, alternando entre suas fases. Na mudança de fase, a corrente precisa ser mantida constante e amplificada nas fases do motor. O controle e amplificação da corrente nas fases do motor são regulados pelo circuito da Figura 27. Neste circuito o transistor Darlington de potência, modelo TIP122 (Anexo D), provê um ganho de corrente para o motor de 1000 vezes. Para a alimentação dos motores, utilizou-se uma fonte com tensão de entrada $110 \mathrm{~V} / 220 \mathrm{~V}$ e tensão de saída de $5 \mathrm{~V}_{\mathrm{DC}}$. 


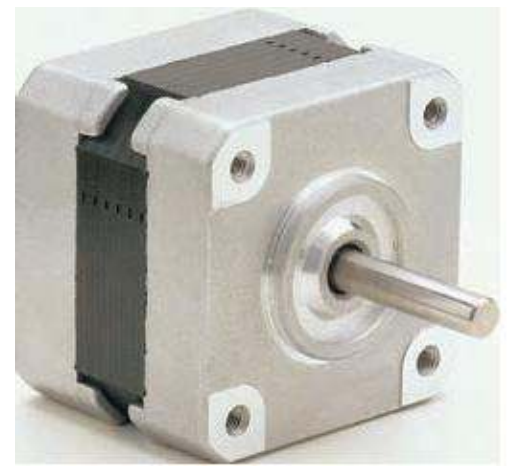

Figura 25 - Motor de passo híbrido com ângulo de passo de $1,8^{\circ}$ por volta (Fonte: Action Motors Ltda.)

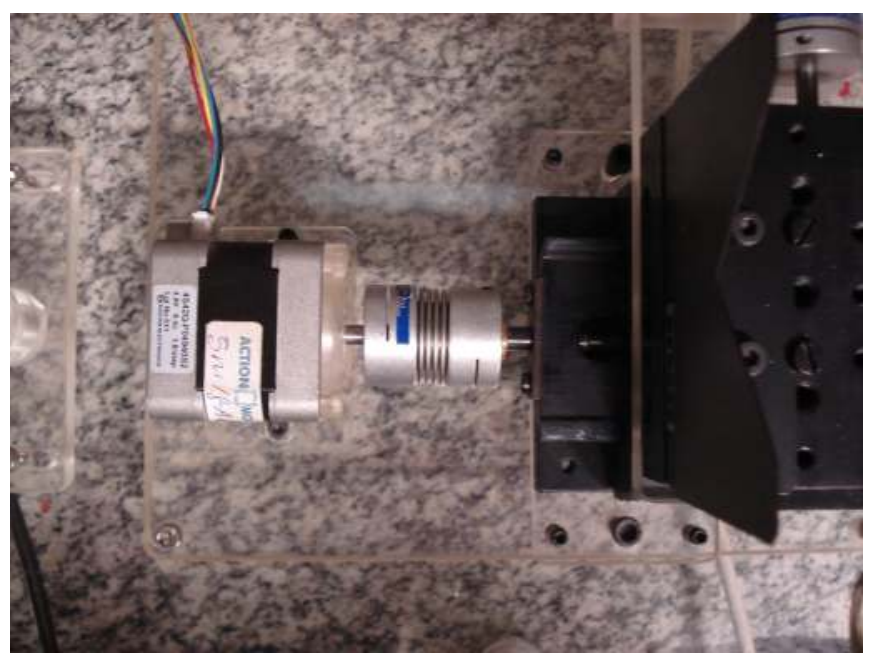

Figura 26 - Vista superior da montagem do acoplador ao motor de passo (esquerda) ao parafuso acionador da mesa XY (direita).

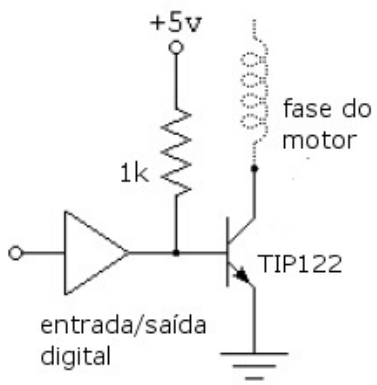

Figura 27 - Circuito chaveador da corrente em cada fase do motor. 


\subsection{Lâmina}

No método da borda-da-lâmina (Item 1.3), a lâmina é deslocada na direção x ou y transversalmente ao feixe eclipsando-o gradativamente. Para efetuar os cortes nos dois sentidos são necessárias duas lâminas movimentadas, cada uma, por um motor de passo.

Na construção do nosso protótipo, confeccionou-se a lâmina conforme apresentado na Figura 28. Com esta geometria eliminamos um motor de passo, pois o deslocamento da lâmina numa direção interceptará o feixe numa direção arbitrária, enquanto durante o recuo da lâmina, a mesma interceptará o feixe numa direção ortogonal a primeira interceptação.

A lâmina foi confeccionada a partir de uma chapa de alumínio medindo $76,67 \mathrm{~mm} \mathrm{x}$ $54,38 \mathrm{~mm} \times 0,5 \mathrm{~mm}$. Para a passagem do feixe foi realizado um corte com altura de $26,65 \mathrm{~mm}$ e com diagonal de $38,84 \mathrm{~mm}$. Essas dimensões permitem medir feixes com área de aproximadamente $3 \mathrm{~cm}^{2}$.

\subsection{Lentes}

$\mathrm{Na}$ focalização do feixe, de modo a criar uma cintura localizada sobre o curso útil do arranjo experimental mesa-lâmina, foi utilizada uma lente de acrílico biconvexa, chamada de $\mathrm{L}_{1}$; com distância focal $f_{1}=150 \mathrm{~mm}$ e diâmetro de $38,94 \mathrm{~mm}$. Na focalização do feixe sobre a área de detecção do fotodetector, utilizamos outra lente de acrílico biconvexa, $\mathrm{L}_{2}$; distância focal $f_{2}=50 \mathrm{~mm}$ e diâmetro de $32,27 \mathrm{~mm}$. As lentes são presas às bases quadradas de alumínio de lado $78,84 \mathrm{~mm}$, e postas numa base de acrílico de altura e posição ajustável. Um diagrama, representando o caminho óptico do feixe através do protótipo, é apresentado na Figura 29. 

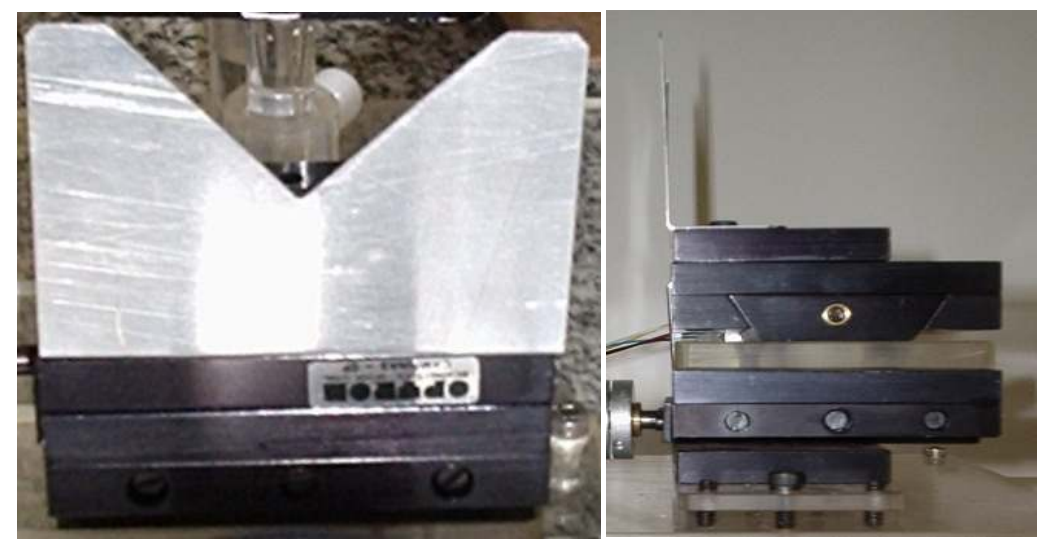

Figura 28 - A esquerda vista frontal da lâmina de alumínio;a direita, vista de perfil da montagem da lâmina sobre a mesa XY.

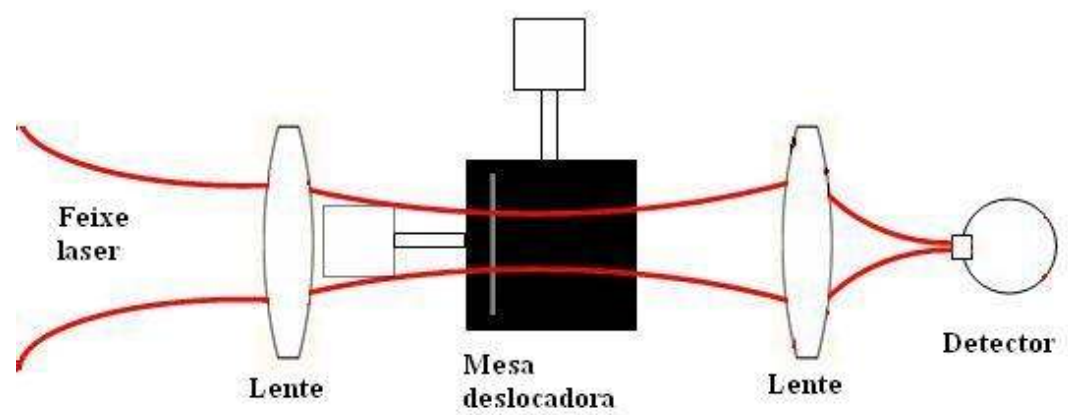

Figura 29 - Diagrama do caminho óptico. 


\subsection{Fotodetector}

$\mathrm{Na}$ detecção da intensidade do feixe, utilizou-se um fotodiodo PIN (Photonic Inc.) (Figura 30), modelo PHFD186, montado numa base de acrílico de altura regulável, medindo $97,55 \mathrm{~mm} \times 36,32 \mathrm{~mm} \times 7,65 \mathrm{~mm}$ (Figura 31), posicionado no foco da lente $\mathrm{L}_{2}$ e fixado por parafusos na base principal. $\mathrm{O}$ fotodiodo de Silício possui sensibilidade espectral entre $300 \mathrm{~nm}$ e $1200 \mathrm{~nm}$ (Figura 32), e sensibilidade espectral máxima em torno de $900 \mathrm{~nm}$. O fotodiodo utilizado possui sensibilidade

Figura 30 - Vista frontal do fotodiodo PIN. espectral máxima em $950 \mathrm{~nm}$ (Anexo E). Para os lasers que emitem em outra faixa espectral, adaptam-se outros detectores. Para lasers que operam na região espectral do ultravioleta, pode-se utilizar fotodiodo de Silício operando nessa faixa; para regiões no infravermelho próximo utilizam-se fotodiodos de Germânio; na região do infravermelho médio e distante, detectores piroelétricos. O fotodiodo possui área sensível à radiação de aproximadamente $7 \mathrm{~mm}^{2}$. Para feixes com área superior é possível adaptar outros fotodiodos com área sensível superior.

A eficiência do fotodiodo com polarização zero é aumentada quando trabalha no modo fotovoltaico. Para isso, construímos um amplificador (Figura 33) que trabalha nesse modo melhorando a sensibilidade do fotodiodo. 

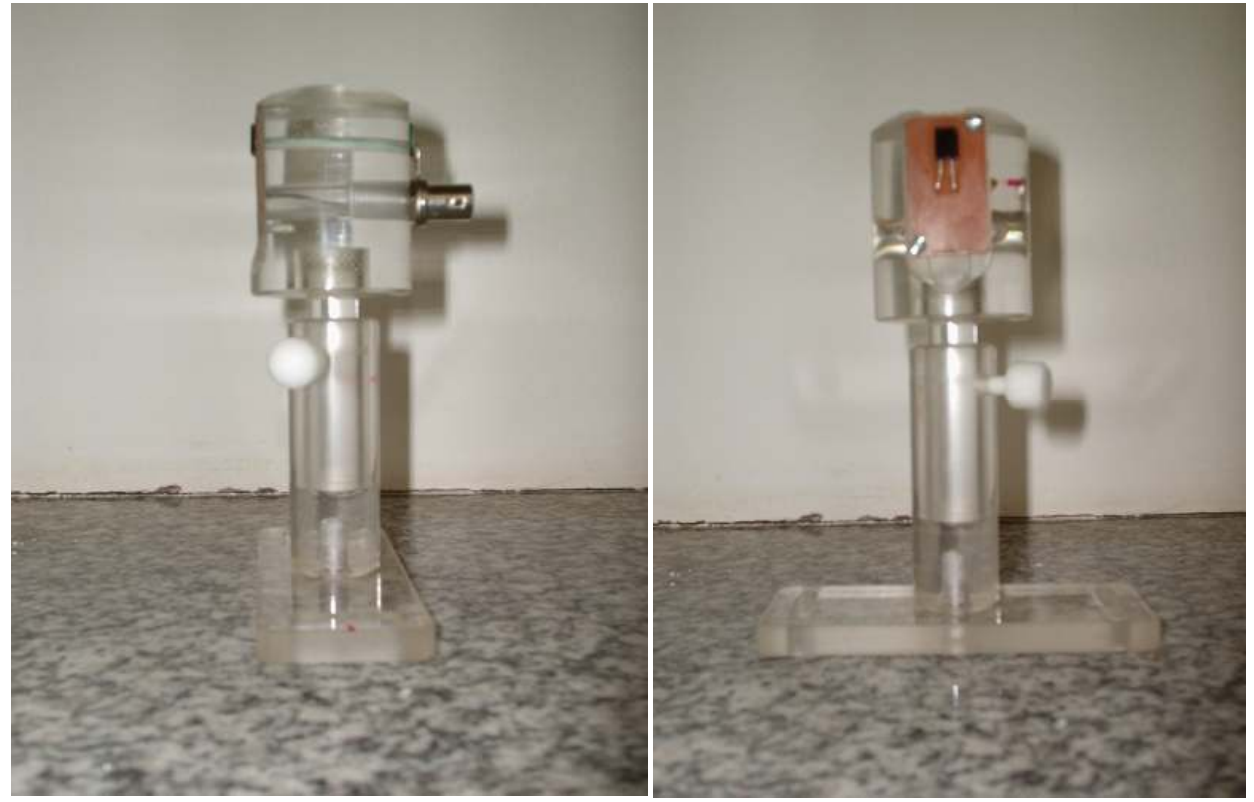

Figura 31 - À esquerda, vista frontal da base de acrílico e do suporte do fotodiodo; à direita vista lateral do suporte para o conector BNC.

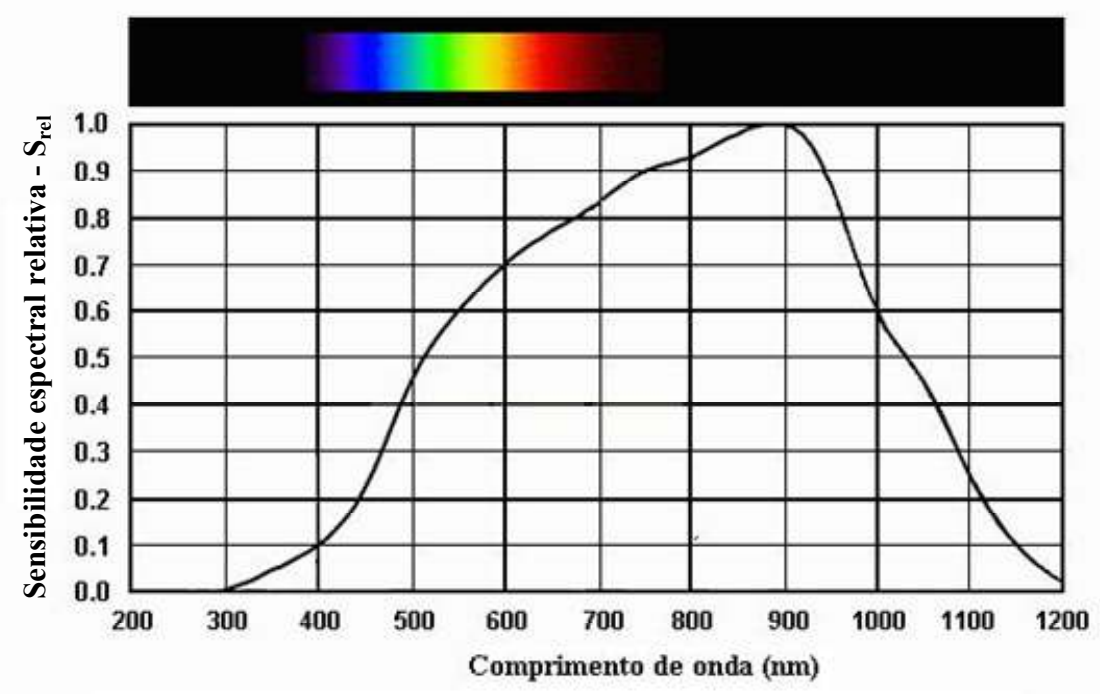

Figura 32 - Resposta espectral típica de um fotodiodo de Silício.

(Fonte: repairfaq.ece.drexel.edu/sam/sipdresp.gif) 


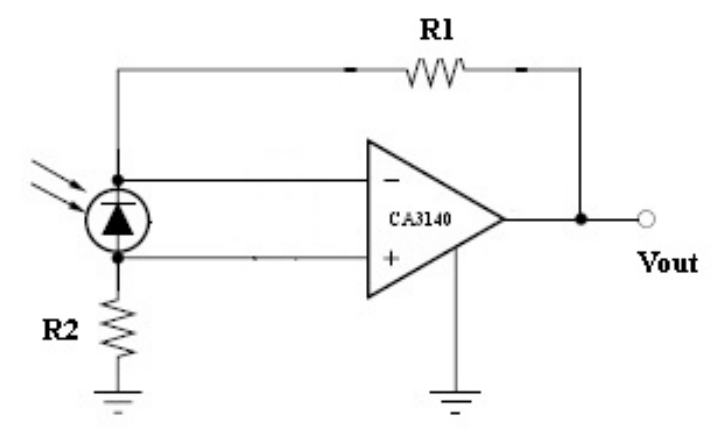

Figura 33 - Circuito amplificador do fotodiodo operando em alta sensibilidade.

\subsection{Placa de aquisição}

A interface de controle/leitura do computador com os motores de passo e o fotodiodo será feita pela placa de aquisição de dados USB-6008 da National Instruments ${ }^{\circledR}$ (Figura 34). Esta placa possui entrada para oito canais analógicos, dois canais de saída analógicos, doze canais de entrada/saída digitais, e um contador com resolução de 32 bits (Anexo F). Para esta aplicação foram utilizadas oito portas digitais e duas portas analógicas, mais a porta de aterramento. A porta analógica possui resolução de 12 bits no modo de leitura diferencial, isto é, o número de bits usados pelo conversor analógico-digital para representar o sinal.

Com os parâmetros utilizados da placa: range de $\pm 10 \mathrm{~V}$, resolução da entrada analógica de 12 bits e um ganho do circuito da placa de aquisição para o sinal igual a 1 , consegue-se como o menor valor de tensão que se pode medir de 2,44 mV.

Os parâmetros de medida dos canais usados na execução das tarefas foram configurados via utilitário NI-DAQmx Base Task Configuration Utility, instalado com o drive NI-DAQmx Base. Neste trabalho, usou-se parâmetros operacionais padrões do aplicativo (Tabela 2). 


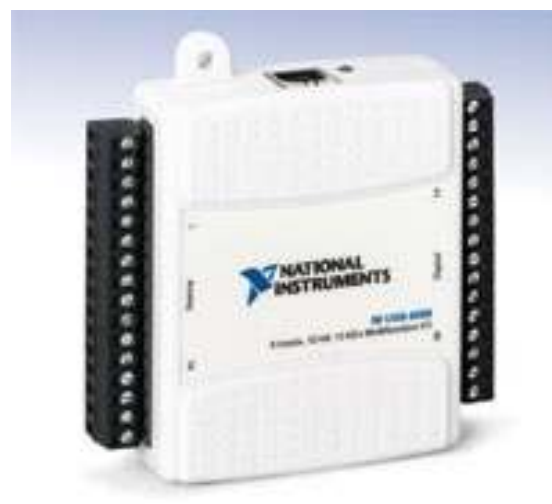

Figura 34 - Placa USB multifuncional de aquisição de dados.

(Fonte: National Instruments ${ }^{\circledR}$ )

\begin{tabular}{|c|c|}
\hline Canal analógico & $0 . .7$ \\
\hline Voltagem diferencial & $\pm 10 \mathrm{~V}$ \\
\hline Taxa de aquisição & $1 \mathrm{KHz}$ \\
\hline Número de scans & 100.000 \\
\hline
\end{tabular}

Tabela 2 - Parâmetros usados nas medidas analógicas.

\subsection{Sistema de automação, aquisição e análise dos dados.}

Para o controle do protótipo e a análise dos dados foi utilizado e recomenda-se um computador que tenha a seguinte configuração mínima: processador Pentium 4, com 3,06GHz, memória RAM de $1 \mathrm{~Gb}$, portas USB e sistema operacional Windows ${ }^{\circledR} \mathrm{XP}$ Professional.

Para gerenciar os componentes do protótipo (mesa eletromecânica, fotodetector e placa de aquisição) foi desenvolvido um sistema automação, baseado na plataforma LabVIEW (National Instruments ${ }^{\circledR}$ ), composto de 3 etapas de funcionamento. Na primeira etapa, são feitos os cortes e aquisição da energia do feixe; na segunda, os dados da aquisição são analisados e determinam-se os perfis transversais do feixe e seus raios; na última etapa, os raios do feixe são analisados e determina-se o perfil longitudinal, o raio do feixe focado e o 
$\mathrm{M}^{2}$. A Figura 35 mostra os passos seguidos na primeira etapa de funcionamento, que executa o método borda-da-lâmina.

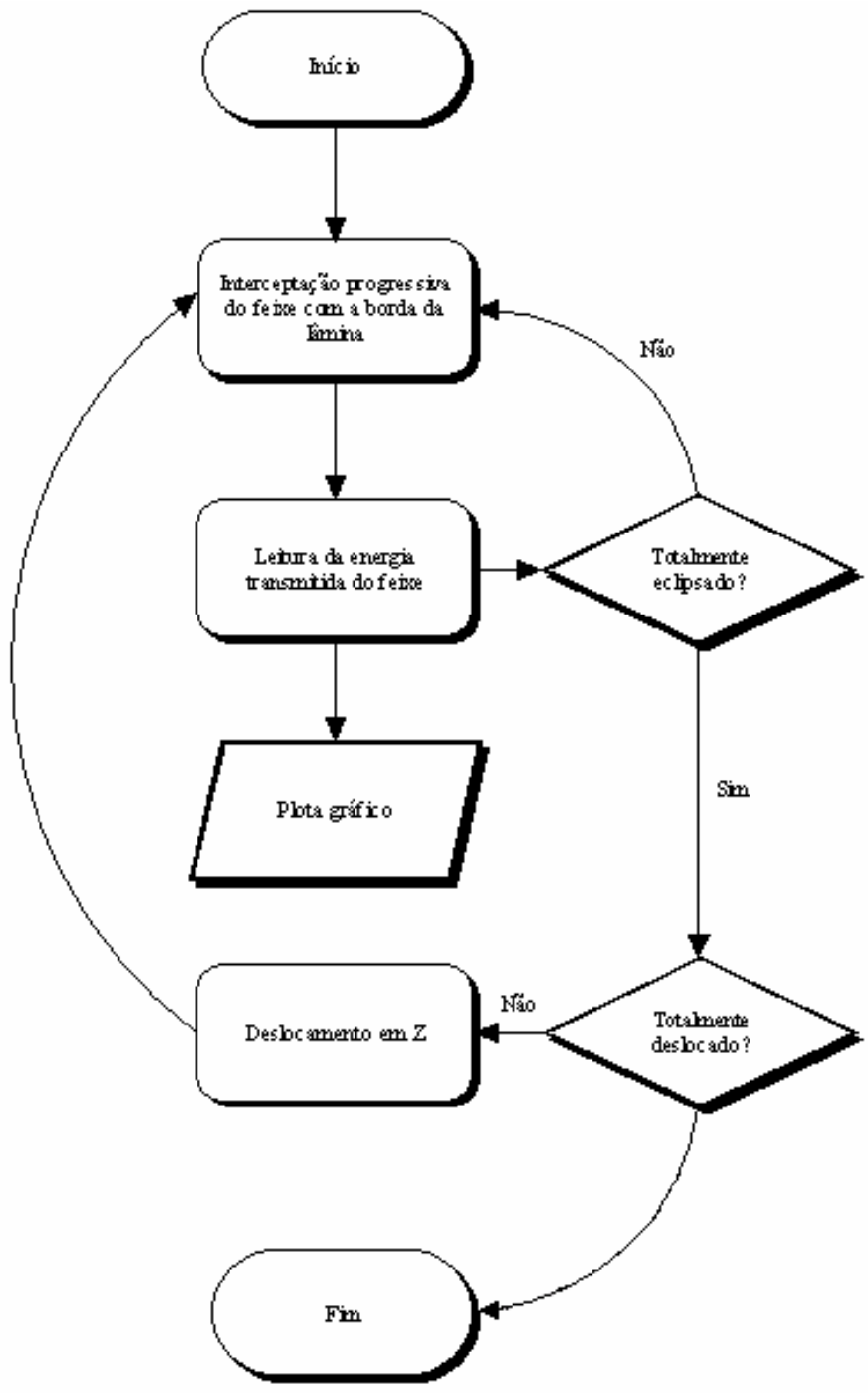

Figura 35 - Diagrama de automação do método borda-da-lâmina. 
$\mathrm{Na}$ Figura 36, observa-se o painel frontal do sistema de automação com os componentes utilizados para a aquisição dos dados geométricos do laser. No painel frontal, constam: a informação sobre o canal utilizado; os indicadores dos deslocamentos transversal e longitudinal da lâmina; os botões que acionam o sentido de deslocamento dos motores; e a área de plotagem, onde é mostrado o perfil do laser no instante da leitura. A forma do painel frontal e dos próximos painéis é semelhante aos componentes de um painel de instrumentos, o que torna mais interativa a aquisição. Os componentes do painel frontal estão associados a variáveis e parâmetros no diagrama de blocos do LabVIEW, onde a lógica do sistema é apresentada de forma gráfica.

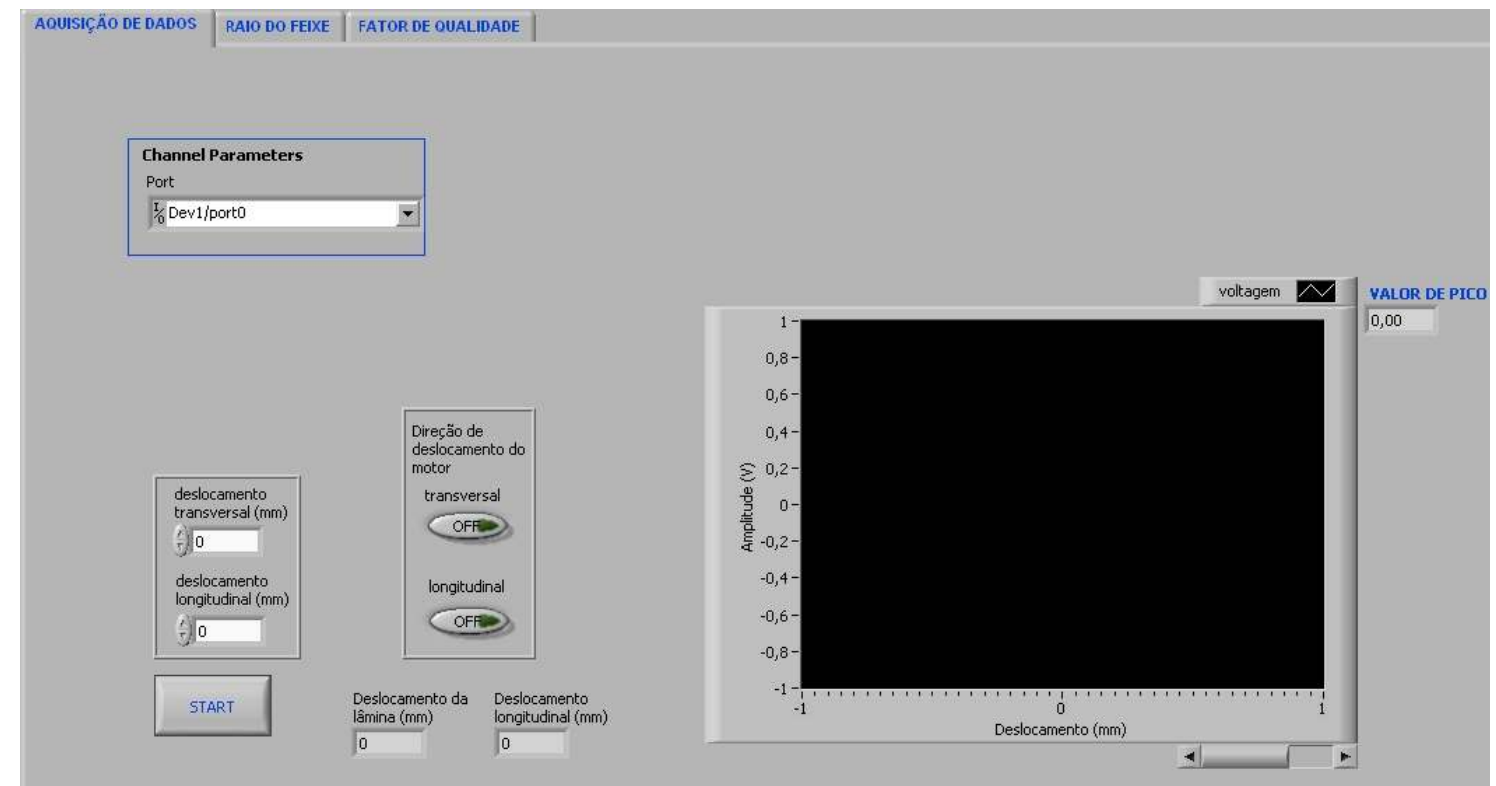

Figura 36 - Tela de análise de dados do sistema de automação. 
O painel frontal de análise do raio do feixe é apresentado na Figura 37. Neste painel aparece em destaque: 1) os indicadores dos valores iniciais do raio do feixe e sua posição, para o ajuste da curva de potência ou energia do sinal, em função do deslocamento da lâmina; 2) as áreas de plotagem das curvas de intensidade do feixe nos eixo x e y com os respectivos ajustes; 3) os indicadores dos valores finais, após ajuste, para o raio do feixe e posição; 4) o erro obtido pelo ajuste; 5) os critérios de parada do ajuste; 6) e os erros na execução da etapa.

O diagrama de funcionamento do painel de análise do raio do feixe é mostrado na Figura 38. Na análise do perfil transversal, ajustam-se as curvas a equação (36), por meio do método iterativo não-linear Levenberg-Marquard. Após o ajuste das curvas, os coeficientes obtidos representam o raio do feixe e sua posição nos eixos x e y.

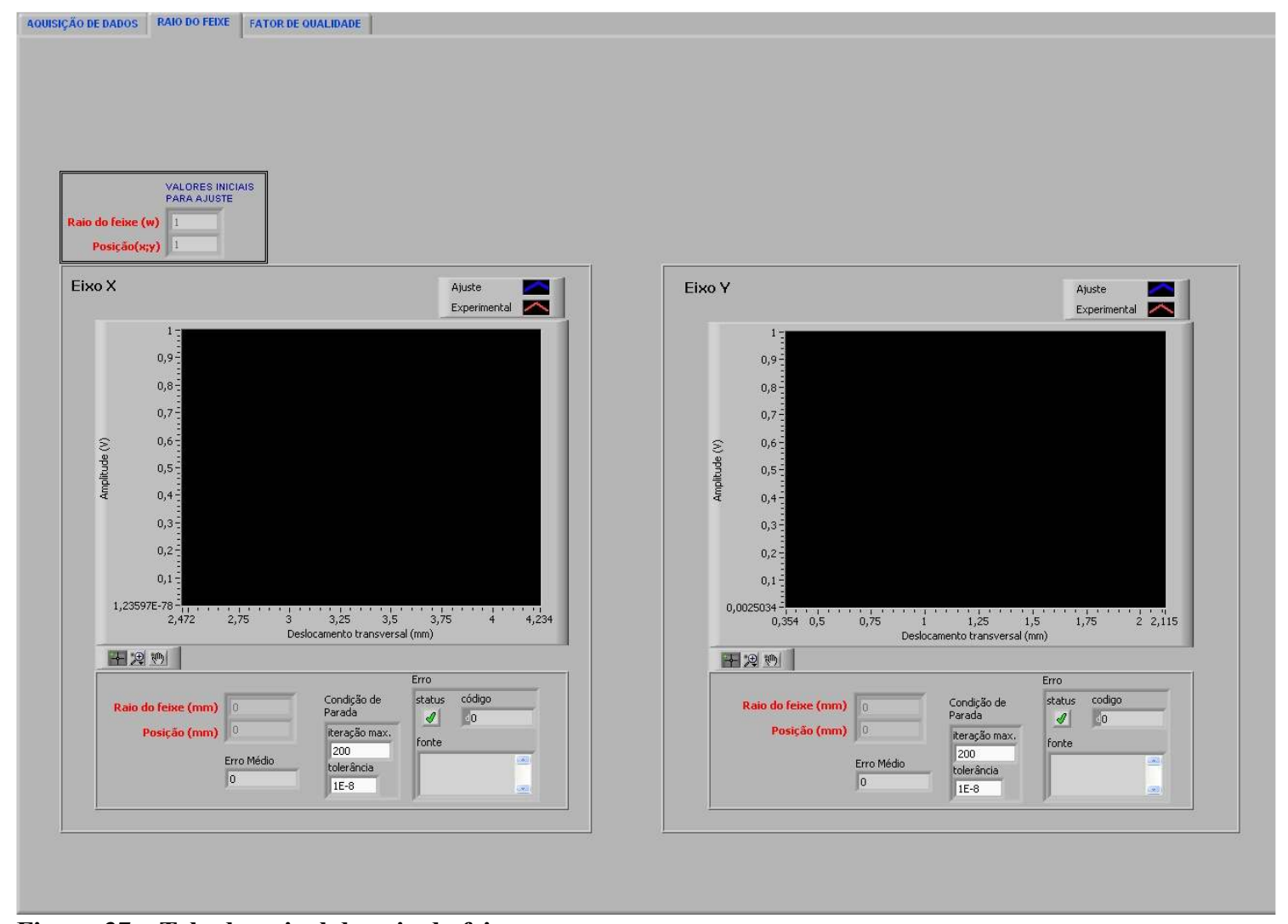

Figura 37 - Tela do painel do raio do feixe.

Encontrado o raio do feixe e posição transversal, o próximo passo é a determinação do raio da cintura do feixe focalizado; sua posição; o $\mathrm{M}^{2}$; e a divergência. A Figura 39 mostra o 
painel de análise do perfil longitudinal, nele estão os indicadores do comprimento de onda e dos valores iniciais de ajuste, que serão usados para aproximar o perfil longitudinal do feixe à função descrita no item 1.2; e a área de plotagem do gráfico onde o ajuste do perfil e os dados obtidos pelo painel de análise são exibidos. Novamente, o ajuste do perfil será pelo método iterativo não-linear Levenberg-Marquard.

As etapas envolvidas no processo de ajuste do perfil longitudinal e determinação do $\mathrm{M}^{2}$ são mostrados na Figura 40.

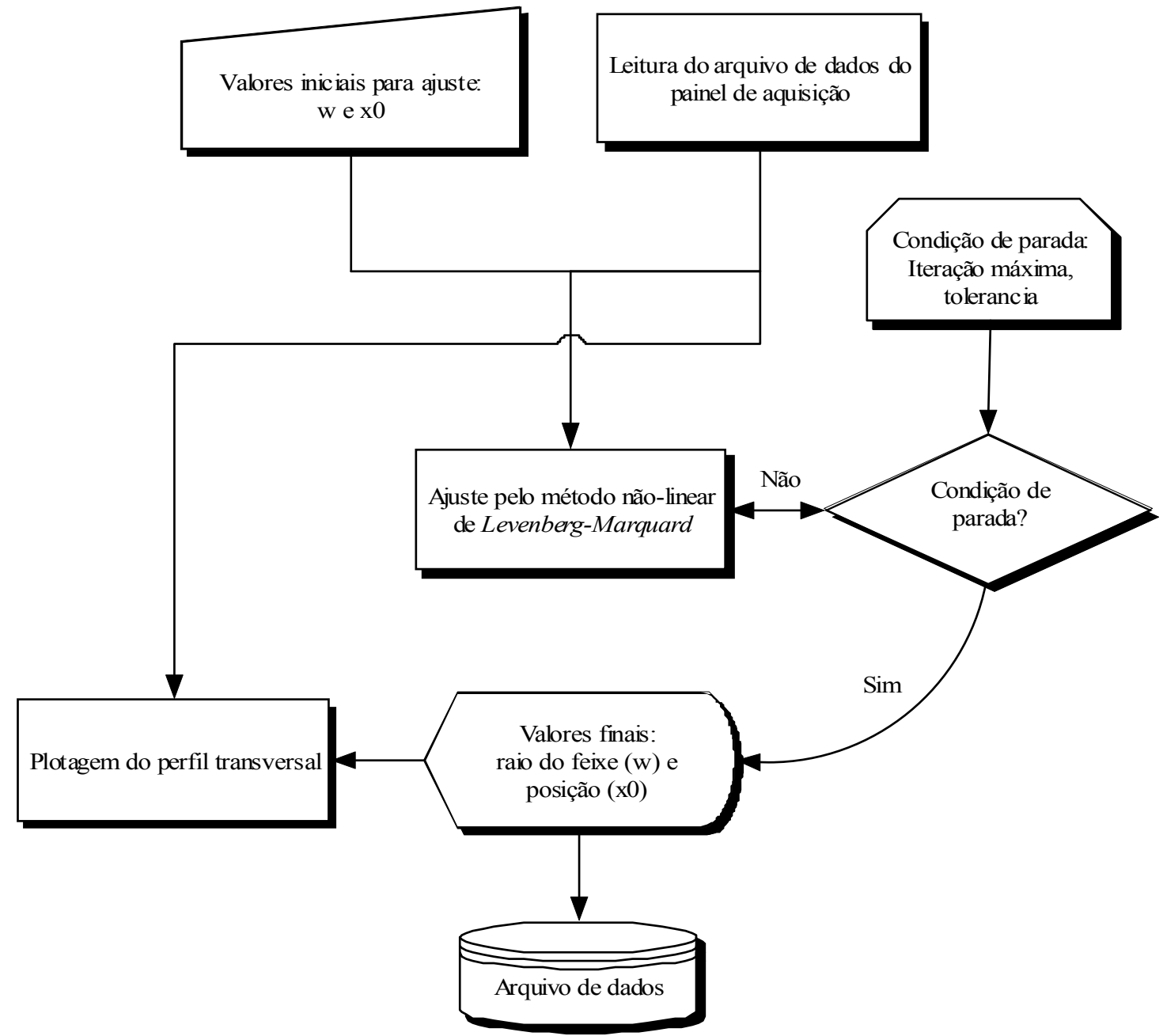

Figura 38 - Diagrama de análise dos dados do perfil transversal. 


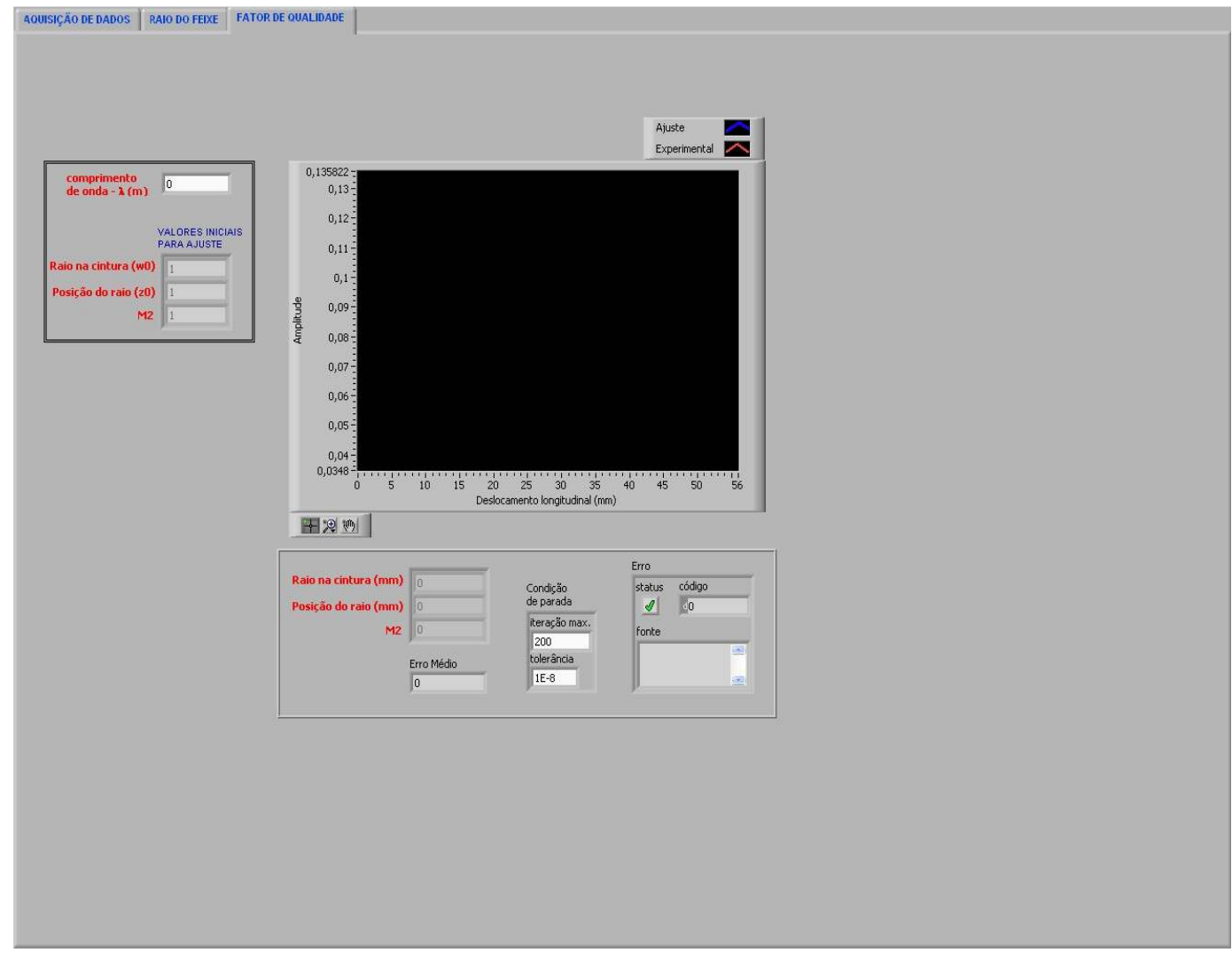

Figura 39 - Tela do painel de análise do fator de qualidade.

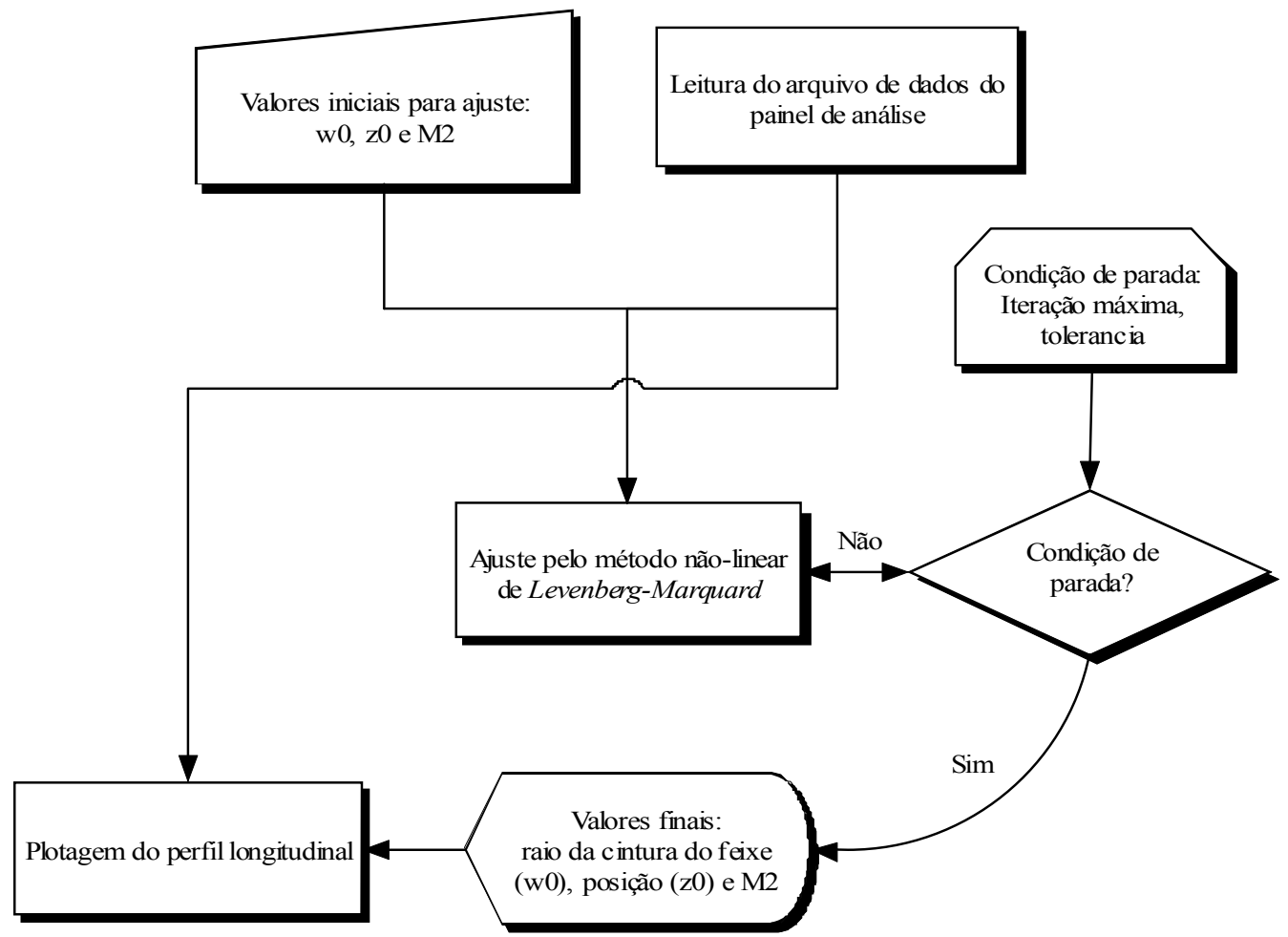

Figura 40 - Diagrama de análise dos dados do perfil longitudinal 


\subsection{Lasers}

A validação do protótipo foi realizada com dois lasers: 1) lasers de $\mathrm{He}-\mathrm{Ne}$ (Opto Eletrônica S.A.), com comprimento de onda de 632,8 nm; e 2) Laser de diodo, adaptado para uso no laboratório didático de óptica, com comprimento de onda de $656 \mathrm{~nm}$. A validação foi conduzida no laboratório com baixa luminosidade para evitar a influência da iluminação ambiente.

\subsection{Dinâmica realizada para a caracterização dos feixes}

No intuito de alcançar o $\mathrm{M}^{2}$ dos feixes analisados neste trabalho, ou outros de interesse, seguiu-se a seguinte dinâmica:

- Alinha-se o laser com centro óptico da lente.

- Focaliza-se o feixe na metade dos deslocamentos máximos: transversal e longitudinal.

- Avalia-se o percurso a ser executado pela lâmina efetuando um deslocamento teste.

- Testa-se a sensibilidade do fotodetector.

- Deslocam-se os cursores dos dois motores para a posição inicial.

- Diminui-se a luminosidade ambiente.

- Inserem-se valores para definir as faixas de deslocamento dos motores

- Inicia-se a execução do programa para os 15 cortes transversais

- Após a aquisição dos dados iniciam-se os ajustes dos perfis transversais para obter os raios e posições do feixe.

- Ajusta-se o perfil longitudinal para obter a cintura do feixe, posição, divergência e o $\mathrm{M}^{2}$. 


\section{Resultados}

\subsection{Instrumentação}

Para avaliar o erro no deslocamento da mesa eletromecânica sob funcionamento, realizamos um conjunto de 8 deslocamentos, cada deslocamento consistiu de um corte da lâmina no feixe com o seu retorno a posição inicial. A posição inicial do deslocador foi escolhida ao acaso e tomada como referência para as medidas. A lâmina percorreu uma distância total de $8 \mathrm{~mm}$, repetindo os cortes 8 vezes. A cada deslocamento de $4 \mathrm{~mm}$, medimos com o paquímetro a real distância, e repetindo a mesma medida 5 vezes e relacionando somente o valor médio das medições. Do conjunto de medidas calculamos um erro, de aproximadamente $5 \mu \mathrm{m}$, sendo da ordem da resolução do motor. Supomos que esse erro seja: (1) do acoplamento do motor ao fuso do translador, que pode girar em falso durante a aplicação do torque; (2) das flutuações da corrente do circuito de acionamento do motor; ou (3) do translador que pode emperrar durante o movimento.

O alinhamento do foco da lente $\mathrm{L}_{1}(f=15 \mathrm{~cm})$, sobre o curso útil de deslocamento da mesa deslocadora foi efetuado visualmente e comprovado com os resultados finais obtidos pelo sistema de automação.

A resolução do deslocamento transversal e longitudinal utilizada para as medidas, foi especificada internamente no sistema de automação e posta como padrão para as medidas. No deslocamento transversal, adotou-se a resolução mínima do aparelho, $5 \mu \mathrm{m}$, devido a elevada precisão necessária para os cortes; no deslocamento longitudinal adotou-se o deslocamento de $2 \mathrm{~mm}$ entre cada corte. Devido à geometria da lâmina, o deslocamento experimentado pela mesa deslocadora não é o mesmo que o observado pela borda da lâmina, pois está posicionada num ângulo de $45^{\circ}$ em relação a horizontal (Figura 41). Assim sendo, na leitura dos dados pelo sistema de automação, os deslocamentos transversais foram ajustados pela equação (58). 


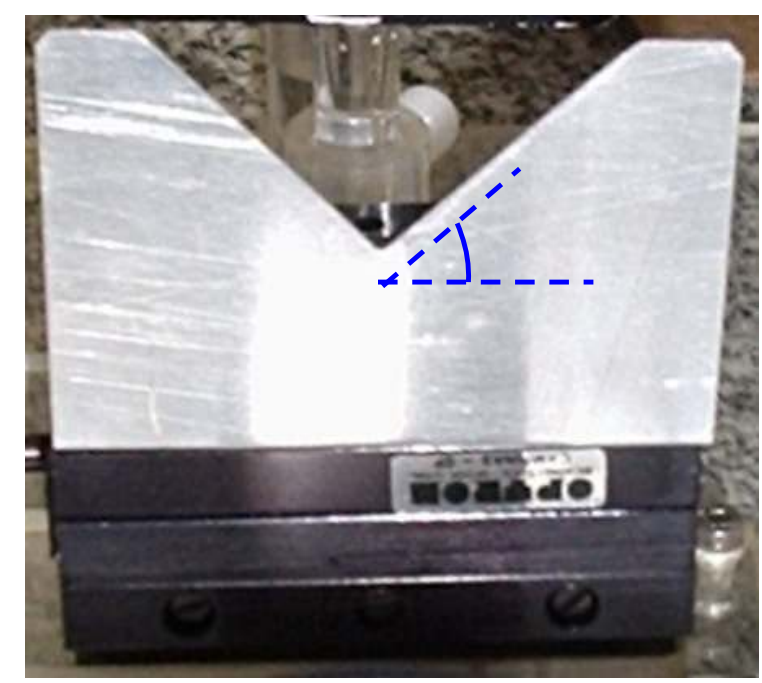

Figura 41 - Diagrama representando o fator de correção para o cálculo do diâmetro do feixe.

Os deslocamentos iniciais escolhidos para os cortes foram de $28 \mathrm{~mm}$ longitudinalmente e de 5 a $7 \mathrm{~mm}$ transversalmente. A distância transversal não possui um valor fixo, pois o posicionamento do feixe é arbitrário sobre a lâmina, mas escolhido próximo a borda da lâmina.

\subsection{Caracterização dos feixes lasers}

A Figura 42 mostra um perfil transversal do feixe obtido a partir do laser de diodo para 0 eixo $\mathrm{x}$. A linha vermelha representa o perfil adquirido pelo protótipo, e em azul, vemos o ajuste pela equação (36), utilizando o método iterativo não-linear de Levenberg-Marquard. Na Figura 44, observa-se o perfil transversal do mesmo feixe, porém agora para o eixo y. O perfil longitudinal do feixe, referente ao eixo x e y, é apresentado nas Figuras 43 e 45 respectivamente. A notação das cores usadas, segue o mesmo padrão do perfil transversal. $\mathrm{Na}$ 
Tabela 3, estão listados os valores determinados para o raio do feixe na cintura $\left(W_{0}\right)$, posição da cintura $\left(Z_{0}\right)$, fator de qualidade $\left(M^{2}\right)$ e a divergência $(\theta)$ do feixe do laser de diodo, obtidos pelo sistema de automação. 


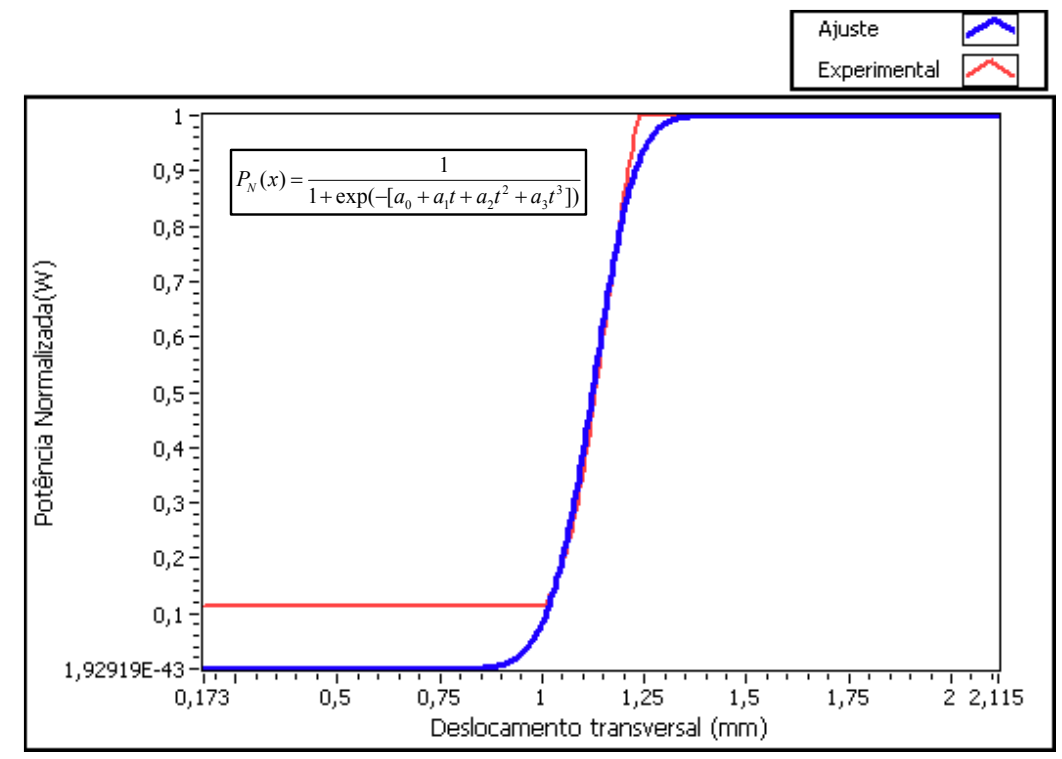

Figura 42 - Perfil transversal no eixo $x$, do feixe normalizado pela potência máxima.

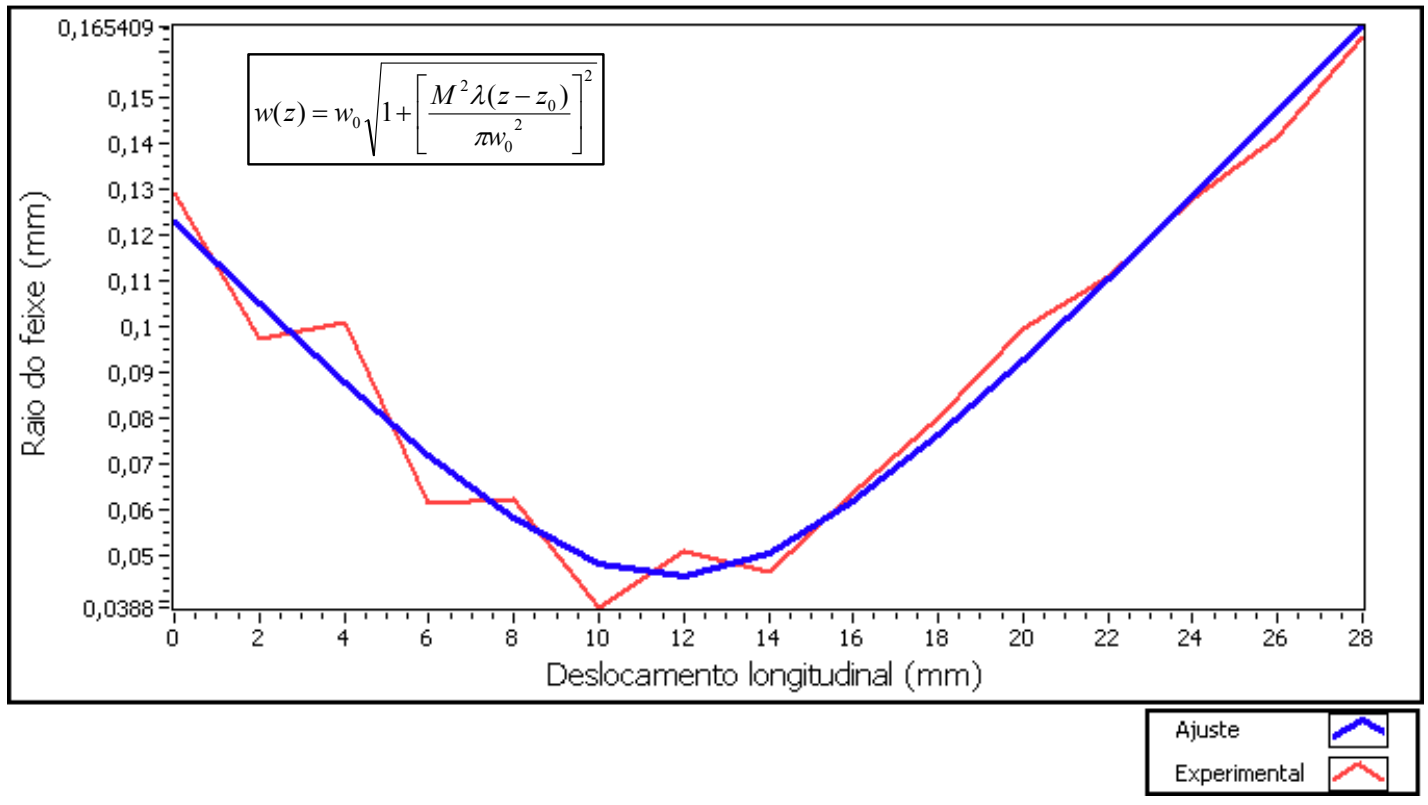

Figura 43 - Perfil transversal do feixe no eixo $x$ obtido do laser pointer. Em vermelho os valores adquiridos; em azul o ajuste da curva. 


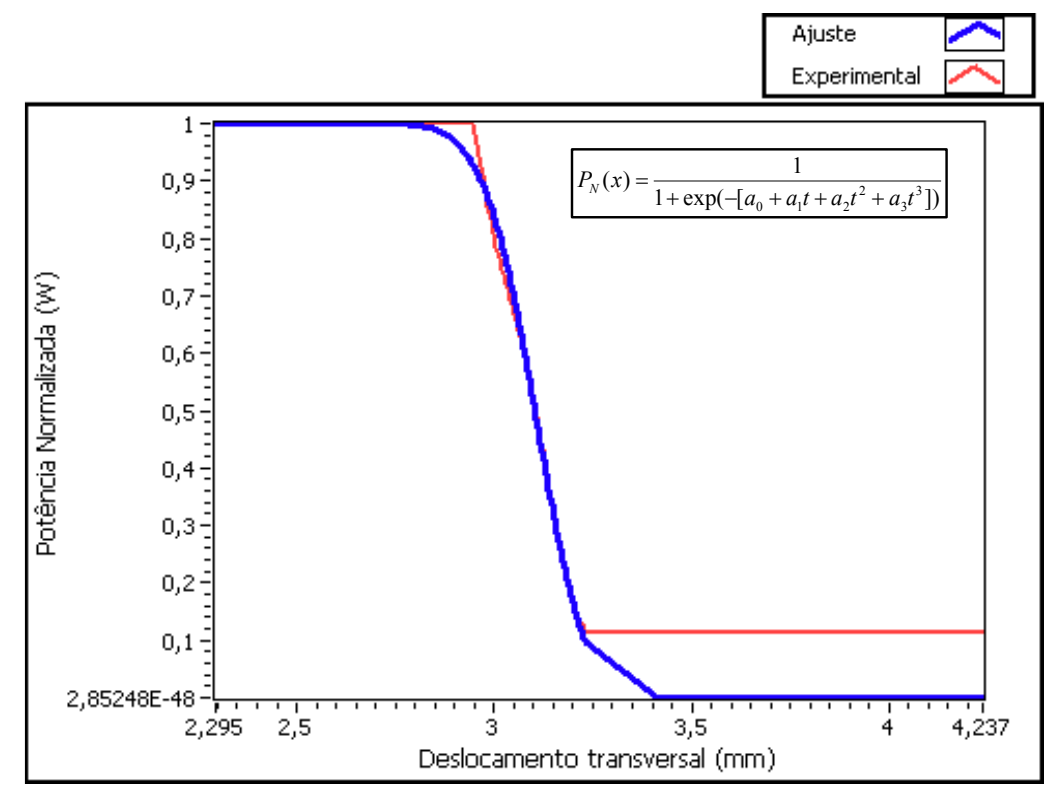

Figura 44 - Perfil transversal no eixo y, do feixe normalizado pela potência máxima.

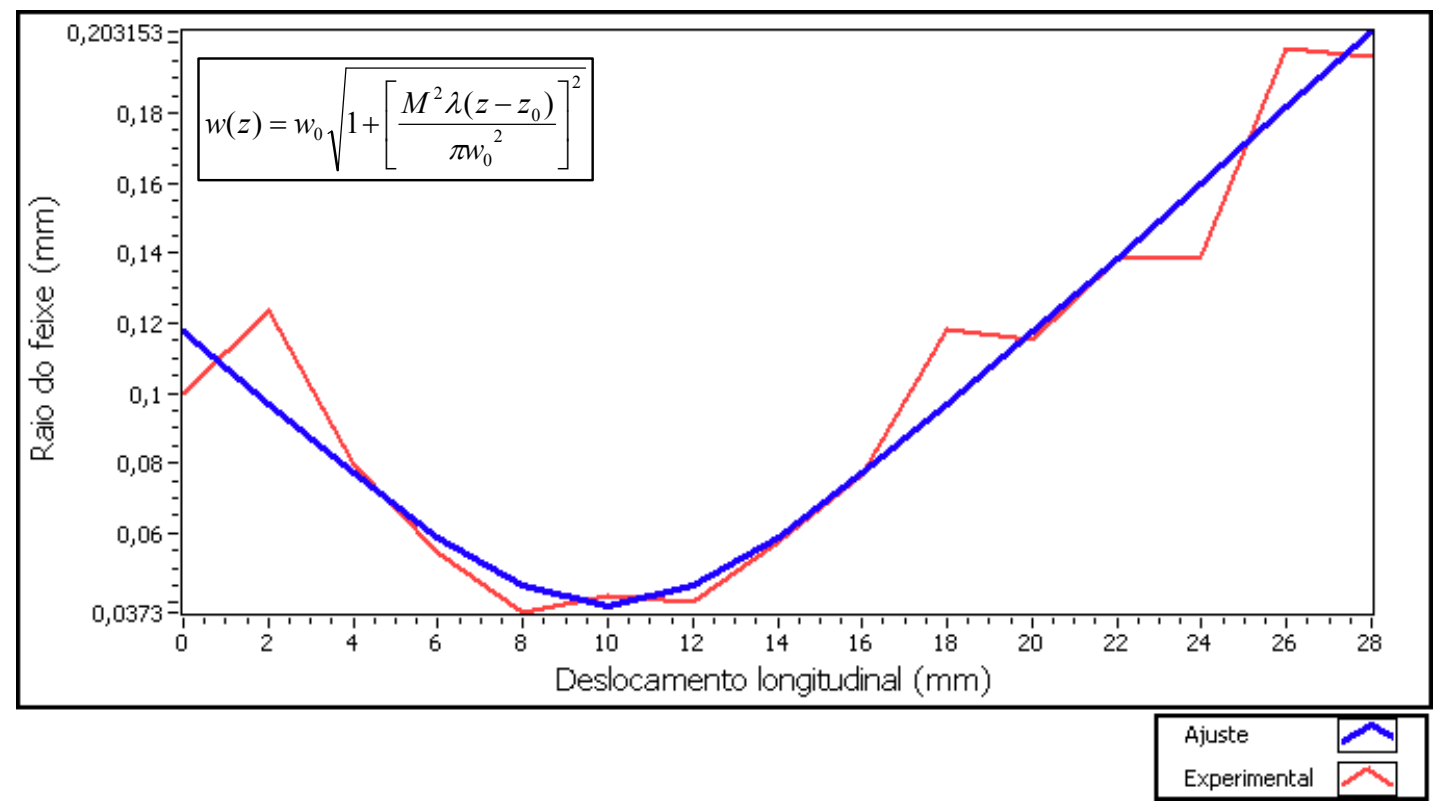

Figura 45 - Perfil transversal do feixe no eixo y obtido do laser pointer. Em vermelho os valores adquiridos; em azul o ajuste da curva. 


\begin{tabular}{|c|c|c|}
\hline & Eixo $\mathrm{x}$ & Eixo y \\
\hline$W_{0}$ & $0,045 \pm 0,004 \mathrm{~mm}$ & $0,038 \pm 0,007 \mathrm{~mm}$ \\
\hline$Z_{0}$ & $11,705 \pm 0,264 \mathrm{~mm}$ & $9,996 \pm 0,463 \mathrm{~mm}$ \\
\hline$M^{2}$ & $2,125 \pm 0,142$ & $2,063 \pm 0,358$ \\
\hline$\theta$ & $9,71 \pm 0,12 \mathrm{mrad}$ & $11,12 \pm 0,22 \mathrm{mrad}$ \\
\hline
\end{tabular}

Tabela 3 - Parâmetros geométricos determinados pelo sistema de automação para o laser de diodo.

Comparando o erro determinado para a mesa eletromecânica $(\sim 5 \mu \mathrm{m})$, e o erro obtido para o raio do feixe nos eixos x e y, observa-se que os valores determinados para o laser de diodo estão dentro da margem de erro.

Nas Figura 46 e 48 são apresentadas os perfis transversais para os eixos x e y, respectivamente, do feixe de He-Ne e seus ajustes. Os perfis longitudinais são mostrados nas Figuras 47 e 49 para os eixos x e y, respectivamente.

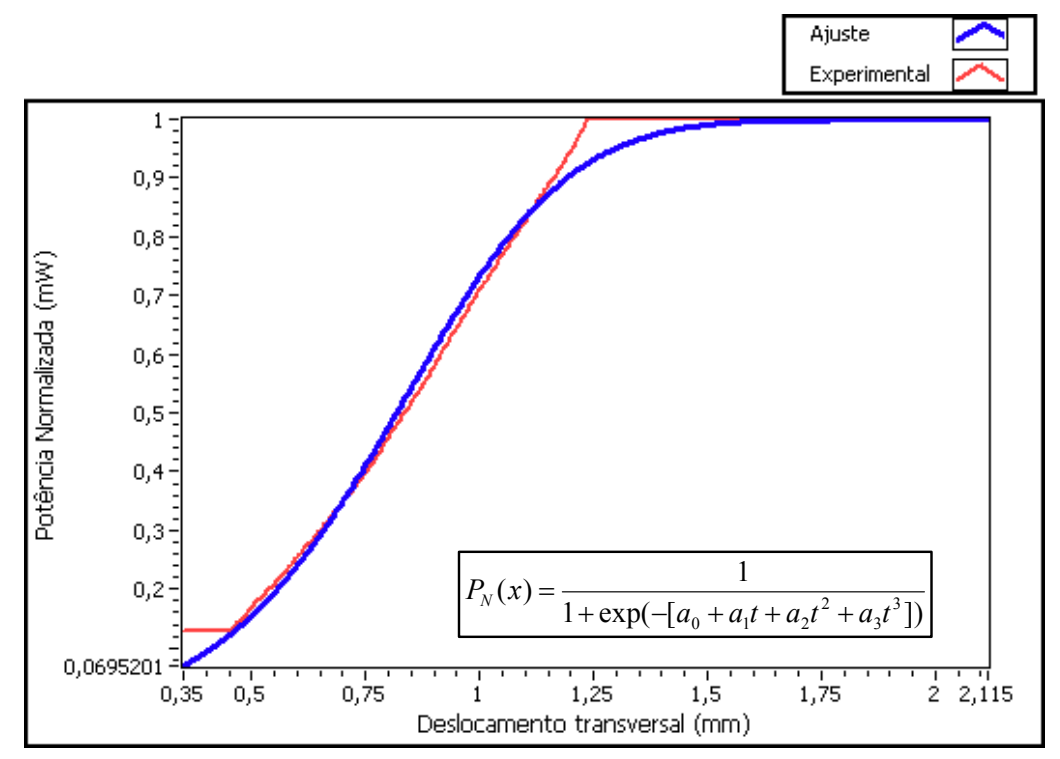

Figura 46 - Perfil transversal no eixo x, para o feixe de He-Ne. 


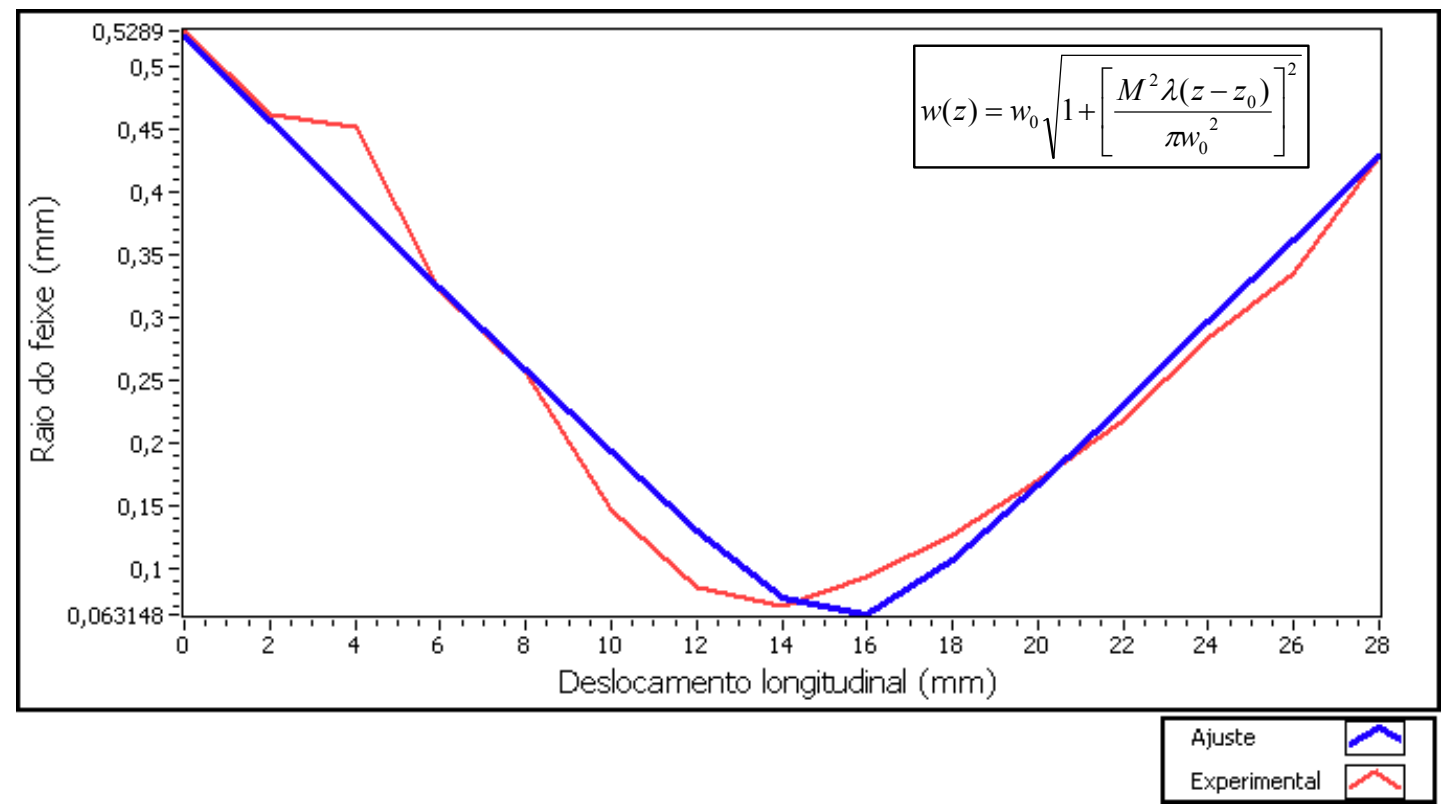

Figura 47 - Perfil longitudinal do feixe de He-Ne no eixo x.

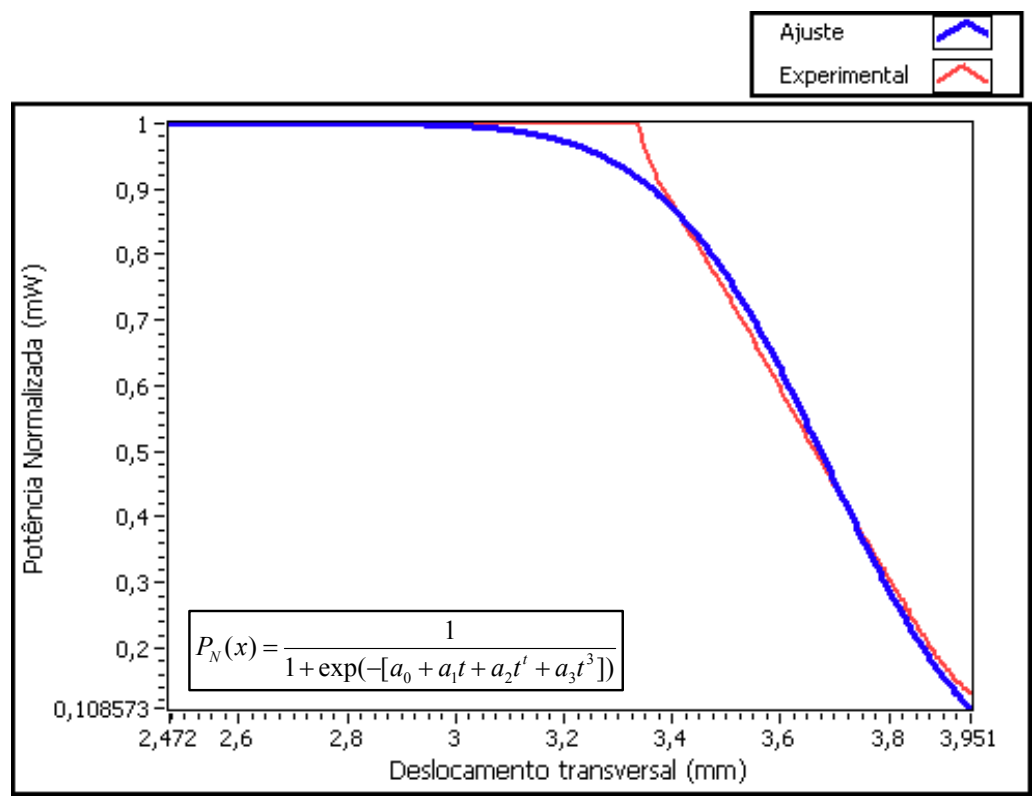

Figura 48 - Perfil transversal no eixo y, para o laser de He-Ne. 


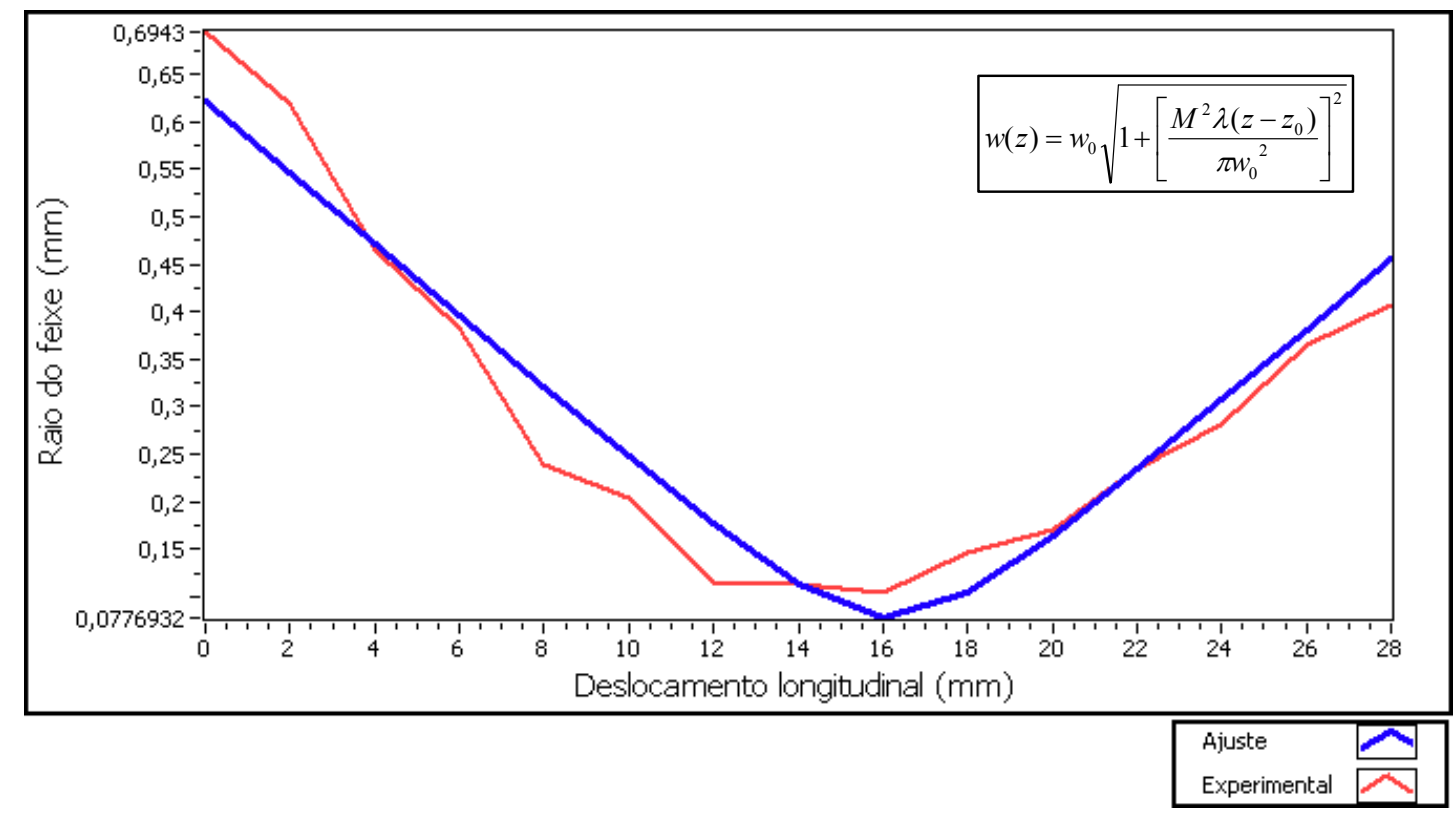

Figura 49 - Perfil longitudinal no eixo y, para o laser de He-Ne

\begin{tabular}{|c|c|c|}
\hline & Eixo x & Eixo y \\
\hline$W_{0}$ & $0,059 \pm 0,02 \mathrm{~mm}$ & $0,077 \pm 0,032 \mathrm{~mm}$ \\
\hline$Z_{0}$ & $15,414 \pm 0,253 \mathrm{~mm}$ & $16,206 \pm 0,39 \mathrm{~mm}$ \\
\hline$M^{2}$ & $10,060 \pm 3,264$ & $14,605 \pm 5,758$ \\
\hline$\theta$ & $35,21 \pm 0,51 \mathrm{mrad}$ & $39,82 \pm 0,9 \mathrm{mrad}$ \\
\hline
\end{tabular}

Tabela 4 - Parâmetros geométricos determinados pelo sistema de automação para o laser de He-Ne. 
Para o laser de $\mathrm{He}-\mathrm{Ne}$ os erros na determinação do raios estão próximos aos do equipamento. Pelo valor obtido para o $\mathrm{M}^{2}$, vemos que o feixe do laser de He-Ne possui divergência maior quando comparada ao laser de diodo. 


\section{Discussão}

O objetivo principal na montagem foi de um protótipo funcional e de custo reduzido, em contrapartida obtivemos um tempo elevado na caracterização do feixe. Fatores que ajudariam a agilizar as etapas envolvidas na caracterização seriam: a) substituição dos motores por modelos mais rápidos, sem comprometer a precisão; e b) escolha de uma linguagem estruturada mais próxima à linguagem de máquina, mantendo a robustez que o interfaceamento e a análise necessitam.

Por se tratar de um equipamento de medição, e este composto por uma parte eletromecânica e outra lógica (programa), faz-se necessário especificar o erro do equipamento levando em considerando as partes que o compõem. Na obtenção do raio do feixe e do $\mathrm{M}^{2}$, por mais fino que seja o ajuste sempre encontraremos um erro nas medidas. Como fonte de erro na medição do raio do feixe, destaca-se o posicionamento do motor e o ajuste do perfil do feixe à função que o descreve.

Os motores possuem erro de posicionamento não acumulativo da ordem de $\pm 5 \%$. O ajuste das funções teóricas aos valores experimentais é outra fonte de erro que é preciso ser levado em consideração na determinação do raio do feixe. Segundo Khosrofian e Garetz [11], um bom ajuste da curva pelo polinômio resulta num erro de $\pm 0,05 \%$. Propagando os erros devido ao motor e ao ajuste da função para o raio do feixe, concluímos que o erro na determinação do raio do feixe é de $\pm 5 \%$.

Do erro acumulado do raio do feixe mais o erro no ajuste do $\mathrm{M}^{2}$, que é da mesma ordem de grandeza anterior, estabelecemos que o erro na determinação do $\mathrm{M}^{2}$ pelo protótipo é de $\pm 10 \%$.

A configuração do protótipo com lentes de acrílico, fotodiodo PIN de Si e placa de aquisição permitem caracterizar feixes na faixa espectral de $300 \mathrm{~nm}$ a $1200 \mathrm{~nm}$, 
aproximadamente, com sensibilidade máxima em $950 \mathrm{~nm}$. Para os lasers que trabalham em outra faixa espectral ou visando melhorar a detecção no infravermelho, sugerimos o uso de detectores de InGaAs (900 nm a 1,7 $\mu \mathrm{m})$ e os piroelétricos $(1,8 \mu \mathrm{m}$ a $10 \mu \mathrm{m})$. Contudo, como utilizamos lentes de acrílico na instrumentação, e estas possuem transmitância de aproximadamente $92 \%$ e índice de refração 1,49 elas não são indicadas para feixes muito divergentes e com comprimento de onda na faixa do ultravioleta. Pelas suas características o protótipo é aplicável a lasers de baixa potência e baixa divergência. A aplicação para laser de alta potência e/ou alta divergência requer a utilização de lentes que atenuem e baixo índice de refração.

As lentes do tipo BK7 são as ideais para uma ampla faixa espectral, abrangendo a região entre $400 \mathrm{~nm}$ e $1600 \mathrm{~nm}$, com percentual de transmitância acima de 92\% e índices de refração que variam de acordo com a cavidade laser.

Não é suficiente que o conjunto óptico esteja bem ajustado com lentes adequadas ao tipo de laser, é preciso saber também os limites mínimos e máximos para a determinação do diâmetro do feixe e sua simetria. Pelas dimensões e geometria da lâmina, resolução do motor e área do fotodiodo sensível à radiação, podemos aplicar o protótipo na caracterização de feixes assimétricos com diâmetros a partir de $3,5 \mu \mathrm{m}$ e no máximo $1,8 \mathrm{~cm}$, podendo ampliar o limite máximo com o auxílio de detectores de área sensível a radiação superior ao do fotodiodo usado.

Pelas características do fotodiodo, a faixa de irradiância detectável está entre 0,5 $\mathrm{mW} / \mathrm{cm}^{2}$ e $2,14 \mathrm{~W} / \mathrm{cm}^{2}$. Os fotodiodos levam certo tempo para responder as mudanças nos níveis de energia, isto é, o tempo requerido para o sinal elevar de $10 \%$ para $90 \%$ do seu valor final e o tempo de queda de $90 \%$ para $10 \%$. Pelos tempos de subida e queda, a largura temporal mínima de detecção do feixe é da ordem de 100 ns e sua máxima freqüência de $20 \mathrm{MHz}$. 
$\mathrm{Na}$ montagem do circuito de amplificação do fotodiodo, deparamo-nos com dois modos de amplificação do sinal: fotovoltaico e fotocondutivo. O modo fotovoltaico possui como característica alta sensibilidade; o fotocondutivo, maior responsividade e largura de banda, porém a polarização reversa tende a criar uma componente de ruído dado por $1 / f$, que tende a dominar o sinal a freqüências menores que $1 \mathrm{kHz}$, necessitando de fontes de polarização externa o que gera um custo adicional maior. $\mathrm{Na}$ instrumentação eletrônica, utilizamos o circuito de amplificação operando no modo fotovoltaico por preferirmos a sensibilidade a responsividade.

$\mathrm{Na}$ validação do protótipo, utilizamos os lasers de $\mathrm{He}-\mathrm{Ne}$ e de diodo, os quais forneceram dados finais satisfatórios, que não só permitiram um melhor ajuste da montagem como avaliar o funcionamento da ferramenta computacional e as características dos lasers. Todavia, na caracterização do laser de He-Ne tivemos que substituir a lente $\mathrm{L}_{1}$ com foco $f=150 \mathrm{~mm}$ por outra lente de acrílico de foco $f=100 \mathrm{~mm}$, devido a convergência obtida anteriormente não ser satisfatória para a caracterização. A regulagem da base da lente permite mudanças sem afetar a instrumentação do sistema. Desta forma, para um modelo final seria interessante que admitisse a troca da lente, pois permitiria aumentar a possibilidade de utilização, abrangendo feixes de alta divergência e, conforme dito, feixes de diâmetros maiores ao da lente utilizada.

$\mathrm{Na}$ validação da instrumentação usando o laser de He-Ne e o laser de diodo, encontramos algumas dificuldades para alinhar o feixe ao eixo óptico das lentes, para ajustar a posição da cintura sobre o curso da mesa deslocadora, e para posicionar o feixe entre as lâminas. As três dificuldades citadas serão recorrentes quando o protótipo for utilizado por outro usuário. Entre as três dificuldades mencionadas, o alinhamento do feixe é a mais importante, pois não depende da calibração inicial do instrumento. Já as outras duas, surgem se a lente for trocada. Alinhado o feixe, passamos para o sistema de automação do protótipo. 
O sistema é dividido em três janelas ou tabs. Os tabs permitem alternar entre as etapas de execução do sistema, como num navegador da internet. Em cada etapa os valores iniciais para a execução aparecem em destaque no canto superior à esquerda e as áreas de plotagem dos perfis são também destacadas junto com o indicador dos valores obtidos na caracterização. Na execução do programa, não encontramos dificuldades no uso, permitindo que outros usuários possam utilizá-lo, mas pode-se tornar mais interativa com o usuário, se pequena janelas de orientação fossem exibidas ao ser acessado os tabs. Assim a interatividade do sistema de automação aliado a dinâmica adotada para a caracterização facilitará demasiadamente a utilização em laboratório por qualquer usuário

O passo final no desenvolvimento do protótipo será a comercialização, deixamos como sugestão alguns fatores que podem ser melhorados no projeto e decisões que podem ser tomadas no intuído de implementar comercialmente. Como inovação ao protótipo, podemos substituir a placa de aquisição e o computador por uma placa controladora (microcontrolador), dedicada a executar funções específicas. Nela podemos programar um chip para que: (1) movimente os motores; (2) adquira os dados pelo detector e (3) faça as análises dos dados fornecendo o raio do feixe e o $\mathrm{M}^{2}$. A programação do chip pode ser feita em linguagem $\mathrm{C}$ e armazenada numa memória apenas de leitura (em inglês: Read Only Memory). A interface do microcontrolador com o usuário pode ser por um pequeno visor $\mathrm{LCD}$, tornando mais ergonômico a leitura dos dados. Se a tela for sensível ao toque, podemos, ainda, tornar mais fácil a inserção de dados para a caracterização; se não, podemos acrescentar um teclado numérico dedicado a essa função. A adoção de um microcontrolador, não só reduziria o tamanho do protótipo final, como reduziria o consumo de energia de Watts para miliwatts, podendo ser alimentado por uma bateria de $9 \mathrm{~V}$. A substituição do computador de propósito geral por um microcontrolador de propósito específico não deixaria a desejar em termos da robustez do processo. 
No entanto, para que o produto seja desenvolvido e posto a venda é preciso definir qual a melhor maneira de implementar comercialmente o protótipo. Uma das formas seria buscar um parceiro da área industrial para que possamos desenvolver o produto em parceria, assim estaremos inserindo o produto diretamente no mercado por meio deste parceiro. Outra forma seria levar o projeto para uma incubadora de empresas, onde a orientação de profissionais habituados nos ajudariam a definir metas e buscar parceiros interessados na produção e comercialização do equipamento. 


\section{Conclusão}

O funcionamento do protótipo mostrou-se eficiente na caracterização de feixes laser e com uma instrumentação de custo reduzido para a comercialização nacional. No entanto, apresentou-se lento na aquisição de dados o que torna a caracterização do laser mais demorada. Fatores como velocidade do motor de passo e linguagem de programação contribuíram para tornar lenta a aquisição.

Outros fatores como lentes adequadas para o laser em uso e detectores com maior área sensível a radiação, auxiliariam na melhoria do equipamento, propiciando caracterizar lasers que operem em outros comprimentos de onda.

Os resultados finais da montagem foram satisfatórios, pela acurácia exigida nas medidas e a precisão dos componentes utilizados na instrumentação. Mostrando que, com mais investimentos em desenvolvimento podemos alcançar um protótipo final pronto para as necessidades de caracterização exigidas nos projetos que utilizam laser. 


\section{Referências}

1 - SCHAWLOW, A. L.; TOWNES, C. H. Infrared and Optical Masers. Physical Review, 1958. v112(6),1940-1949.

2 - MAIMAN, T. H. Stimulated Optical Radiation in Ruby. Nature, 1960. v187(8), 493494.

3 - GORDON GOULD. Optically Pumped Laser Amplifiers; Light Amplifiers Employing Collisions to Produce a Population Inversion Laser. Patent Number(s) 4,053,845; 4,704,583. 1991.

4 - MEISTER, J.; APEL, C.; FRANZEN, R.; GUTKNECHT, N. Influence of the spatial beam profile on hard tissue ablation Part I: Multimode emitting Er:YAG lasers. Lasers in Medical Science. 2003. v18. 112-118.

5 - ARNAUD, J. A.; HUBBARD, W. M. et al. Technique for Fast Measurement of Gaussian Laser Beam Parameters. Applied Optics.1971. v10 (12). 2775-2776.

6 - SIEGMAN, E. A. Lasers. University Science Books. 1986. p630.

7 - KOGELNIK, H. e LI, T. Laser Beams and Resonators. Applied Optics. 1966. v5(10). $1550-1567$.

8 - JOHNSTON JUNIOR, T. F. $\mathbf{M}^{2}$ Concept Characterizes Beam Quality. Laser Focus World. 1990(05). 173-184.

9 - DOMINGUES, C. e PIRES, M. Medição de Feixes Laser: Aplicação à Segurança Laser. INETI. 2005.

10 - ISO 11146:1999 - Test methods for laser beam parameters - Beam width, divergence angle and beam propagation factor.

11 - KHOSROFIAN, J. M. e GARETZ, B. A. Measurement of a Gaussian Laser Beam Diameter Through the Direct Inversion of Knife-Edge Data. Applied Optics. 1983. v22(21). 3406-3410.

12 - JONES, D. W. Control of Stepping Motors: A Tutorial. The University of Iowa Department of Computer Science. 1995. 
13 - REZENDE, S. M. A Física de Materiais e Dispositivos Eletrônicos. Editora Universitária da UFPE. 1996. p321-322.

14 - BOSCHETTI, C. Junções em Semicondutores e o Efeito Voltaico. Hospedado no LAS - Laboratório Associado de Sensores e Materiais. Disponível em: < http://www.las.inpe.br/ cesar/Infrared/detetor/fotocorr2.gif>. Acesso em: 30/06/2007.

15 - SZE, S. M. Physics of Semiconductor Devices. John Wiley and Sons. 1981. p 743-760.

16 - LANG, S. B. Pyroelectricity: From Ancient. Curiosity to Modern Imaging Tool. Physics Today. 2005(8). 31-36.

17 - NATIONAL INSTRUMENTS. Data Acquisition Fundamentals. 2006. v7.

18 - NATIONAL INSTRUMENTS. LabVIEW ${ }^{\text {TM }}$ Basics I. Course Manual. 2000. v6.

19 - ROUNDY, C. Beam Profilers Provide Crucial Laser Statistics. Optics and Lasers Europe. 2006. 37-39.

20 - MCCALlY, R. L. Measurement of Gaussian Beam Parameters. Applied Optics. 1984 (14). v23. 227.

21 - BACHMANN, L. ZEZELL, D. M. e MALDONADO, E. P. Determination of Beam Width and Quality for Pulsed Lasers Using the Knife-Edge Method. Instrumentation Science \& Technology. 2003(1). v31. 47-52.

22 - OPTICAL SOCIETY OF AMÉRICA. Laser Beam Quality Characterization. 1996.

23 - SKINNER, D. R. e WHITCHER, R. E. Measurement of the Radius of a High-Power Laser Beam Near the Focus of a Lens. Journal of Physics E: Scientific Instruments. 1972. v5. 237-238.

24 - MAGNES, J. ODERA, D. et al. Quantitative and Qualitative Study of Gaussian Beam Visualization Techniques. Department of Physics, U.S. Military Academy. 2006. 1-5. 


\section{Anexos}

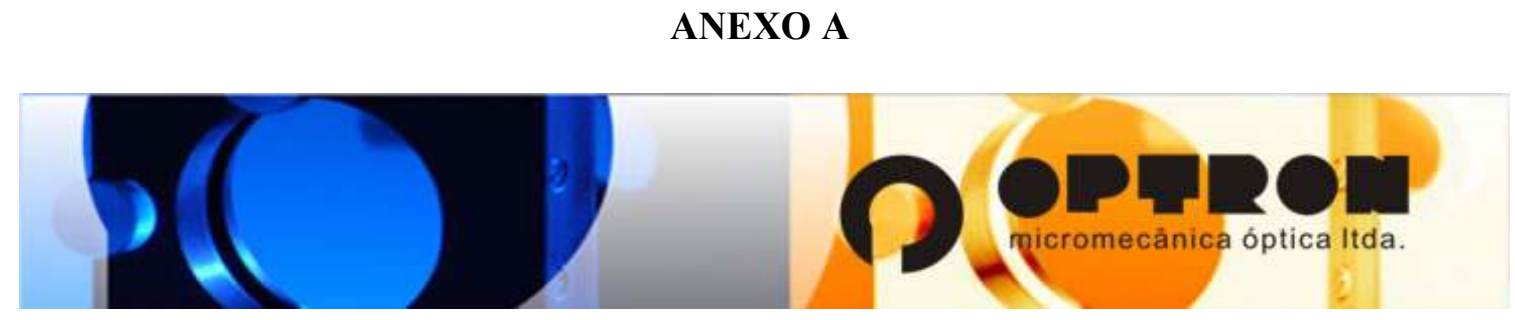

\section{Translador Horizontal TX1}

Translador de guia prismático com diferentes opções de dimensão da base e de curso. Parafusos laterais permitem retirar qualquer jogo no cursor ou travá-lo em determinada posição. Parafuso acionador com passo de 1,0 mm.

Duas peças podem ser justapostas em ângulo reto para formar um posicionador de coordenadas XY. O acionamento é feito com parafuso e porca com apenas uma pequena folga de retorno. A furação da placa permite a fixação de componentes para diversos arranjos.

Componentes em alumínio anodizado preto.

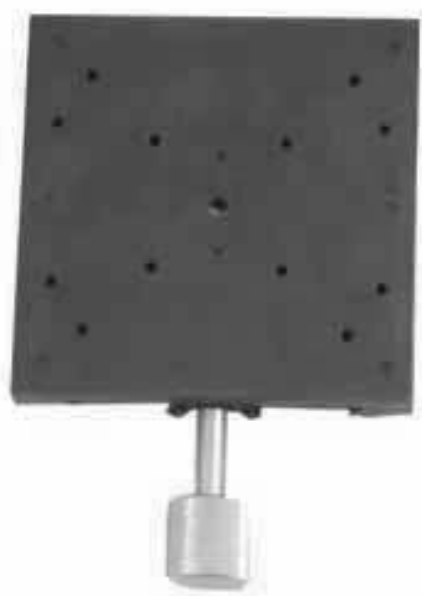

TX1-76.30 base quadrada com $76 \mathrm{~mm}$ de lado e curso útil de $30 \mathrm{~mm}$. 
ANEXO B

\section{MOTOR DE PASSO - SMI.8 - A17}

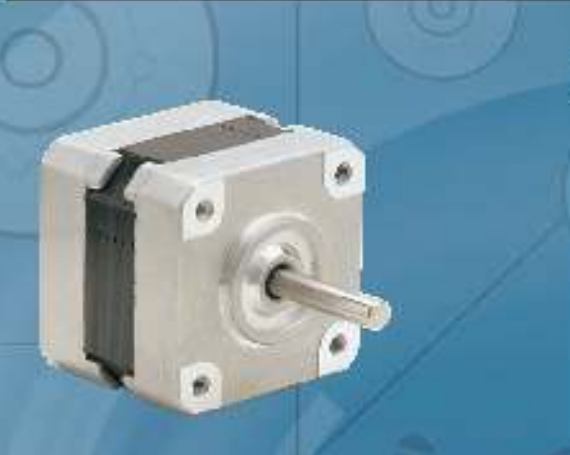

DIMEMSIOHAL

ESPECIFICACDESS

\begin{tabular}{|c|c|c|c|c|c|c|c|c|c|}
\hline MODELO & $\begin{array}{l}\text { TENSÄO } \\
\text { NOMIMAL } \\
(N d)\end{array}$ & $\begin{array}{l}\text { CORREMTI } \\
\text { (A/Togs) }\end{array}$ & $\begin{array}{l}\text { RESISTEMAA } \\
\text { OHWS/Togal }\end{array}$ & $\begin{array}{l}\text { IHDUtiNaA } \\
\text { (nt/fose) }\end{array}$ & $\begin{array}{l}\text { HOLDING } \\
\text { TOROUE } \\
\text { (Kf.cm) }\end{array}$ & $\begin{array}{l}\text { DETENT } \\
\text { TOROUE } \\
\text { OKd.am) }\end{array}$ & $\begin{array}{c}\text { INERCA } \\
\text { DO ROTOR } \\
\text { (gom?) }\end{array}$ & $\begin{array}{l}\text { PESO } \\
\text { (s) }\end{array}$ & $\begin{array}{c}1 \\
\text { (mm) }\end{array}$ \\
\hline Sa1.8A1740חSE & 4,9 & 0,77 & 6,4 & 5,1 & 2.8 & 0,14 & 45 & 250 & 40 \\
\hline SAl.8A1734CMN & 12 & 0,40 & 30 & 27 & 2,6 & 0,12 & 38 & 200 & 34 \\
\hline SM1.8A17362SE & 12 & 0,40 & 45 & 28 & 1,2 & 0,06 & 48 & 220 & 35,5 \\
\hline
\end{tabular}

\begin{tabular}{|c|c|}
\hline Angule de Passo & $1.8^{\circ}$ \\
\hline Passos / Volte & 200 \\
\hline Enrolament. & mipolar \\
\hline Tenif. Anbiente & $-10^{\circ} \mathrm{C}+50^{\circ} \mathrm{C}$ \\
\hline Resisténcia do Isolocio & 100 ohn / DC50ov \\
\hline Rigider Dieletrica & Ac $500 \mathrm{~V} / 1$ min. \\
\hline Clesse de laslaçáe & 1 \\
\hline Folgu Radial (náx.) & 0,03 mn $/$ màx. - Carga $=0,4 k g$ \\
\hline Folga Axisl (nix.) & 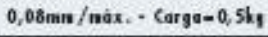 \\
\hline
\end{tabular}

rOMUE Ifing

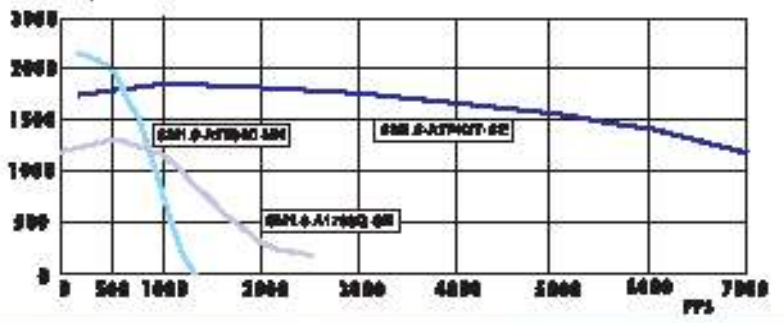

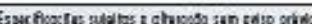

SEQUENCIA DE FASES

Dotecto heritio - visto ledo sciomanento

Kodeb SK1 841740IT/A17360-SE

\begin{tabular}{|c|c|c|c|c|c|c|}
\hline Poss: & A & B & A $^{\prime}$ & B $^{\prime}$ & Branco & Proto \\
\hline 0 & + & + & & & + & + \\
\hline 1 & & + & + & & + & + \\
\hline 2 & & & + & + & + & + \\
\hline 3 & + & & & + & + & + \\
\hline
\end{tabular}

Nodelo SHI 8A1734CWW

\begin{tabular}{|c|c|c|c|c|}
\hline Pass: & A & B & A & B $^{\prime}$ \\
\hline 0 & + & + & & \\
\hline 1 & & + & + & \\
\hline 2 & & & + & + \\
\hline 3 & + & & & + \\
\hline
\end{tabular}

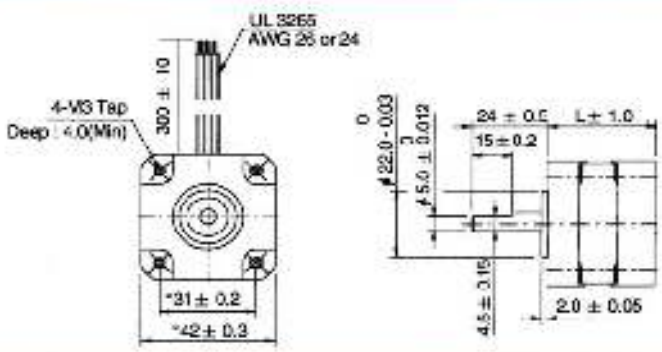


ANEXO C

DKN SERIES MINIATUREMETAL BUTOLLWCAO COUPLINGS WITH COLLET CLAMP

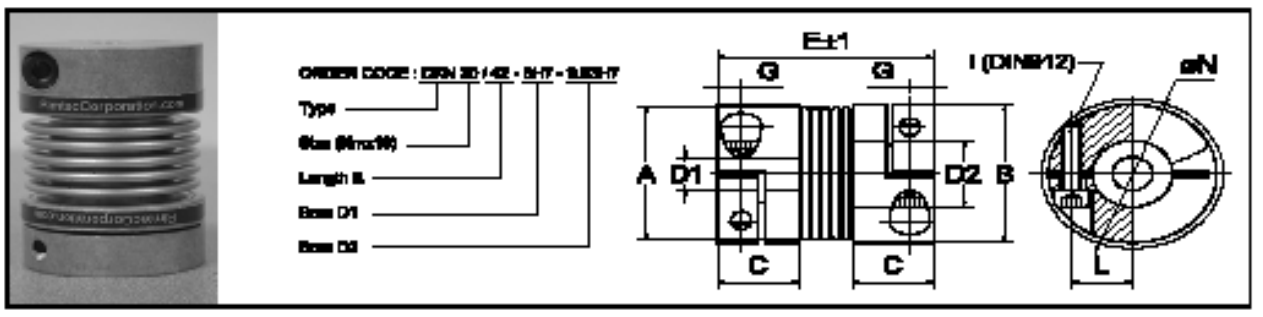

DIMENSIONS: (mm)

\begin{tabular}{|c|c|c|c|c|c|c|c|c|c|}
\hline Type DKN & A & B & c & $D 1-D 2^{20}$ & E & 0 & 1 & $\mathbf{L}$ & $\mathrm{N}$ \\
\hline & & & & 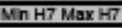 & & & DIN 912 & & \\
\hline DKN4/21 & 15 & 15.5 & 70 & $3-6.5$ & 21 & 2.4 & M2 & 5.6 & 17.5 \\
\hline DKN99/28 & 15 & 15.5 & 70 & $3-6.5$ & 25 & 2.4 & M2 & 5.6 & 17.5 \\
\hline DKNA9:30 & 15 & 15.5 & 70 & $3-6.5$ & 30 & 2.4 & $\mathrm{M} 2$ & 5.6 & 17.5 \\
\hline DKN1E/28 & 19 & 20.0 & 9.0 & $3-10$ & 26 & 3.0 & M25 & 7.0 & 21.0 \\
\hline DKNY20132 & 24 & 25.0 & 12.0 & $3-12.7$ & 32 & 3.5 & $M 3$ & 9.0 & 27.0 \\
\hline DKNN20142 & 24 & 25.0 & 12.0 & $3-12.7$ & 42 & 3.5 & $\mathrm{M} 3$ & 9.0 & 27.0 \\
\hline DKM46/41 & 32 & 32.5 & 14.0 & $6-16$ & 41 & 4.5 & M4 & 11.5 & 34.0 \\
\hline DKM46/41(8) & 32 & 32.5 & 140 & $6-16$ & 41 & 4.5 & $M 4^{40}$ & 11.5 & 34.0 \\
\hline DKNASIEO & 32 & 32.5 & 14.0 & $6-16$ & 50 & 4.5 & M4 & 11.5 & 34.0 \\
\hline DKN100147 & 40 & 40.5 & 14.5 & $6-22$ & 47 & 5.0 & M4 & 15.5 & 41.5 \\
\hline DKN100167 & 40 & 40.5 & 14.5 & $6-22$ & 57 & 5.0 & M4 & 15.5 & 41.5 \\
\hline
\end{tabular}

STANDARD BORE SIZES: 3mm, 6mm, 8mm, 10mm, 12mm, 14mm, 1/4", 3/8', 1/2, 5/8', 3/4"

1) Huba mase of AL 6061 T6, avallabie in steel on request.

The

standard $\mathrm{H7}$ according to the cuatamer's dsis.

3) Clearance of Keyway, Standard sas 9.

4) Clamp and screw mirror imaped (180") to the standard

TECHNICAL RATINGS:

\begin{tabular}{|c|c|c|c|c|c|c|c|c|c|c|}
\hline \multirow[t]{2}{*}{ Type DKN } & \multirow{2}{*}{\begin{tabular}{|c|}
$\begin{array}{c}\text { Rated } \\
\text { Torque (M) }\end{array}$ \\
(Nm) \\
\end{tabular}} & \multirow{2}{*}{$\begin{array}{l}\begin{array}{c}\text { Toreional } \\
\text { stittnoce }\end{array} \\
\text { (Nmirad) } \\
\end{array}$} & \multicolumn{2}{|c|}{$\begin{array}{l}\text { 8pring stifinoce } \\
\text { (Nimm) }\end{array}$} & \multicolumn{2}{|c|}{$\begin{array}{l}\text { Miles gnment } \\
(\mathrm{mm})(+1-A)\end{array}$} & \multirow{2}{*}{ 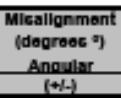 } & \multirow{2}{*}{$\begin{array}{c}\begin{array}{c}\text { Momont of } \\
\text { Inertla }\end{array} \\
1 \text {. }\end{array}$} & \multirow{2}{*}{$\begin{array}{c}\text { Torque to } \\
\text { Tlighten } \\
\text { Clamos } \\
\text { I MA = (Nm) }\end{array}$} & \multirow{2}{*}{$\begin{array}{l}\text { Mack } \\
m(p)\end{array}$} \\
\hline & & & Lateral & Axial & Lateral & Axtial & & & & \\
\hline DKN4/21 & 0.4 & 254 & 43 & 13 & 0.10 & 0.20 & 1.2 & 2.6 & 0.3 & 9 \\
\hline DKNY9/28 & 0.9 & 380 & 16 & 16 & 0.15 & 0.30 & 2.0 & 2.9 & 0.3 & 10 \\
\hline DKN99130 & 0.9 & 305 & 16 & 16 & 0.20 & 0.40 & 2.0 & 3.2 & 0.3 & 11 \\
\hline DKN16/28 & 1.5 & 748 & 59 & 15 & 0.10 & 0.25 & 1.2 & 11 & 0.8 & 22 \\
\hline DKKN20/32 & 2.0 & 1530 & 67 & 12 & 0.10 & 0.30 & 1.2 & 25 & 1.0 & 35 \\
\hline DKN20142 & 2.0 & 1030 & 11 & 9 & 0.25 & 0.50 & 2.0 & 28 & 1.0 & 40 \\
\hline DKNM45/41 & 4.5 & 6450 & 168 & 32 & 0.10 & 0.30 & 1.2 & 98 & 3.0 & 74 \\
\hline DKN45/41(8) & 10.0 & 8200 & 428 & 89 & 0.10 & 0.20 & 1.0 & 110 & 3.0 & $8 B$ \\
\hline DKM44N60 & 4.5 & 4030 & 41 & 20 & 0.20 & 0.50 & 2.0 & 103 & 3.0 & 78 \\
\hline DKN100147 & 10.0 & 8070 & 120 & 27 & 0.15 & 0.40 & 1.2 & 231 & 3.0 & 120 \\
\hline DKN100V67 & 10.0 & 6720 & 24 & 17 & 0.25 & 0.50 & 2.0 & 250 & 3.0 & 130 \\
\hline
\end{tabular}

The dimensioning of the couplings is sways based on the peak borque (Mmax) which is to be tranamitted regularty by the servo motors.

For basls of the calculation of the coupling's rated torque, see ordering data.

The couplings, under no creumstances, should be sutemilted bo a borque grester than 25 times the rated torque. 
ANEXO C

\section{PIITHIL}

E्नMICONOUCTOR

TIP120/121/122

Medium Power Linear Switching Applications

- Complenentary to TIP $125 / 126 / 127$

\section{NPN Epitaxial Darlington Transistor}

Absolute Maximum Ratings $T_{\mathrm{C}}-25^{\circ} \mathrm{C}$ unless otherwise noted

\begin{tabular}{|c|c|c|c|}
\hline Symbol & Parameter & Value & Unlts \\
\hline $\mathrm{V}_{\mathrm{CeO}}$ & $\begin{array}{cc}\text { Collector-Base Vorage } & : T 1 P 120 \\
& : T P 121 \\
& : T P 122\end{array}$ & $\begin{array}{c}60 \\
80 \\
100\end{array}$ & $\begin{array}{l}\mathrm{V} \\
\mathrm{V} \\
\mathrm{V}\end{array}$ \\
\hline $\mathrm{V}_{\text {CEO }}$ & $\begin{aligned} \text { Collector-Emitter Volitage } & \text { TIP120 } \\
& : T P 121 \\
& : T P 122\end{aligned}$ & $\begin{array}{c}60 \\
80 \\
100 \\
\end{array}$ & $\begin{array}{l}\mathrm{v} \\
\mathrm{v} \\
\mathrm{v}\end{array}$ \\
\hline$V_{E B O}$ & Emitter-Base Voltage & 5 & V \\
\hline lc & Collector Current (DC) & 5 & A \\
\hline $\mathrm{lcp}$ & Collector Current (Puise) & 8 & A \\
\hline $\mathrm{l} 8$ & Base Current (DC) & 120 & $\mathrm{~mA}$ \\
\hline \multirow[t]{2}{*}{$P_{C}$} & Collector Dissipation $\left(\mathrm{T}_{\mathrm{z}}-25^{\circ} \mathrm{C}\right)$ & 2 & 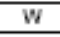 \\
\hline & Collector Dissipation $\left(\mathrm{T}_{\mathrm{C}}-25^{\circ} \mathrm{C}\right)$ & 65 & $w$ \\
\hline$T_{4}$ & Junction Temperature & 150 & ${ }^{\circ} \mathrm{C}$ \\
\hline$T_{\text {8TO }}$ & Storage Temperature & $-65 \sim 150$ & ${ }^{\circ} \mathrm{C}$ \\
\hline
\end{tabular}

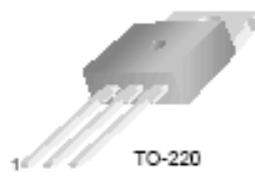

1.Base 2.Collector 3.Emilter

Equlvaient Clrault

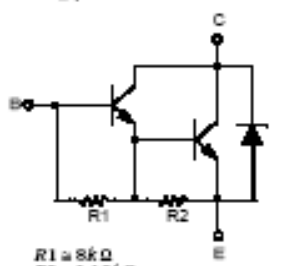
$R 1$
$R 2=0.12 k \Omega$

Electrical Characteristics $\mathrm{T}_{\mathrm{C}}-25^{\circ} \mathrm{C}$ unless ctherwise noted

\begin{tabular}{|c|c|c|c|c|c|}
\hline Symbol & Parameter & Test Condition & Min. & Max. & Units \\
\hline $\mathrm{V}_{\text {CEO }}$ (SUE) & $\begin{aligned} \text { Collector-Emitter Sustaining Voltage } \\
\\
: \text { TIP } 120 \\
: T \text { TIP121 } \\
: \text { TIP122 }\end{aligned}$ & $I_{C}=100 \mathrm{~mA}, l_{B}=0$ & $\begin{array}{r}60 \\
80 \\
100\end{array}$ & & $\begin{array}{l}\mathrm{v} \\
\mathrm{v} \\
\mathrm{v}\end{array}$ \\
\hline IEEO & $\begin{aligned} \text { Collector Cut-oft Current } & \\
& \begin{aligned}: T P 120 \\
\\
: T I P 121 \\
: T P 122\end{aligned}\end{aligned}$ & $\begin{array}{l}V_{C E}=30 V, l_{B}=0 \\
V_{C E}=40 V, l_{g}=0 \\
V_{C E}=50 V, l_{B}=0\end{array}$ & & $\begin{array}{l}0.5 \\
0.5 \\
0.5\end{array}$ & $\begin{array}{l}m A \\
m A \\
M A\end{array}$ \\
\hline$i_{c 90}$ & $\begin{aligned} \text { Collector Cut-oft Current } & \\
& \text { TIP120 } \\
& \operatorname{TIP}_{121} \\
& \text { TIP122 }\end{aligned}$ & $\begin{array}{l}V_{C B}=60 \mathrm{~V}, I_{E}=0 \\
V_{C B}=80 \mathrm{~V}, \mathrm{I}_{E}=0 \\
V_{C g}=100 \mathrm{~V}, \mathrm{I}_{E}=0\end{array}$ & & $\begin{array}{l}0.2 \\
0.2 \\
0.2\end{array}$ & $\begin{array}{l}m A \\
m A\end{array}$ \\
\hline EAO & Emilter Cut-orf Current & $V_{\mathrm{BE}}-5 \mathrm{~V}, \mathrm{C}=0$ & & 2 & $\mathrm{~mA}$ \\
\hline$h_{\text {FE }}$ & "DC Current Gain & $\begin{array}{l}V_{C E}=3 V_{V} I_{C}=0.5 \mathrm{~A} \\
V_{C E}=3 V_{C} I_{C}=3 \mathrm{~A}\end{array}$ & $\begin{array}{l}1000 \\
1000\end{array}$ & & \\
\hline $\mathrm{v}_{\mathrm{CE}}$ (sat) & " Colector-Emitter Saturation Voltage & $\begin{array}{l}\mathrm{c}_{c}=3 \mathrm{~A}, \mathrm{l}_{\mathrm{B}}=12 \mathrm{~mA} \\
c_{c}=5 \mathrm{~A}, \mathrm{l}_{\mathrm{g}}=20 \mathrm{~mA}\end{array}$ & & $\begin{array}{l}2.0 \\
4.0\end{array}$ & $\begin{array}{l}\mathrm{V} \\
\mathrm{v}\end{array}$ \\
\hline 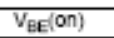 & "Base-Emilter ON Voltage & $V_{C E}-3 V, I_{C}=3 A$ & & 2.5 & $\mathrm{~V}$ \\
\hline $\mathrm{C}_{\mathrm{cb}}$ & Output Capacrance & $V_{C B}-10 V, V_{E}=0,1=0.1 \mathrm{MHz}$ & & 200 & $\mathrm{pF}$ \\
\hline
\end{tabular}


ANEXO D

\begin{tabular}{|l|l|l|}
\hline Thollonic & FoTOdIODo PIN DE SILÍcIo & PHFDl86 \\
\hline
\end{tabular}

VALORES MÁXTMOS ABSOLUTOS $\left(\mathrm{T}=25^{\circ} \mathrm{C}\right)$

$\mathrm{V}_{\mathrm{R}}$ (tensão reversa)

$\mathrm{P}_{\mathrm{D}}^{\mathrm{R}}$ (potência de dissipação)

$\mathrm{T}_{\text {op }}$ (temperatura de operação)

30
150
$-30 a+60$
$-40 a+60$

V

$T_{\text {stg }}$ (temperatura de armazenagem)

$-40 a+60$

$\mathrm{mW}$

${ }^{\circ} \mathrm{C}$

CARACTERISTICAS ELÉTRICAS E ÓTICAS $\left(\mathrm{T}=25^{\circ} \mathrm{C}\right)$

$\begin{array}{rrrr}\text { min tip máx } & \text { unid } \\ 350 & & \mathrm{mV} \\ & & \\ 40 & & \mu \mathrm{A} \\ 20 & & \mathrm{pF} \\ 1 & 30 & \mathrm{nA} \\ 950 & & \mathrm{~nm}\end{array}$

\section{CARACTERISTICAS DE CHAVEAMENTO}

$t_{\mathrm{r}}$ e $\mathrm{t}_{\mathrm{f}}\left(\mathrm{V}_{\mathrm{R}}=10 \mathrm{~V}, \mathrm{R}_{\mathrm{L}}=1 \mathrm{l} \mathbf{\Omega} \mathbf{\Omega}\right)$

50

ns

DRMENSÕES EISICAS (em mm)

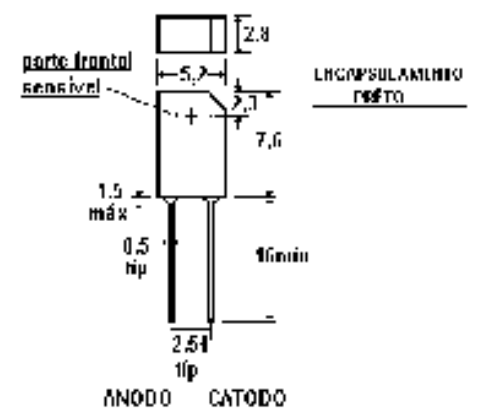

Especificaçôes Técnicas phfd186 - 09/99 
ANEXO F

\section{Low-Cost Multifunction DAQ for USB}

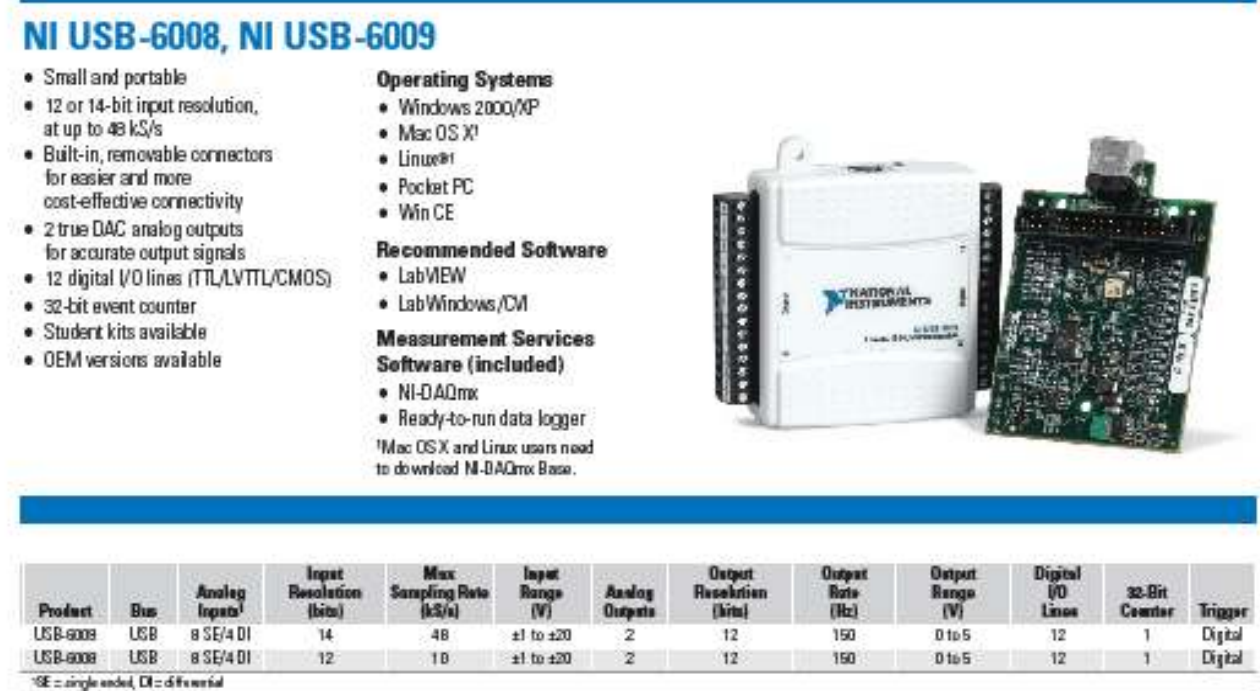

\section{Hardware Description}

The National Instruments USB-6008 and USB-6009 multifunction data acquisition (DAQD) modulas provide reliable data acquisition at a low price. With plug-and-play USB connectivity, these modules are simple enoughfor quick maaserements but versatile enough for more complex maasurement applications.

\section{Software Description}

The NI USB-6008 and USB-6009 use NI-DAOMru high-performance, multithreaded driver software for irteractive ocnfiguration and data acquisition on Windows OSa. AII II data acqu isition dericas shipped with NI-DACMx a bo irclude V Loger Lite, a configuration-based data-logging software package.

Mac OS X and Linux users can dowriced NI-DADmu Base, a multiplatforn driver with a limited NI-DAOmx progamming interface. You can use NI-DAOmx Base to develop customizad data acquisition applications with National Instruments LabVEW or C-based development environments. NI-DAOmx Base includes a reedy-to-run data loggar application that acquires and logs 4 to eight channels of analog data.

PDA users can download NI-DA.Omx Base for Pocket PC and Win CE to develop customized handheld data acquisition applications.

\section{Recommended Accessories}

The USB-6008 and USB-6009 have remorable screw temrinals for easy signal cornectivity for extra flevibility when handling multiple wring configrations, NI offers the LSB-6008/09 Aocessery Kit, which includas two extra sets of screw terminak, extra labels, and a screwdrier. haddition, the USB-800609 Prototyping Acossacry provides spaca for adding more cicuitry to the inputs of the USB-6008 or LSB-6009.

\section{Common Applications}

The USB-6008 and USB-6000 are idaal for a number of applications where economy, small size, and simplicity are essential, such as: - Data logging - Log errironmertal or voltage data quichly and easilf.

- Acadernic lab use - The low price facilitates student ownership of DAQ hardware for complately interactive lab-based courses. (Academic pricing available. Visit ni.com/academic for details.) - Embedded OEM applications. 